\title{
The CSIRO Mk3L climate system model version 1.0 - Part 2: Response to external forcings
}

\author{
S. J. Phipps ${ }^{1,2,3,4}$, L. D. Rotstayn ${ }^{5}$, H. B. Gordon ${ }^{5}$, J. L. Roberts ${ }^{2,3,6}$, A. C. Hirst ${ }^{5}$, and W. F. Budd ${ }^{1,2,3}$ \\ ${ }^{1}$ Institute of Antarctic and Southern Ocean Studies, University of Tasmania, Australia \\ ${ }^{2}$ Antarctic Climate \& Ecosystems CRC, Hobart, Tasmania, Australia \\ ${ }^{3}$ Tasmanian Partnership for Advanced Computing, Hobart, Tasmania, Australia \\ ${ }^{4}$ Climate Change Research Centre, University of New South Wales, Australia \\ ${ }^{5}$ Centre for Australian Weather and Climate Research: A partnership between CSIRO and the Bureau of Meteorology, \\ Aspendale, Victoria, Australia \\ ${ }^{6}$ Australian Antarctic Division, Kingston, Tasmania, Australia
}

Correspondence to: S. J. Phipps (s.phipps@unsw.edu.au)

Received: 14 November 2011 - Published in Geosci. Model Dev. Discuss.: 7 December 2011

Revised: 12 April 2012 - Accepted: 24 April 2012 - Published: 14 May 2012

\begin{abstract}
The CSIRO Mk3L climate system model is a coupled general circulation model, designed primarily for millennial-scale climate simulation and palaeoclimate research. Mk3L includes components which describe the atmosphere, ocean, sea ice and land surface, and combines computational efficiency with a stable and realistic control climatology. It is freely available to the research community. This paper evaluates the response of the model to external forcings which correspond to past and future changes in the climate system.

A simulation of the mid-Holocene climate is performed, in which changes in the seasonal and meridional distribution of incoming solar radiation are imposed. Mk3L correctly simulates increased summer temperatures at northern mid-latitudes and cooling in the tropics. However, it is unable to capture some of the regional-scale features of the mid-Holocene climate, with the precipitation over Northern Africa being deficient. The model simulates a reduction of between 7 and $15 \%$ in the amplitude of El NiñoSouthern Oscillation, a smaller decrease than that implied by the palaeoclimate record. However, the realism of the simulated ENSO is limited by the model's relatively coarse spatial resolution.

Transient simulations of the late Holocene climate are then performed. The evolving distribution of insolation is imposed, and an acceleration technique is applied and assessed. The model successfully captures the temperature changes in
\end{abstract}

each hemisphere and the upward trend in ENSO variability. However, the lack of a dynamic vegetation scheme does not allow it to simulate an abrupt desertification of the Sahara.

To assess the response of Mk3L to other forcings, transient simulations of the last millennium are performed. Changes in solar irradiance, atmospheric greenhouse gas concentrations and volcanic emissions are applied to the model. The model is again broadly successful at simulating larger-scale changes in the climate system. Both the magnitude and the spatial pattern of the simulated 20th century warming are consistent with observations. However, the model underestimates the magnitude of the relative warmth associated with the Mediaeval Climate Anomaly.

Finally, three transient simulations are performed, in which the atmospheric $\mathrm{CO}_{2}$ concentration is stabilised at two, three and four times the pre-industrial value. All three simulations exhibit ongoing surface warming, reduced sea ice cover, and a reduction in the rate of North Atlantic Deep Water formation followed by its gradual recovery. Antarctic Bottom Water formation ceases, with the shutdown being permanent for a trebling and quadrupling of the $\mathrm{CO}_{2}$ concentration. The transient and equilibrium climate sensitivities of the model are determined. The short-term transient response to a doubling of the $\mathrm{CO}_{2}$ concentration at $1 \%$ per year is a warming of $1.59 \pm 0.08 \mathrm{~K}$, while the long-term equilibrium response is a warming of at least $3.85 \pm 0.02 \mathrm{~K}$. 


\section{Introduction}

The CSIRO Mk3L climate system model is a computationally-efficient atmosphere-land-sea ice-ocean general circulation model, designed for the study of climate variability and change on millennial timescales. It incorporates a spectral atmospheric general circulation model, a $z$-coordinate ocean general circulation model, a dynamic-thermodynamic sea ice model and a land surface scheme with static vegetation. The zonal and meridional resolutions used by all components are $5.625^{\circ}$ and $\sim 3.18^{\circ}$, respectively, with 18 vertical levels in the atmosphere and 21 vertical levels in the ocean. Flux adjustments are applied to improve the realism of the simulated control climate and to minimise drift. Mk3L represents a new version of the CSIRO climate model, the history of which is described by Smith (2007). The atmosphere, land and sea ice models are reduced-resolution versions of those used by the CSIRO Mk3 coupled model (Gordon et al., 2002), while the ocean model is taken from the CSIRO Mk2 coupled model (Gordon and O'Farrell, 1997). A 1000-yr climate simulation can be completed in around 45 days on a typical state-of-the-art (Intel Core 2 Duo) desktop computer, with greater throughput being possible on high-performance computing facilities. Mk3L is freely available to the research community, and access to the Subversion repository can be obtained by completing the online application form at http://www.tpac.org.au/main/csiromk31/.

Part 1 of this paper (Phipps et al., 2011) describes the model physics and software, analyses the control climatology, and evaluates the ability of the model to simulate the modern climate. The simulated states of the atmosphere, cryosphere and ocean are found to be in broad agreement with observations. However, biases on the regional scale include excessive cloud cover and precipitation in the tropics, deficient winter sea ice cover in the Northern Hemisphere, and a deep ocean which is too cold and too fresh. Mk3L produces reasonable representations of the leading modes of internal climate variability in both the tropics and extratropics. However, the simulated El Niño-Southern Oscillation is too weak, too slow and characterised by excessive modulation on interdecadal timescales.

This paper describes and evaluates the response of version 1.0 of $\mathrm{Mk} 3 \mathrm{~L}$ to external forcings which correspond to past and future changes in the climate system. A variety of simulations are performed and the response of the model is compared, as appropriate, with observations, proxy-based reconstructions of past climate and with the response of other models. Section 2 evaluates the ability of Mk3L to simulate the climate of the mid-Holocene. Section 3 then analyses the transient response of the model to the changing seasonal and meridional distribution of insolation during the late Holocene. Section 4 presents a transient simulation of the last millennium, and evaluates the response of Mk3L to changes in solar irradiance, greenhouse gas concentrations and vol- canic emissions. Finally, Sect. 5 explores the transient and equilibrium responses of the model to scenarios in which the atmospheric $\mathrm{CO}_{2}$ concentration is stabilised at two, three and four times the pre-industrial level.

The aim of this paper is to characterise the response of Mk3L to external forcings and to identify possible deficiencies in the model physics. As such, the focus is upon describing the response of the model, rather than upon conducting detailed analyses of each experiment. Many of the simulations presented herein justify more extensive scientific analysis, which will form the basis of future manuscripts.

\section{The climate of the mid-Holocene}

\subsection{Introduction}

The climate of the mid-Holocene $(6000 \mathrm{yr}$ Before Present, where the present is defined as the year 1950 CE) has frequently been used to evaluate the ability of climate models to simulate climatic change (e.g. Joussaume et al., 1999; Masson et al., 1999; Braconnot et al., 2000; Bonfils et al., 2004; Braconnot et al., 2007a,b). This epoch represents the relatively recent past, and extensive and high-quality reconstructions of the mid-Holocene climate are available against which to evaluate the performance of the models (Yu and Harrison, 1996; Cheddadi et al., 1997; Hoelzmann et al., 1998; Jolly et al., 1998a,b; Prentice and Webb, 1998; Kohfeld and Harrison, 2000; Prentice et al., 2000; Brewer et al., 2007; Bartlein et al., 2011). The external forcing, which is mainly due to changes in the seasonal and meridional distribution of insolation arising from changes in the Earth's orbital parameters, is also well-known and can be precisely defined (Berger, 1978; Braconnot et al., 2007a). Changes in sea level and the extent of land ice relative to the present day are sufficiently small that they can be neglected.

During the mid-Holocene, the Earth's axial tilt was slightly greater than it is today $\left(24.105^{\circ}\right.$ at $6000 \mathrm{yr} \mathrm{BP}$, as opposed to the present-day value of $23.446^{\circ}$ ). This gave rise to a slight change in the meridional distribution of annualmean insolation, with a reduction of $\sim 1 \mathrm{~W} \mathrm{~m}^{-2}$ in the tropics and an increase of $\sim 4.5 \mathrm{~W} \mathrm{~m}^{-2}$ at the poles (Fig. 1a). However, as a result of the precession of the equinoxes, there were much larger differences in the seasonal cycle (Fig. 1b). Insolation was considerably greater than today during the Northern Hemisphere summer and Southern Hemisphere spring, and considerably reduced during the Southern Hemisphere summer.

The differences between the climate of the mid-Holocene and that of the present day are therefore predominantly seasonal in nature, with the most significant feature being the strengthening and northward migration of the Northern Hemisphere monsoons, particularly over Africa (Braconnot et al., 2007a). Geomorphological and biostratigraphic data indicates that Northern Africa was considerably wetter than it is today, while biome reconstructions generated from pollen 


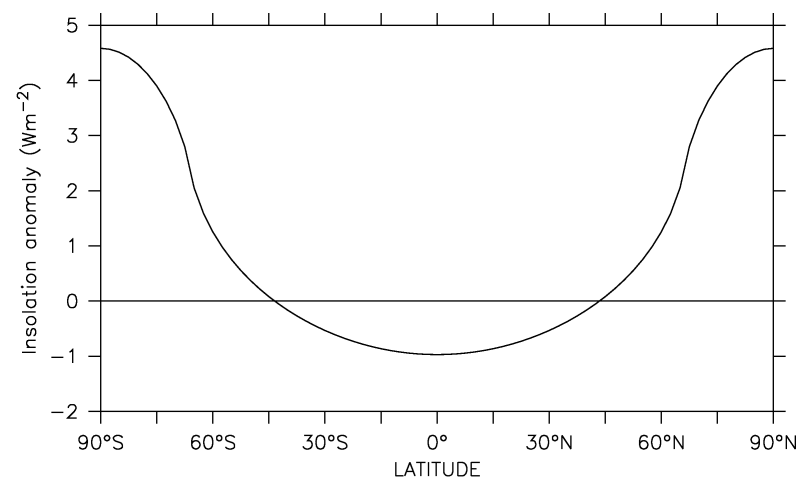

(a) Annual-mean insolation

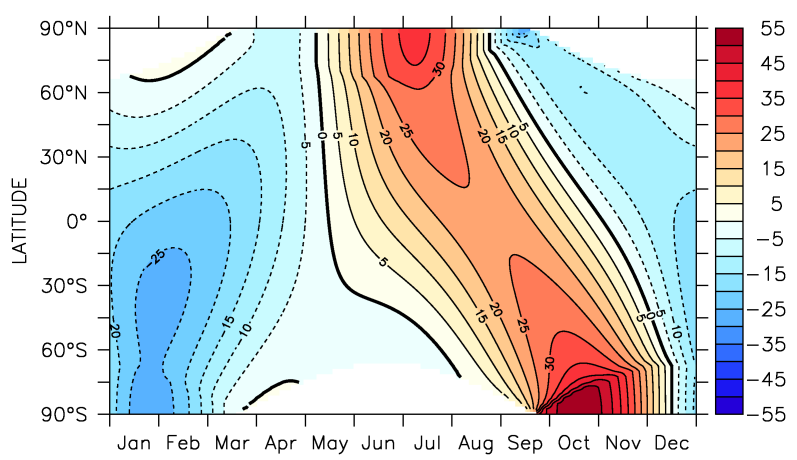

(b) Daily insolation

Fig. 1. The insolation $\left(\mathrm{W} \mathrm{m}^{-2}\right)$ at $6000 \mathrm{yr} \mathrm{BP}$, expressed as an anomaly relative to the present day: (a) the annual mean, and (b) daily values.

and plant macrofossils indicate that it was extensively vegetated (Jolly et al., 1998a,b; Joussaume et al., 1999; Bartlein et al., 2011).

Many studies have used climate models to simulate the climate of the mid-Holocene, often motivated by a desire to evaluate the performance of the models. In particular, the Paleoclimate Modelling Intercomparison Project (PMIP) has used the climate of the mid-Holocene as a basis to systematically compare the performance of different models. PMIP1 used stand-alone atmospheric general circulation models forced by present-day sea surface temperatures (Harrison et al., 1998; Joussaume et al., 1999; Masson et al., 1999; Braconnot et al., 2000; Bonfils et al., 2004; Hoar et al., 2004), while PMIP2 has employed coupled atmosphere-ocean general circulation models (Braconnot et al., 2007a,b). The models are successful at capturing both an intensification and northward migration of the African monsoon; however, they are unable to capture the magnitude of the northward shift (Braconnot et al., 2007a,b).

The failure to adequately capture the changes in the African monsoon can be attributed, at least in part, to the static nature of the vegetation and land surface types within these simulations. The vegetation is unable to respond fully to the changed atmospheric conditions, and the extent of vegetation feedbacks cannot therefore be simulated. Early studies which incorporated dynamic vegetation models into atmosphere-ocean general circulation models confirmed the role of both oceanic and vegetation feedbacks in giving rise to the wetter conditions that prevailed over Northern Africa during the mid-Holocene (Braconnot et al., 1999; Levis et al., 2004). While further confirming the role of the vegetation feedback, PMIP2 found that the magnitude of the feedback was smaller than in previous studies, possibly because of an inconsistency in the experimental design (Braconnot et al., 2007a,b). Changes in surface albedo have also been shown to be important (Vamborg et al., 2011). Thus the mid-Holocene African monsoon remains a daunting test of the ability of models to simulate climatic change.

In addition to changes in the mean state of the climate, changes in the nature of climate variability during the mid-Holocene have also received attention. Proxy records indicate a strengthening of interannual variability in the tropical Pacific Ocean during the Holocene. For example, analysis of corals from Papua New Guinea reveals that El Niño-Southern Oscillation (ENSO) activity at $\sim 6500 \mathrm{yr}$ BP was much weaker than at present (Tudhope et al., 2001). A 15000-yr sedimentation record from an alpine lake in Ecuador indicates a lack of variability on El Niño timescales prior to $7000 \mathrm{yr} \mathrm{BP}$, with ENSO-type variability beginning at $\sim 7000 \mathrm{yr} \mathrm{BP}$ and reaching its modern strength at $\sim 5000 \mathrm{yr}$ BP (Rodbell et al., 1999). A further analysis of a $12000-y r$ sedimentation record from the same lake confirms the initiation of ENSO at $\sim 7000 \mathrm{yr} B$, with strong variability on millennial timescales thereafter (Moy et al., 2002). Pollen evidence from Northern Australia also indicates a strengthening of ENSO during the Holocene, with the onset of an ENSO-dominated climate at $\sim 4000 \mathrm{yr} \mathrm{BP}$ (Shulmeister and Lees, 1998).

Coupled atmosphere-ocean general circulation models, including those participating in PMIP2, have been used to investigate the nature of ENSO during the mid-Holocene (Otto-Bliesner, 1999; Liu et al., 2000; Otto-Bliesner et al., 2006; Zheng et al., 2008). The change in the amplitude of the ENSO variability in the PMIP2 models varies from an increase of $3.3 \%$ to a decrease of $22.5 \%$ relative to the present day (Zheng et al., 2008). However, proxy records indicate a reduction in ENSO amplitude of up to $60 \%$ (Rodbell et al., 1999; Tudhope et al., 2001). This mismatch between the models and the proxies suggests deficiencies in either the model physics or the reconstructions. Nonetheless, the models exhibit a consistent relationship between the large-scale atmospheric circulation and the amplitude of ENSO variability. The enhanced insolation during the Northern Hemisphere summer causes an increase in the land-sea temperature contrast, which leads to a strengthening of the Asian summer monsoon system. This enhances the easterly trade winds over the equatorial Pacific Ocean, causing anomalous upwelling which suppresses the development of El Niño events (Zheng et al., 2008). 


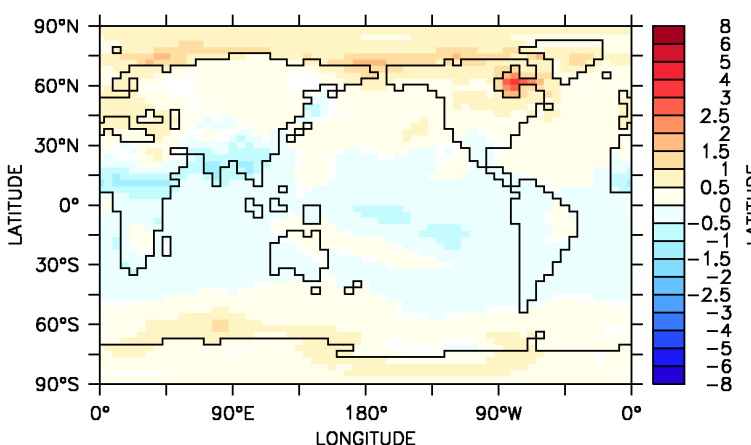

(a) Annual mean

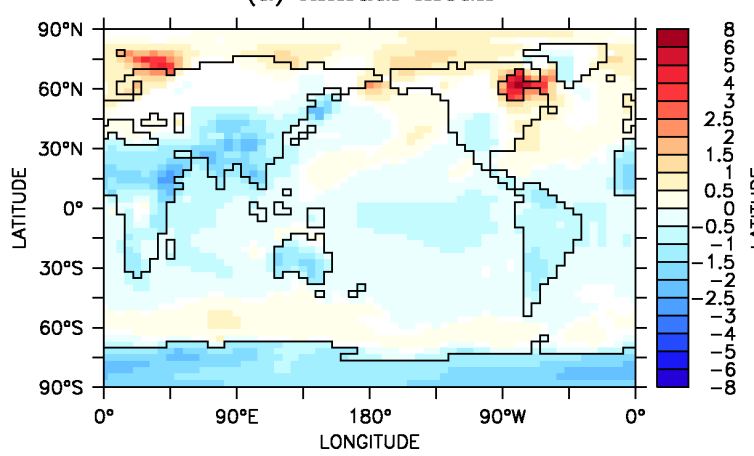

(c) February

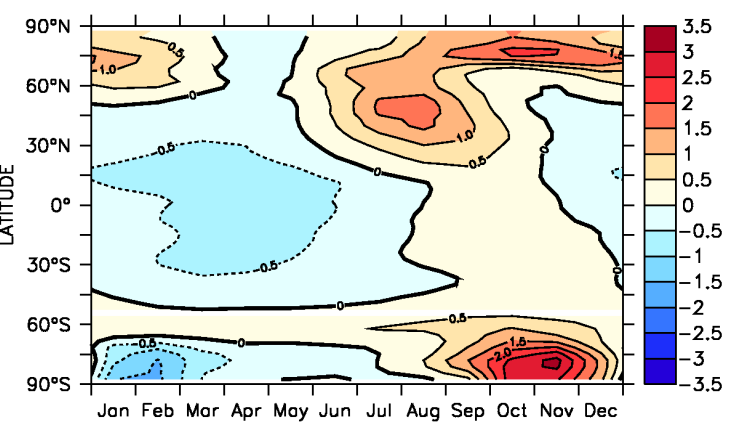

(b) Zonal mean

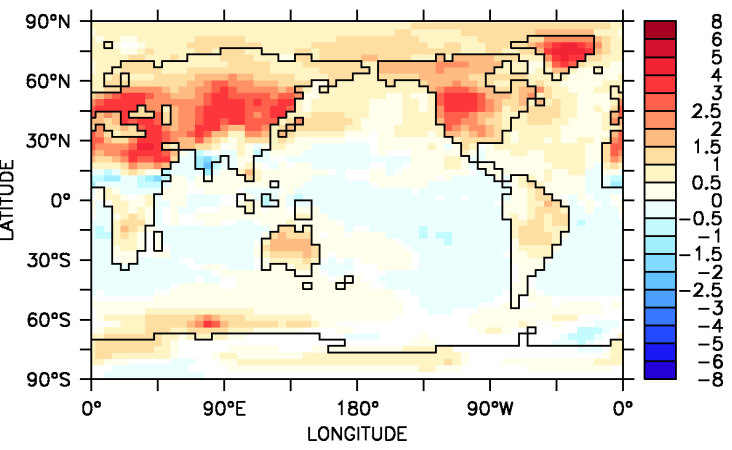

(d) August

Fig. 2. The average surface air temperature (K) for years 201-1200 of experiment 6KA, expressed as an anomaly relative to CONTROL: (a) the annual mean, (b) the zonal mean, (c) February, and (d) August. In (a), (c) and (d), only values that are significant at the $95 \%$ confidence level are shown.

\subsection{Experimental design}

The ability of Mk3L to simulate the climate of the midHolocene is evaluated in this section. The model was integrated under mid-Holocene boundary conditions, following the protocol specified by PMIP2 (http://pmip2.lsce.ipsl.fr/) and PMIP3 (http://pmip3.lsce.ipsl.fr/). Relative to the preindustrial control simulation (Part 1; Phipps et al., 2011), the Earth's orbital parameters were changed to values appropriate for $6000 \mathrm{yr} \mathrm{BP}$. The atmospheric $\mathrm{CO}_{2}$ concentration was also reduced from $280 \mathrm{ppm}$ to $277 \mathrm{ppm}$, in order to impose a radiative forcing equivalent to the specified reduction in the atmospheric $\mathrm{CH}_{4}$ concentration from 760 to $650 \mathrm{ppb}$. This was necessary as the radiation scheme in version 1.0 of Mk3L does not directly account for the radiative effects of anthropogenic greenhouse gases other than $\mathrm{CO}_{2}$.

The model was initialised from the state of the control simulation at the end of model year 100 . The first $100 \mathrm{yr}$ of the mid-Holocene simulation are excluded from analysis to allow the model to respond to the change in external forcing. This was sufficient for it to reach equilibrium, with globalmean surface air temperature (SAT) and sea surface temperature (SST) changing by less than $0.01 \mathrm{~K}$ between the first and second centuries of the simulation. The following analysis is therefore based on model years 201 to 1200 . The control and
mid-Holocene simulations shall be referred to hereafter as CONTROL and 6KA, respectively. Over the 1000-yr analysis period, global-mean SAT changes by $-0.08 \mathrm{~K}$ in CONTROL and $+0.02 \mathrm{~K}$ in $6 \mathrm{KA}$. The results presented here are not corrected for drift.

\subsection{Surface air temperature}

The average SAT for experiment 6KA, expressed as an anomaly relative to CONTROL, is shown in Fig. 2. The seasonal nature of the differences in the mid-Holocene climate is apparent. Consistent with the changes in the annual-mean insolation, the differences in annual-mean SAT (Fig. 2a) are small, with only a slight cooling at low latitudes and a slight warming at high latitudes. Ice-albedo feedbacks amplify the high-latitude warming around the fringes of the Antarctic and Arctic sea ice zones, particularly in Hudson Bay. However, the seasonal redistribution of insolation drives larger changes in the annual cycle of SAT at each latitude (Fig. 2b). A clear correlation between insolation and SAT is apparent, albeit with the temperature anomalies lagging the insolation anomalies by approximately one month at most latitudes. This reflects the fact that surface temperatures represent a time-integrated response to the surface heat flux, and not an instantaneous response. Ice-albedo feedbacks lead to a more complex relationship between insolation and 


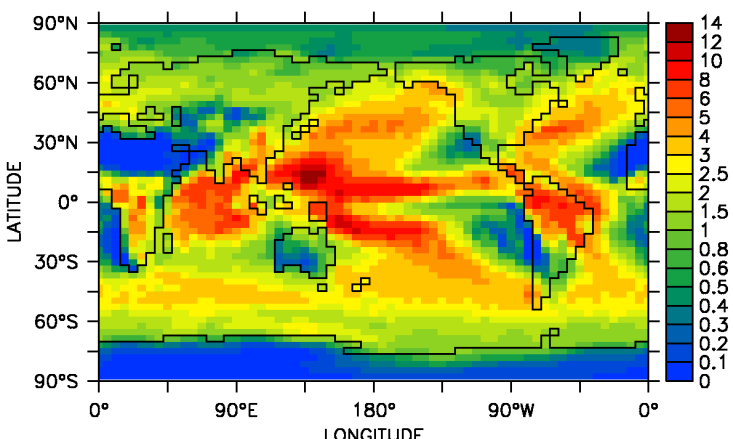

(a) CONTROL

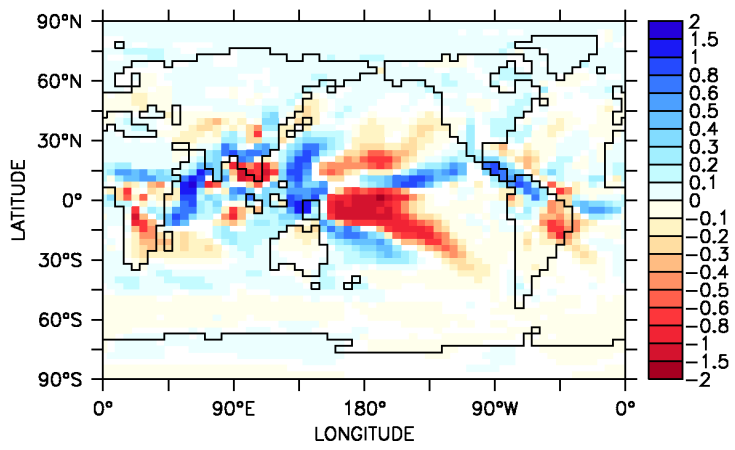

(c) 6KA minus CONTROL

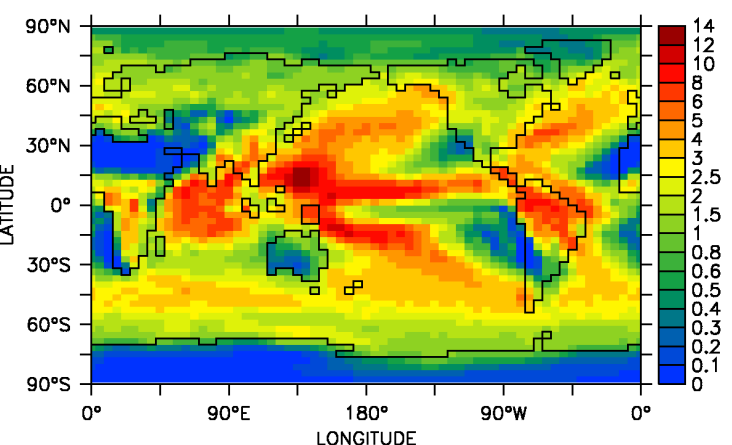

(b) 6KA

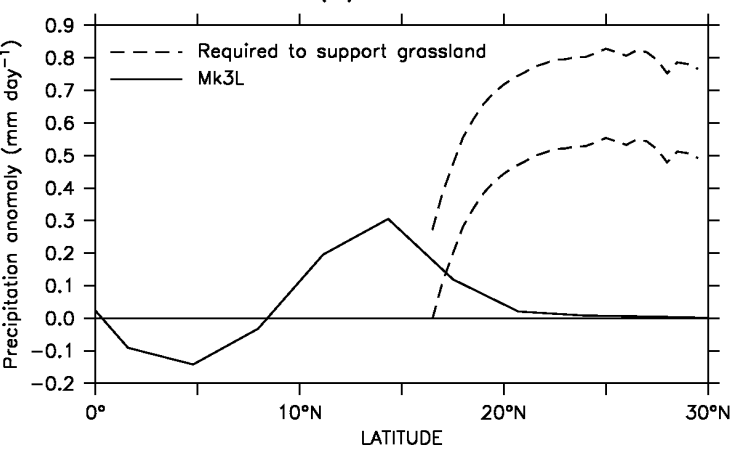

(d) Anomaly over Northern Africa

Fig. 3. The annual-mean precipitation $\left(\mathrm{mm} \mathrm{day}^{-1}\right.$ ) for years $201-1200$ of experiments CONTROL and 6KA: (a) CONTROL, (b) 6KA, (c) 6KA minus CONTROL, and (d) the zonal-mean difference over Northern Africa $\left(20^{\circ} \mathrm{W}-30^{\circ} \mathrm{E}\right)$. In (c), only values that are significant at the $95 \%$ confidence level are shown. In (d), minimum and maximum estimates of the precipitation increase required to support grassland at each latitude are also shown (Joussaume et al., 1999).

temperature at high latitudes; for example, there is no cooling over the Southern Ocean in response to the negative insolation anomalies between December and July.

The strongest warming at northern mid-latitudes occurs in August. SAT is higher across the Northern Hemisphere landmasses, with summer warming of up to $5.0 \mathrm{~K}$ over Greenland and up to $4.3 \mathrm{~K}$ over Eurasia (Fig. 2d). As a result of the seasonal nature of the insolation anomalies and the large thermal inertia of the ocean, the warming over the ocean is modest. The average SAT increase across the Northern Hemisphere for the period June-September is $0.55 \mathrm{~K}$; this is consistent with the PMIP2 models, which exhibit temperature increases of between 0.35 and $0.8 \mathrm{~K}$ (Braconnot et al., 2007a).

In contrast, cooling occurs at low latitudes and throughout the Southern Hemisphere in February (Fig. 2c). SAT is reduced by up to $2.7 \mathrm{~K}$ over land in the tropics, and by up to $2.2 \mathrm{~K}$ over Antarctica. The average SAT change across the Northern Hemisphere for the period December-February is $-0.15 \mathrm{~K}$; this is also consistent with the PMIP2 models, which exhibit temperature changes ranging from approximately -0.9 to $+0.1 \mathrm{~K}$ (Braconnot et al., 2007a).

\subsection{Precipitation}

The annual-mean precipitation for experiments CONTROL and $6 \mathrm{KA}$, respectively, is shown in Fig. $3 \mathrm{a}$ and $\mathrm{b}$, while Fig. $3 \mathrm{c}$ shows the difference between the two simulations. The intensification and northward migration of the AfricanAsian monsoon is reflected in the annual-mean precipitation, with increased precipitation over Northern Africa and Southeast Asia.

The changes in the African monsoon are apparent from Fig. 3d, which shows the change in the zonal-mean precipitation over Northern Africa. Also shown are the minimum and maximum estimates of the increase in precipitation, relative to the present day, that would be required in order to support grassland at each latitude (Joussaume et al., 1999). Biome reconstructions indicate that grasslands were present at least as far north as $23^{\circ} \mathrm{N}$ during the mid-Holocene (Jolly et al., 1998b; Joussaume et al., 1999); the simulated precipitation anomaly should therefore exceed these estimated amounts at latitudes up to $23^{\circ} \mathrm{N}$. While an intensification and northward migration of the African monsoon is apparent, with a decrease of $0.14 \mathrm{~mm} \mathrm{day}^{-1}$ in the annual-mean precipitation at $\sim 5^{\circ} \mathrm{N}$ and an increase of $0.31 \mathrm{~mm} \mathrm{day}^{-1}$ at $\sim 14^{\circ} \mathrm{N}$, the simulated precipitation is deficient at latitudes 


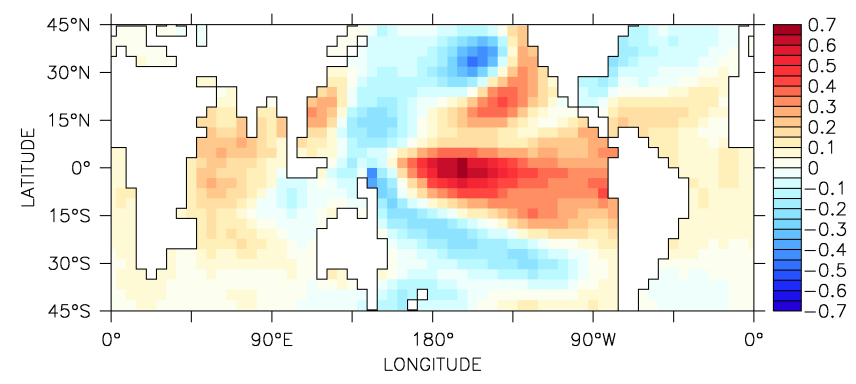

(a) CONTROL

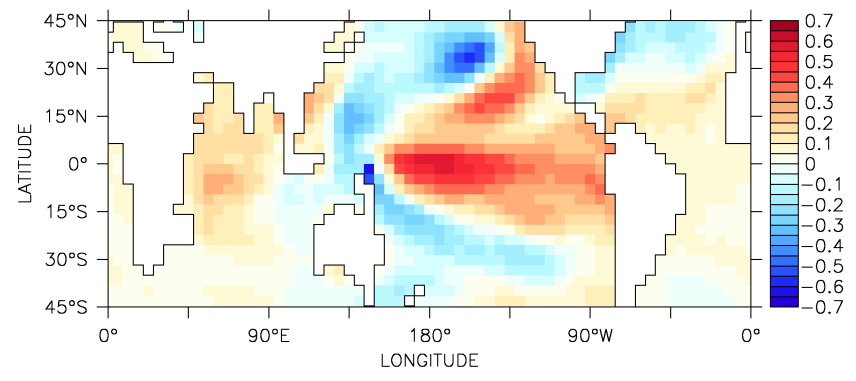

(b) $6 \mathrm{KA}$

Fig. 4. The leading principal component $(\mathrm{K})$ of the monthly sea surface temperature anomalies in the region $45^{\circ} \mathrm{S}-45^{\circ} \mathrm{N}$ for years 201-1200 of experiments CONTROL and 6KA: (a) CONTROL, and (b) 6KA.

greater than $\sim 17^{\circ} \mathrm{N}$. The majority of models which participated in PMIP2 also fail to simulate sufficient precipitation over Northern Africa (Braconnot et al., 2007a). The reasons for this deficiency are unclear, with vegetation feedbacks found to increase the simulated precipitation in only one of the three models which were integrated both with and without dynamic vegetation schemes. One possibility is that the models do not include schemes which represent the radiative effects of dust; studies using models which incorporate dust schemes have shown that this is an important control on Northern African precipitation (Yoshioka et al., 2007).

The magnitudes of the changes in the African-Asian monsoon, as simulated by Mk3L, are consistent with the PMIP2 models. For the period June-September, the simulated precipitation over Northern Africa (defined here as the region $20^{\circ} \mathrm{W}-30^{\circ} \mathrm{E}, 10-25^{\circ} \mathrm{N}$ ) increases by $0.35 \mathrm{~mm} \mathrm{day}^{-1}$ or $28 \%$ relative to CONTROL; this is consistent with the PMIP2 models, which exhibit increases relative to the pre-industrial control simulations ranging from 0.2 to $1.6 \mathrm{~mm} \mathrm{day}^{-1}$ and from 5 to $140 \%$. For North India (defined here as the region $70-100^{\circ} \mathrm{E}, 20-40^{\circ} \mathrm{N}$ ), the simulated precipitation increases by $0.69 \mathrm{~mm} \mathrm{day}^{-1}$ or $22 \%$; again, this is consistent with the PMIP2 models, which exhibit increases ranging from 0.2 to $0.8 \mathrm{~mm} \mathrm{day}^{-1}$ and from 5 to $33 \%$ (Braconnot et al., 2007a).
Table 1. El Niño-Southern Oscillation statistics for years 201-1200 of experiments CONTROL and 6KA: The standard deviation $(\mathrm{K})$ of the monthly sea surface temperature anomaly in the Niño 3 $\left(150-90^{\circ} \mathrm{W}, 5^{\circ} \mathrm{S}-5^{\circ} \mathrm{N}\right)$, Niño $3.4\left(170-120^{\circ} \mathrm{W}, 5^{\circ} \mathrm{S}-5^{\circ} \mathrm{N}\right)$ and Niño $4\left(160^{\circ} \mathrm{E}-150^{\circ} \mathrm{W}, 5^{\circ} \mathrm{S}-5^{\circ} \mathrm{N}\right)$ regions; the maximum temperature anomaly $(\mathrm{K})$ associated with the leading principal component (PC1) of monthly sea surface temperature anomalies in the region $45^{\circ} \mathrm{S}-45^{\circ} \mathrm{N}$; and the percentage change (6KA minus CONTROL).

\begin{tabular}{lccc}
\hline & Control & 6KA & \% change \\
\hline Niño 3 & 0.395 & 0.367 & -7 \\
Niño 3.4 & 0.513 & 0.453 & -12 \\
Niño 4 & 0.501 & 0.520 & +4 \\
PC1 & 0.673 & 0.572 & -15 \\
\hline
\end{tabular}

\subsection{El Niño-Southern Oscillation}

The leading principal component of the monthly SST anomalies within the region $45^{\circ} \mathrm{S}-45^{\circ} \mathrm{N}$, for experiments $\mathrm{CON}-$ TROL and 6KA, is shown in Fig. 4. El Niño-Southern Oscillation (ENSO; Philander, 1990) is the leading mode of variability in tropical SSTs for both experiments. However, in $6 \mathrm{KA}$, the principal components are shifted slightly to the west. The largest positive anomalies occur at $163^{\circ} \mathrm{W}$ in the case of CONTROL, whereas they occur at $180^{\circ} \mathrm{E}$ in the case of experiment 6KA. This shift causes the maximum variability to lie outside the Niño 3.4 region, with the result that the principal component more closely resembles the observed present-day interdecadal variability in the Pacific Ocean (Zhang et al., 1997; Lohmann and Latif, 2005).

The amplitude of ENSO variability within experiments CONTROL and 6KA is shown in Table 1. The simulated ENSO is weaker in experiment 6KA, with decreases of $7 \%$ and $12 \%$ in the amplitude of the SST anomaly in the Niño 3 $\left(150-90^{\circ} \mathrm{W}, 5^{\circ} \mathrm{S}-5^{\circ} \mathrm{N}\right)$ and Niño $3.4\left(170-120^{\circ} \mathrm{W}, 5^{\circ} \mathrm{S}-\right.$ $5^{\circ} \mathrm{N}$ ) regions, respectively. These simulated reductions are smaller in magnitude than those implied by the palaeoclimate record (Rodbell et al., 1999; Tudhope et al., 2001). They are consistent, however, with the PMIP2 models, which simulate changes in the amplitude of variability in the Niño 3 region that range from +3.3 to $-22.5 \%$ (Zheng et al., 2008). They are also consistent with other modelling studies, which simulate decreases in the strength of ENSO that range from zero (Otto-Bliesner, 1999) to $20 \%$ (Liu et al., 2000; Otto-Bliesner et al., 2006). Despite the overall reduction in the strength of ENSO in experiment 6KA, the westward shift in the location of greatest variability causes a $4 \%$ increase in the amplitude of the SST anomaly in the Niño 4 region $\left(160^{\circ} \mathrm{E}-150^{\circ} \mathrm{W}, 5^{\circ} \mathrm{S}-5^{\circ} \mathrm{N}\right)$. As a spatiallyindependent measure of the amplitude of ENSO variability, Table 1 therefore shows the maximum temperature anomalies associated with the principal components displayed in Fig. 4. Based on this metric, the simulated ENSO is $15 \%$ weaker in experiment 6KA than in CONTROL. 


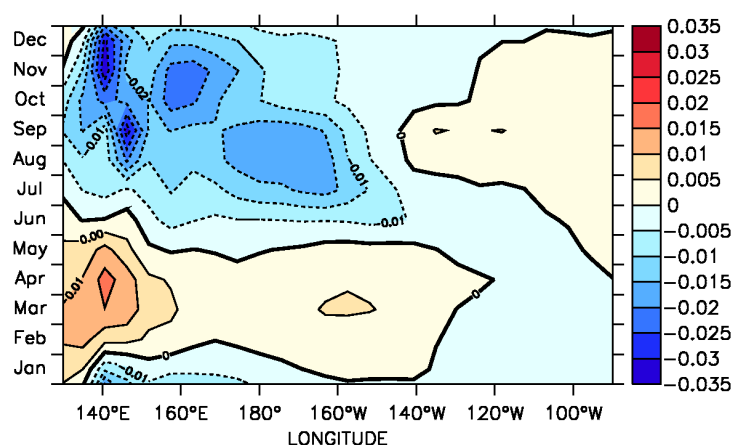

(a) Monthly-mean zonal wind stress

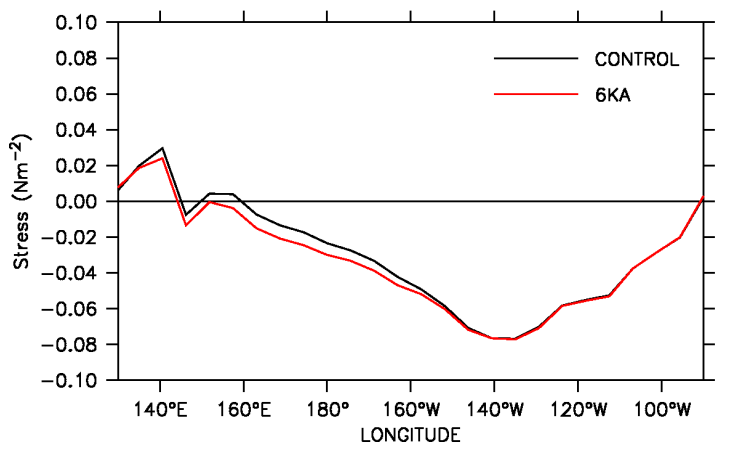

(c) Annual-mean zonal wind stress

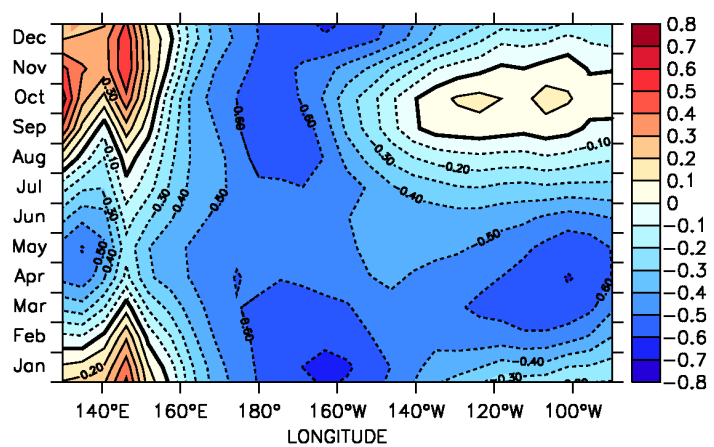

(b) Monthly-mean SST

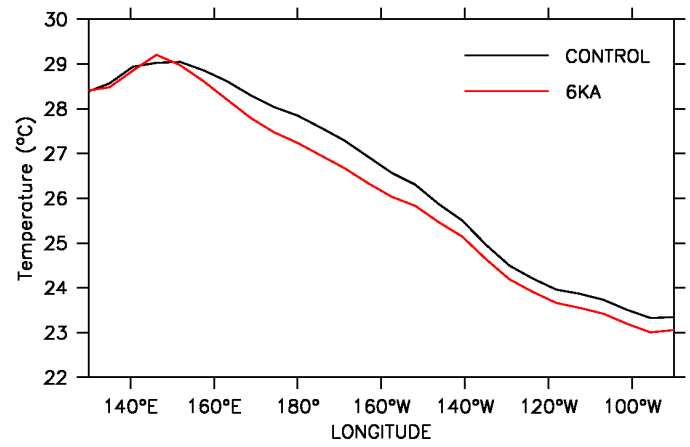

(d) Annual-mean SST

Fig. 5. The equatorial zonal wind stress $\left(\mathrm{N} \mathrm{m}^{-2}\right)$ and sea surface temperature (SST, $\left.{ }^{\circ} \mathrm{C}\right)$ for years $201-1200$ of experiment $6 \mathrm{KA}$ : (a) monthlymean zonal wind stress, expressed as anomalies relative to CONTROL, (b) monthly-mean sea surface temperature, expressed as anomalies relative to CONTROL, (c) annual-mean zonal wind stress, and (d) annual-mean sea surface temperature. The values shown are averages over the region $5^{\circ} \mathrm{S}-5^{\circ} \mathrm{N}$.

The simulated changes in the zonal wind stress and SST over the equatorial Pacific Ocean are shown in Fig. 5. Consistent with the hypothesis of Zheng et al. (2008), the increased insolation during the boreal summer leads to an increase in the strength of the easterly trade winds during the boreal summer and autumn (Fig. 5a). This gives rise to an increase in the zonal temperature gradient (Fig. 5d), and acts to suppress the development of El Niño events. The magnitudes of the zonal wind stress and SST changes are similar to those simulated by Liu et al. (2000).

The wavelet power spectra of the simulated Niño 3.4 SST anomalies, for experiments CONTROL and 6KA, are shown in Fig. 6. Wavelet spectra were calculated using the method of Torrence and Compo (1998), modified following Liu et al. (2007) to ensure a physically consistent definition of energy. As reflected in the reduced variability in the Niño 3 and Niño 3.4 regions, experiment 6KA exhibits less power at almost all timescales. There is also an increase in the period of the simulated ENSO, with peak variability occurring at $6.6 \mathrm{yr}$ in 6KA as opposed to $6.0 \mathrm{yr}$ in CONTROL.

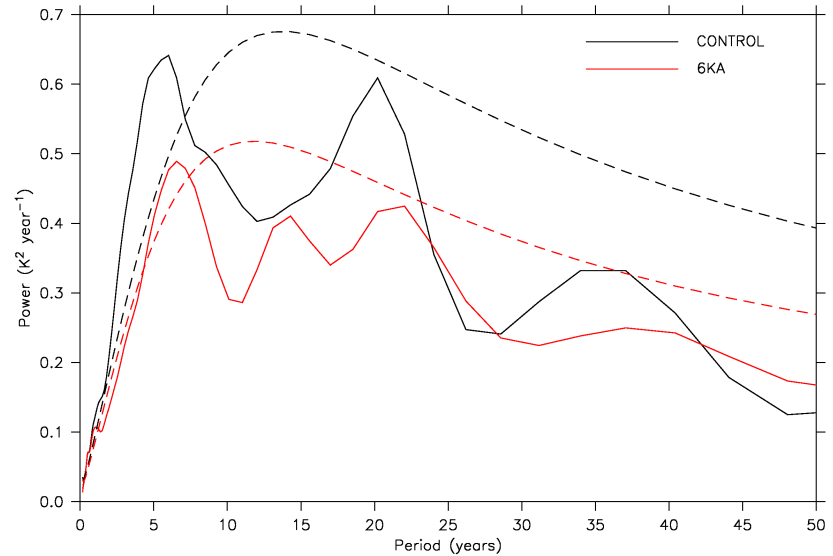

Fig. 6. The wavelet power spectrum of the monthly sea surface temperature anomaly in the Niño 3.4 region $\left(170-120^{\circ} \mathrm{W}, 5^{\circ} \mathrm{S}-5^{\circ} \mathrm{N}\right)$ for years 201-1200 of experiments CONTROL (solid black) and 6KA (solid red). Dashed lines show the $95 \%$ confidence level for a lag-one autoregressive process with the same variance and autocorrelation coefficient as the input data. 


\subsection{Summary}

Mk3L is capable of simulating the larger-scale differences between the climate of the mid-Holocene and that of the present day, with warmer summers at northern mid-latitudes and slight cooling in the tropics. However, discrepancies arise on the regional scale, with the model being unable to capture the full extent of the estimated precipitation changes over Northern Africa. The incorporation of a dynamic vegetation scheme and/or a dust scheme into Mk3L might improve its ability to simulate such changes.

The model simulates a reduction in the strength of $\mathrm{El}$ Niño-Southern Oscillation, accompanied by a westward shift in the location of greatest variability. The simulated reduction in the strength of ENSO is smaller in magnitude than that implied by the palaeoclimate record. This discrepancy may reflect deficiencies in the representation of ENSO within the model, with the simulated present-day ENSO being too weak and too slow relative to observations (Part 1; Phipps et al., 2011). These deficiencies are likely to be a consequence of the model's reduced spatial resolution.

Flux adjustments are applied in $\mathrm{Mk} 3 \mathrm{~L}$, both to improve the realism of the simulated control climate and to minimise drift. Studies using two other climate system models have shown that flux-adjusted and non-flux-adjusted versions of the same model can exhibit differences in the response to mid-Holocene boundary conditions. Brown et al. (2008) find that the large-scale changes in temperature and precipitation are similar between two different versions of HadCM3, and therefore that flux adjustments have no leading-order impact. However, there are regional-scale differences in the response of the model, particularly in the tropical Pacific. Kitoh et al. (2007) analyse two different versions of MRI-CGCM2.3, and reach a similar conclusion. However, flux adjustments are found to influence the simulated response of ENSO to external forcings in both models. In the flux-adjusted versions, the changes in ENSO amplitude in response to mid-Holocene boundary conditions are $+4 \%$ and $-2 \%$ in $\mathrm{HadCM} 3$ and MRI-CGCM2.3, respectively. In contrast, in the non-fluxadjusted versions, the ENSO amplitude changes by $-14 \%$ and $-15 \%$, respectively. These differences in the response of each model are attributed to the effect of flux adjustments on seasonal phase-locking (Brown et al., 2008) and on the strength of the ocean-atmosphere feedback (Kitoh et al., 2007). A comparison with proxy data therefore suggests that the non-flux-adjusted versions of HadCM3 and MRI-CGCM2.3 are more realistic, as they simulate stronger reductions in ENSO variability. However, as the flux adjustments act via their effects on the control climate, there is no evidence that they directly affect the response of either model. Notable biases exist in the control climates of both non-flux-adjusted models, and it is therefore hard to argue that these versions are more realistic overall (Brown et al., 2008; Kitoh et al., 2007).

\section{Transient simulations of the late Holocene}

\subsection{Introduction}

In recent years, the computational power of highperformance computing facilities has increased to the point where it is now possible to use fully-coupled atmosphereocean general circulation models (AOGCMs) such as Mk3L to carry out multi-millennial simulations. This has enabled the use of AOGCMs to explore the transient evolution of the climate system over periods such as the late Holocene (Lorenz and Lohmann, 2004; Liu et al., 2006; Lorenz et al., 2006; Schurgers et al., 2006; Fischer and Jungclaus, 2011; Varma et al., 2012). The computational expense of a stateof-the-art AOGCM can be sufficiently prohibitive that it is necessary to reduce the execution time, and some of these studies have therefore employed the acceleration technique of Lorenz and Lohmann (2004). This technique accelerates the rate of change in the Earth's orbital parameters, on the assumption that the response timescale of the climate system is much shorter than the timescales on which orbital forcing is significant.

This section examines the transient response of $\mathrm{Mk} 3 \mathrm{~L}$ to the insolation changes that arose during the late Holocene from the pseudo-cyclical variations in the Earth's orbital parameters. Using the mid-Holocene simulation from Sect. 2 as the initial state, the model is used to conduct transient simulations of the period from $6000 \mathrm{yr} \mathrm{BP}$ to the present day.

\subsection{Experimental design}

Three transient simulations were conducted for the period from $6000 \mathrm{yr} \mathrm{BP}$ to the present day $(0 \mathrm{yr} \mathrm{BP}$, equivalent to $1950 \mathrm{CE}$ ). The acceleration technique of Lorenz and Lohmann (2004) was employed, with acceleration factors of 5, 10 and 20. These experiments are designated HOLO5, HOLO10 and HOLO20, and have total durations of 1200 , 600 and 300 model years, respectively.

Each experiment was initialised from the state of experiment 6KA at the end of model year 1000. The Earth's orbital parameters were then varied, with the appropriate acceleration factors being applied. As the intention of these experiments is to study the response of the model to orbital forcing, all the other boundary conditions were held constant, with a solar constant of $1365 \mathrm{~W} \mathrm{~m}^{-2}$ and an atmospheric $\mathrm{CO}_{2}$ concentration of $277 \mathrm{ppm}$. Although this is $3 \mathrm{ppm}$ lower than the concentration of $280 \mathrm{ppm}$ used in the control simulation, this equates to a radiative forcing of only $0.06 \mathrm{~W} \mathrm{~m}^{-2}$. Apart from the orbital parameters and this difference in the atmospheric $\mathrm{CO}_{2}$ concentration, the boundary conditions were otherwise identical to the control.

Relative to the present day, the initial insolation anomalies were the same as those applied in the mid-Holocene simulation (Fig. 1b). Over the course of the transient simulations, these anomalies reduced in magnitude towards zero. Figure 7 


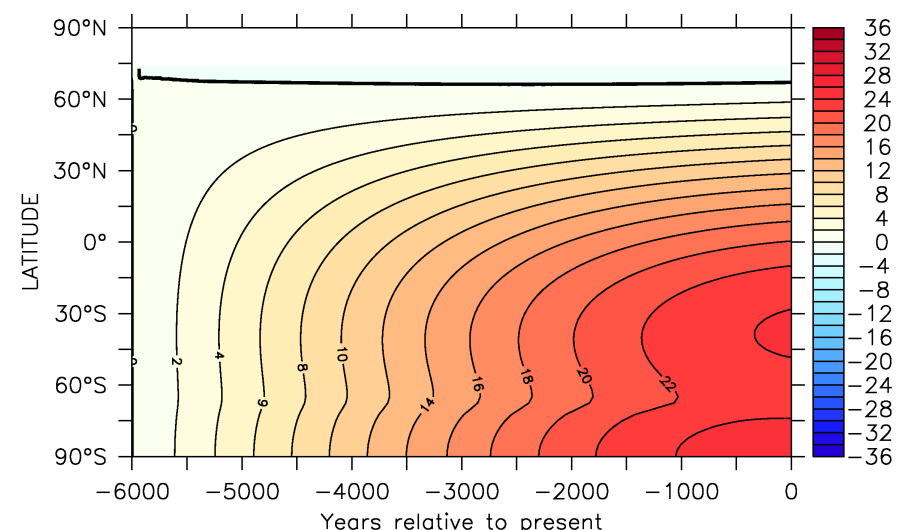

(a) January

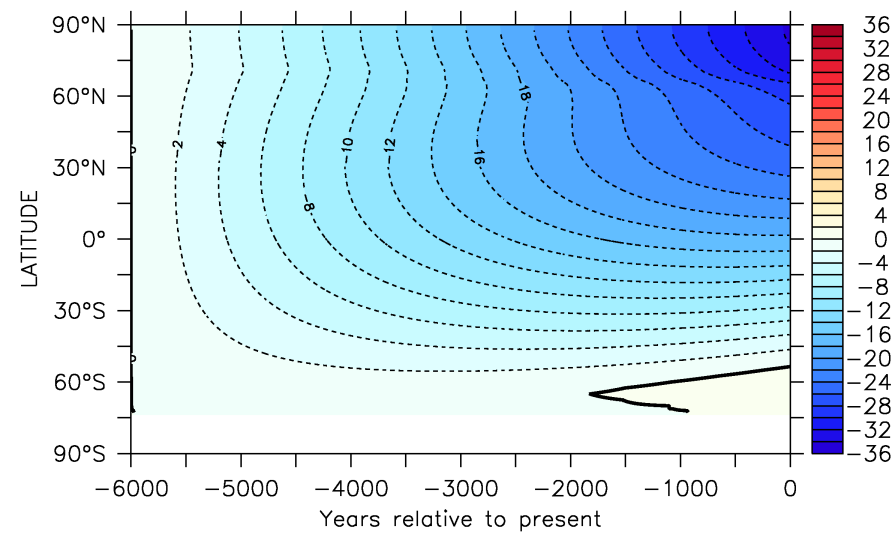

(b) July

Fig. 7. The evolution of monthly-mean insolation $\left(\mathrm{W} \mathrm{m}^{-2}\right)$ during the late Holocene, expressed as an anomaly relative to $6000 \mathrm{yr} \mathrm{BP}$ : (a) January, and (b) July.

shows the evolution of the mean January and July insolation during the late Holocene as a function of latitude, and shows that the trends at most latitudes are monotonic. The forcing applied to the model can therefore be characterised as consisting of decreasing insolation during the Northern Hemisphere summer and Southern Hemisphere spring, with increasing insolation during the Southern Hemisphere summer.

\subsection{Surface air temperature}

The evolution of the simulated mean SAT during the Northern and Southern Hemisphere summers is shown in Fig. 8. Starting from the relatively warm mid-Holocene state, the Northern Hemisphere cools steadily in response to the decreasing insolation. Likewise, the Southern Hemisphere, starting from the relatively cool mid-Holocene state, warms steadily in response to the increasing insolation. In both hemispheres, the mean temperatures stabilise during the final millennium as the rates of change in insolation decrease. Any differences between the three experiments are consistent with the amplitude of the simulated internal variability. This

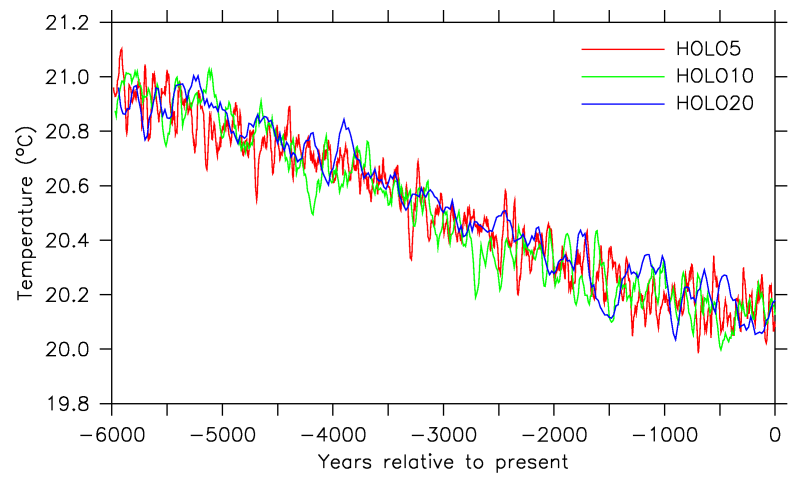

(a) Northern Hemisphere: August

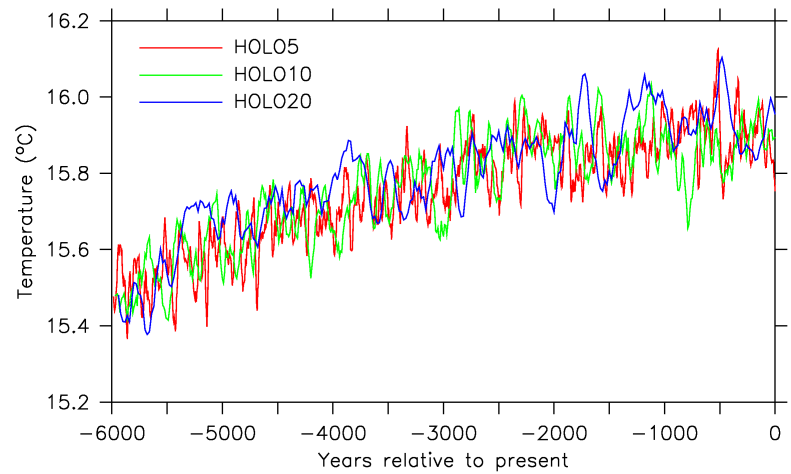

(b) Southern Hemisphere: February

Fig. 8. The evolution of hemispheric-mean surface air temperature during experiments HOLO5 (red), HOLO10 (green) and HOLO20 (blue): (a) Northern Hemisphere, August, and (b) Southern Hemisphere, February. The values shown are running means across five model years.

demonstrates that the assumption underlying the acceleration technique is valid, at least in these circumstances. Neither is there any evidence from Fig. 8 that model drift accounts for any divergence between the experiments. Because of the use of accelerated boundary conditions, none of the experiments span more than 1200 model years; the acceleration technique therefore acts to reduce the contribution of any background model drift towards the simulated long-term trends.

The linear trends in February and August SAT, derived by calculating the line of best fit at each gridpoint, are shown in Fig. 9. The spatial variations in the sign and magnitude of the trends reflect the anomalies in the SAT, relative to the present day, that existed at the start of the simulation period (Fig. 2c and d). In February, warming occurs at low latitudes and over Antarctica, with cooling over the high-latitude oceans. Particularly strong cooling over the Arctic Ocean is also simulated by Lorenz and Lohmann (2004) and Fischer and Jungclaus (2011), and represents the amplification of the forcing signal by sea ice feedbacks. In August, there is strong cooling over almost all the continental landmasses, particularly in the Northern Hemisphere, accompanied by some localised warming in the tropics and the Southern Ocean. 


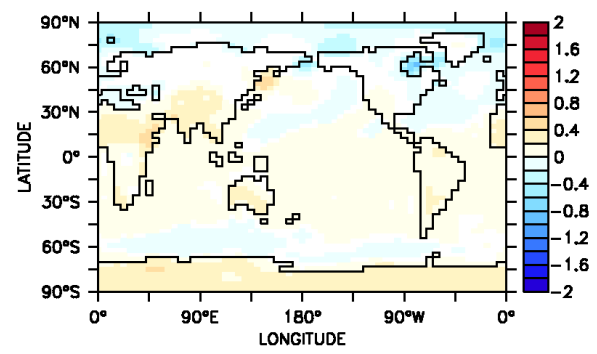

(a) February: HOLO5

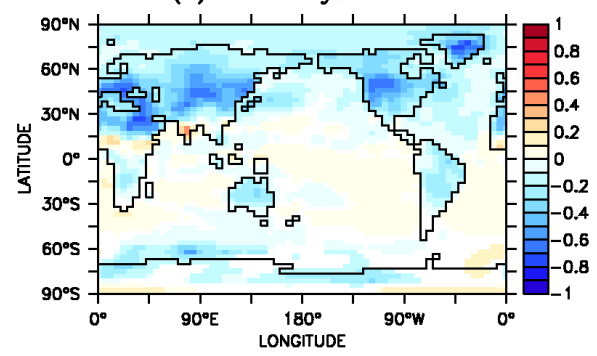

(d) August: HOLO5

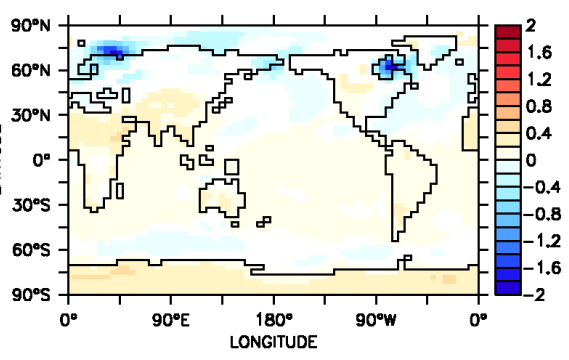

(b) February: HOL010

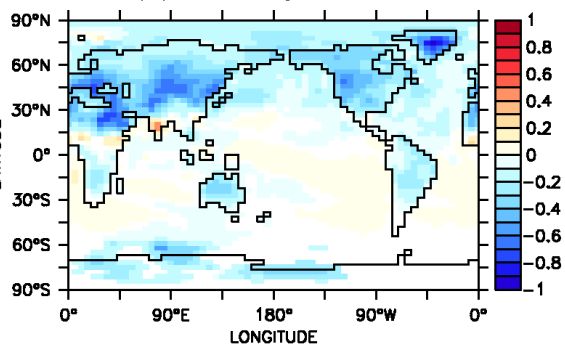

(e) August: HOLO10

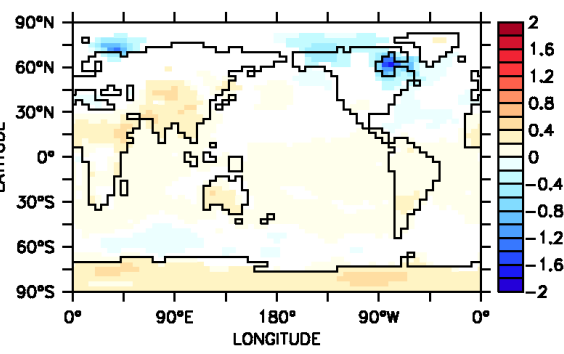

(c) February: HOLO20

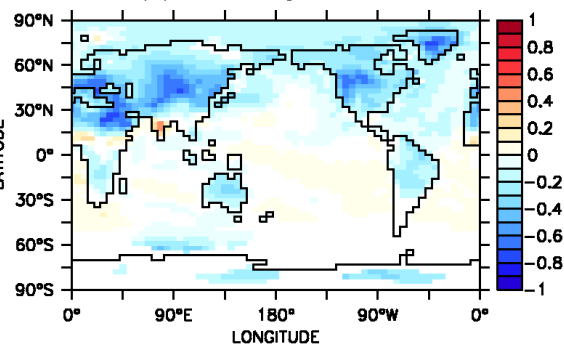

(f) August: HOLO2O

Fig. 9. The linear trend in surface air temperature (K per $1000 \mathrm{yr}$ ) during the late Holocene: (a-c) February, experiments HOLO5, HOLO10 and HOLO20, respectively, and (d-f) August, experiments HOLO5, HOLO10 and HOLO20, respectively. Only values that are significant at the $95 \%$ confidence level are shown. Note the different scale bars for the February and August plots.

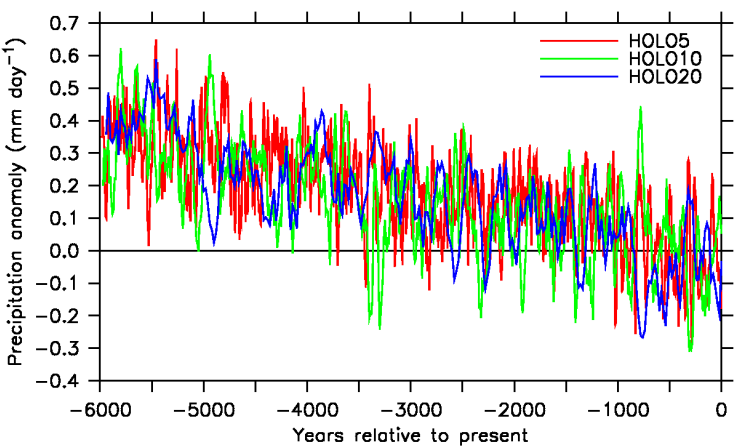

(a) June-September: Northern Africa

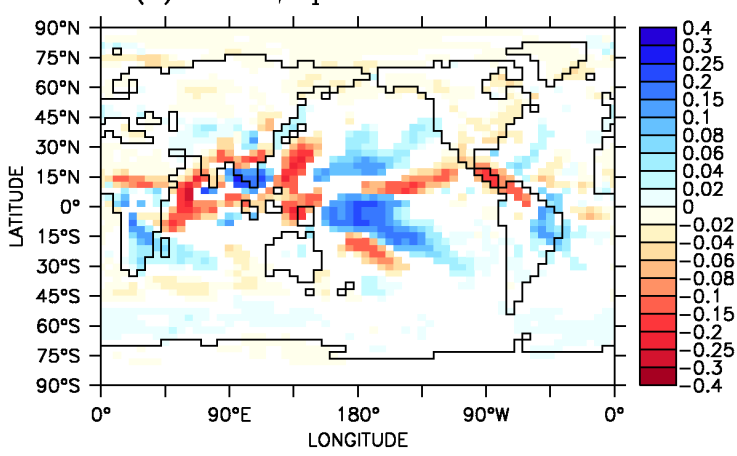

(c) Annual: HOLO10

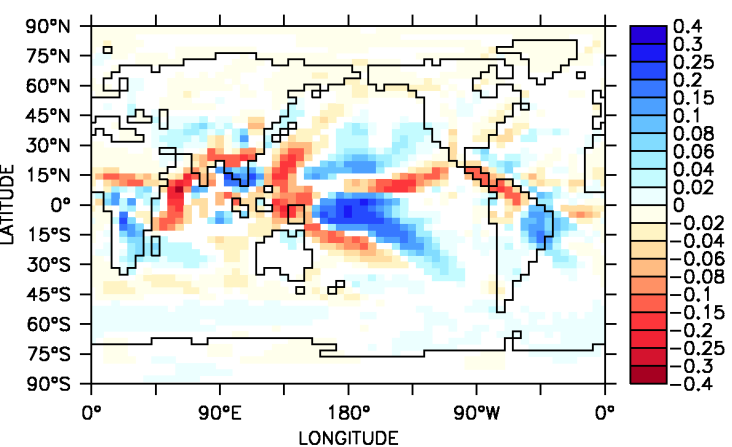

(b) Annual: HOLO5

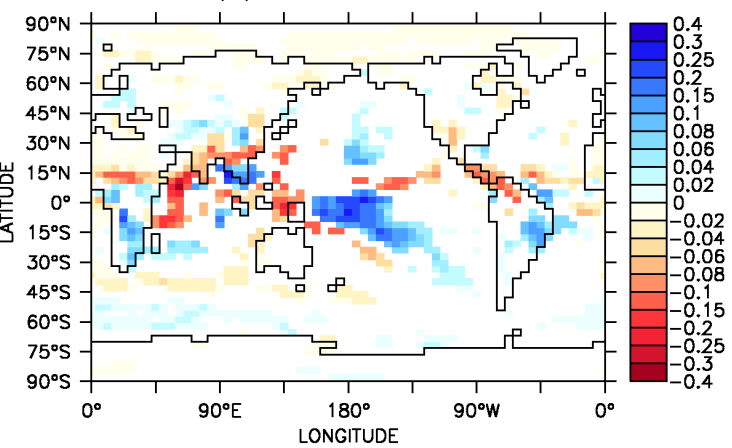

(d) Annual: HOLO20

Fig. 10. The evolution of precipitation during the late Holocene: (a) June-September precipitation over Northern Africa $\left(20^{\circ} \mathrm{W}-30^{\circ} \mathrm{E}, 10-\right.$ $25^{\circ} \mathrm{N}$ ), expressed as an anomaly relative to CONTROL; the values shown are running means across five model years, and (b-d) the linear trend in annual-mean precipitation $\left(\mathrm{mm} \mathrm{day}^{-1}\right.$ per $1000 \mathrm{yr}$ ) for experiments HOLO5, HOLO10 and HOLO20, respectively. In (b-d), only values that are significant at the $95 \%$ confidence level are shown. 
Over most of the Earth's surface, the trends are independent of the magnitude of the acceleration factor used. However, as the acceleration factor is increased, there are fewer values that are significant at the $95 \%$ confidence level. Over sea ice in the winter hemisphere, there are also locations where the magnitude of the trend differs between experiments; this is most apparent over the Barents Sea and Hudson Bay in February. With the sea ice cover acting to insulate the atmospheric boundary layer from the underlying ocean, the magnitude of the interannual variability in SAT is large compared to the long-term trend. As the acceleration factor is increased, the trend therefore becomes increasingly poorly constrained. Lorenz and Lohmann (2004), who use a larger range of acceleration factors (10 and 100), also find that the SAT trends in some regions can depend upon the factor. The mismatches in their case are attributed to a combination of stochastic variability and model drift.

\subsection{Precipitation}

The evolution of the June-September precipitation over Northern Africa $\left(20^{\circ} \mathrm{W}-30^{\circ} \mathrm{E}, 10-25^{\circ} \mathrm{N}\right)$ during each experiment is shown in Fig. 10a, with the total precipitation exhibiting a slow and steady decline towards the present-day value. As with the surface air temperature, any diffences between the three experiments are consistent with the amplitude of the simulated internal variability.

The gradual drying trend exhibited by the model contrasts with the abrupt desertification of Northern Africa that appears to have occurred in reality. Terrigenous marine sediments indicate that the Sahara underwent a transition from a vegetated state to an arid state over a period of several decades to centuries, centred at $5490 \pm 190 \mathrm{yr}$ BP (deMenocal et al., 2000); however, the spatial extent and duration of these changes is still under discussion (Kröpelin et al., 2008; Brovkin and Claussen, 2008). Mk3L includes a land surface scheme with static vegetation, and the model is therefore incapable of simulating such a transition. The lack of dynamic vegetation means that the model omits an important feedback within the climate system and, as discussed in Sect. 2, it is possible that this accounts for the deficiency in the simulated mid-Holocene precipitation over Northern Africa. Rather, Mk3L simulates a physically-driven precipitation trend that might have occurred in the absence of vegetation feedbacks. This is consistent with transient simulations conducted using models with dynamic vegetation schemes, which show an ongoing precipitation decline even after the Sahara has transitioned to an arid state (deMenocal et al., 2000; Liu et al., 2006).

The linear trends in annual-mean precipitation, derived by calculating the line of best fit at each gridpoint, are shown in Fig. 10b-d. As with SAT, the spatial variations in the trends reflect the precipitation anomalies, relative to the present day, that existed at the start of the simulation period (Fig. 3c). Negative trends over Northern Africa, India and southeast
Asia reflect the weakening and southward migration of the African-Asian monsoon system. There is also a southward migration of the South American monsoon and an eastward migration of the monsoonal precipitation associated with the South Pacific Convergence Zone. The spatial patterns of the trends exhibited by the three experiments are in good agreement, indicating the robustness of the acceleration technique. However, as with SAT, increases in the acceleration factor cause a reduction in the area over which the trends are significant at the $95 \%$ confidence level.

\subsection{Ocean temperature}

Figure 11a-c shows the evolution of the simulated annualmean SST in the southern extratropics $\left(90-30^{\circ} \mathrm{S}\right)$, the tropics $\left(30^{\circ} \mathrm{S}-30^{\circ} \mathrm{N}\right)$ and the northern extratropics $\left(30-90^{\circ} \mathrm{N}\right)$. Starting from a time when annual-mean insolation in the tropics was lower than today (Fig. 1a), tropical SSTs warm steadily as insolation increases (Fig. 11b). In contrast, starting from a time when annual-mean insolation at high latitudes was higher than today, SSTs in the northern extratropics cool steadily as insolation decreases (Fig. 11c). No equivalent cooling signal is seen in the southern extratropics (Fig. 11a), as the Southern Ocean spans the mid-latitudes where the change in annual-mean insolation is small. Any differences between the three experiments are consistent with the amplitude of the simulated internal variability, indicating that the assumption underlying the acceleration technique is valid, at least for the surface ocean. However, the use of acceleration does cause interdecadal variability within each simulation to manifest itself as centennial- to millennialscale variations; this is most apparent in the southern extratropics.

The evolution of the mean potential temperature for the upper ocean $(0-800 \mathrm{~m})$, mid-ocean $(800-2350 \mathrm{~m})$ and deep ocean (2350-4600 m) is shown in Fig. 11d-f. A cooling trend is apparent at all depths, which is driven by the reduction in SSTs at high northern latitudes and hence a reduction in the temperature of North Atlantic Deep Water (not shown). However, the responses of the three experiments differ. In the upper ocean, experiments HOLO5 and HOLO10 exhibit consistent trends, but the simulated rate of cooling is slower in HOLO20. The divergence between the three experiments becomes greater with depth; in the deep ocean, the cooling simulated by experiment HOLO5 is almost completely absent in HOLO20. The assumption underlying the acceleration technique - namely, that the response timescale of the climate system is negligibly short compared to the timescales on which orbital forcing is significant - therefore breaks down when considering changes in the ocean interior.

If the accurate simulation of ocean temperatures is critical, then acceleration should not be used. The simulated temperature of the deep ocean differs by less than $0.1 \mathrm{~K}$ between the three experiments considered here, but the simulations continue to diverge throughout. If longer periods of time were 


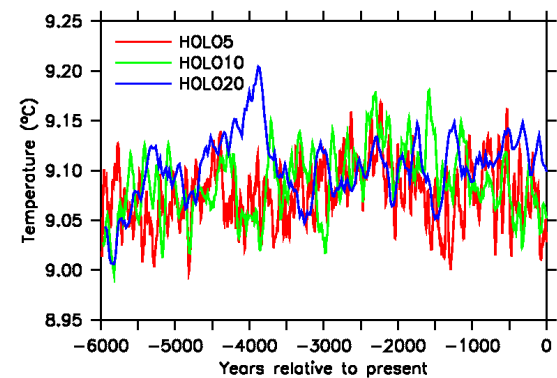

(a) Sea surface $\left(90^{\circ} \mathrm{S}-30^{\circ} \mathrm{S}\right)$

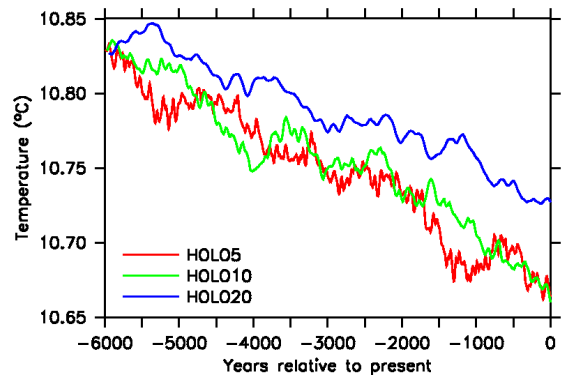

(d) Upper ocean $(0-800 \mathrm{~m})$

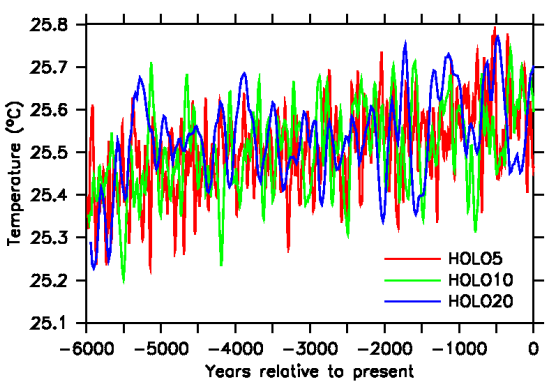

(b) Sea surface $\left(30^{\circ} \mathrm{s}-30^{\circ} \mathrm{N}\right)$

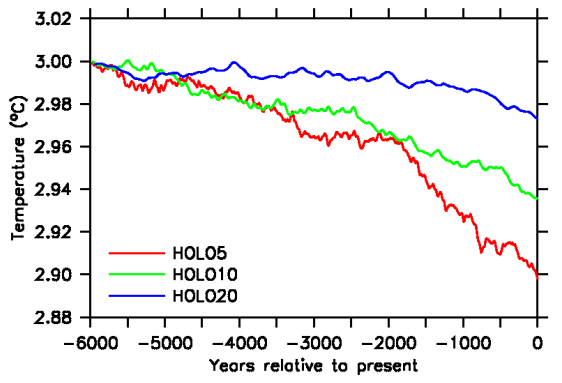

(e) Mid-ocean (800-2350 m)

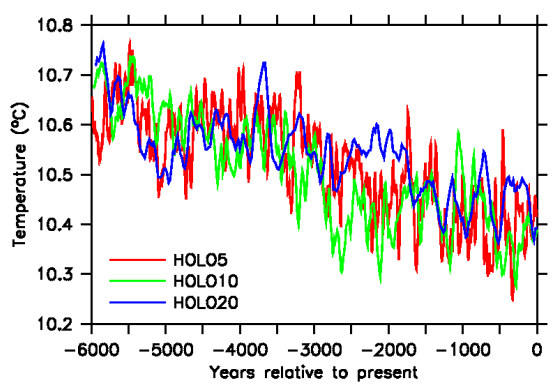

(c) Sea surface $\left(30^{\circ} \mathrm{N}-90^{\circ} \mathrm{N}\right)$

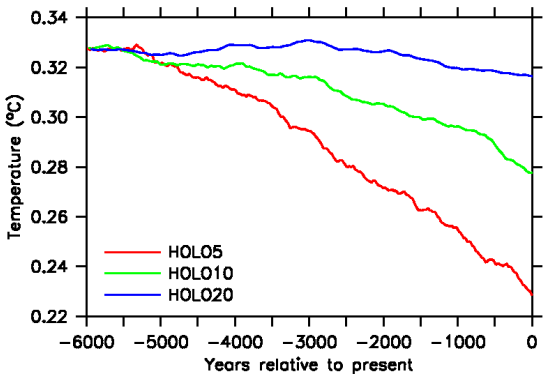

(f) Deep ocean $(2350-4600 \mathrm{~m})$

Fig. 11. The evolution of annual-mean potential temperature during experiments HOLO5 (red), HOLO10 (green) and HOLO20 (blue): (a) the sea surface $\left(90-30^{\circ} \mathrm{S}\right)$, (b) the sea surface $\left(30^{\circ} \mathrm{S}-30^{\circ} \mathrm{N}\right)$, (c) the sea surface $\left(30-90^{\circ} \mathrm{N}\right)$, (d) the upper ocean $(0-800 \mathrm{~m})$, (e) the mid-ocean $(800-2350 \mathrm{~m})$, and (f) the deep ocean $(2350-4600 \mathrm{~m})$. The values shown are running means across five model years.

being simulated, such as glacial cycles, then it is likely that the use of large acceleration factors would give rise to significant errors in the simulated ocean temperatures. These might influence the density structure of the ocean to such an extent as to have a significant impact upon the thermohaline circulation, with consequences for the accuracy of the simulated climate at the Earth's surface. Nonetheless, there is no evidence of any such errors arising for the acceleration factors and time periods considered here.

\subsection{El Niño-Southern Oscillation}

The evolution of ENSO variability during each experiment, as measured by the standard deviation in the monthly Niño 3.4 SST anomaly, is shown in Fig. 12. A moving window with a width of 1000 calendar years is used to determine the standard deviation; this is equivalent to 200,100 and 50 model years, respectively, for experiments HOLO5, HOLO10 and HOLO20. To allow the variability to be sampled right up to the present day, each experiment was integrated for a further 500 calendar years.

An overall upward trend in ENSO variability is simulated by experiment HOLO5, which is consistent with the suppressed variability, relative to the present day, at the start of the simulation period. Considerable millennial-scale variability is also apparent, with a period of relatively weak ENSO variability centred at around $3800 \mathrm{yr} \mathrm{BP}$, and a period of stronger-than-present ENSO variability centred at around $300 \mathrm{yr}$ BP. Strong millennial-scale variability is also encoun- tered in proxy-based reconstructions such as that of Moy et al. (2002), although the use of an acceleration technique here prevents any direct comparison between the model and reconstructions.

Experiments HOLO10 and HOLO20 simulate an overall upward trend in ENSO variability over the late Holocene, as for HOLO5. However, there are considerable differences between the three experiments. In particular, the natures of the simulated millennial-scale variations differ, and the amplitude of the millennial-scale variability is larger in experiment HOLO20 than in the others. The sampling interval corresponds to just 50 model years for the latter experiment. This lack of robustness displayed by the results is consistent with the model-based analysis of Wittenberg (2009), which concludes that at least $500 \mathrm{yr}$ of data may be required in order to adequately sample ENSO variability. While this is a formidable requirement from an observational perspective, the use of large ensembles can allow for adequate sampling of ENSO variability within model simulations.

\subsection{Summary}

Mk3L is capable of simulating some of the main features of the transient response of the climate system to insolation changes over the late Holocene. Decreasing insolation during the Northern Hemisphere summer results in large-scale cooling, while increasing insolation during the Southern Hemisphere summer results in large-scale warming. A gradual drying trend in Northern Africa is apparent, although the 
lack of a dynamic vegetation scheme prevents the model from simulating the abrupt desertification that appears to have occurred in reality. There is also a gradual increase in ENSO variability.

The acceleration technique of Lorenz and Lohmann (2004) was used to reduce the duration of each experiment. Trends in hemispheric-mean surface air temperature, and in precipitation over Northern Africa, are found to be independent of the acceleration factor used. This is consistent with the underlying assumption that orbital forcing operates on timescales much longer than the response timescale of the climate system. However, the use of acceleration reduces the sampling frequency such that there is insufficient data to adequately constrain trends in surface air temperature or precipitation at locations with large interannual variability, or to adequately sample changes in ENSO variability on millennial timescales. This is due to the acceleration technique, and is not a shortcoming of the model itself. The use of acceleration also influences the simulated temperatures in the ocean interior, which might introduce significant errors if large acceleration factors were to be used to simulate very long periods of time.

\section{Transient simulation of the last millennium}

\subsection{Introduction}

The last millennium provides a valuable opportunity to evaluate climate system models and to study the sensitivity of the climate system. Proxy-based reconstructions are available that have both high temporal resolution and widespread geographical coverage (e.g., Mann et al., 2009). The boundary conditions on the climate system over this period, including atmospheric trace gases, solar irradiance and volcanic emissions, are also reasonably well constrained (e.g., Schmidt et al., 2011). The sensitivity of the climate system to different forcings can therefore be studied, and climate system models can be evaluated by forcing them with the known boundary conditions and then comparing the resulting simulations against the available proxy data. For these reasons, recent studies have used a range of climate system models to study the climate of the last millennium (Fan et al., 2009; Liu et al., 2009; Jungclaus et al., 2010; Servonnat et al., 2010; Hofer et al., 2011).

In this section, the transient response of $\mathrm{Mk} 3 \mathrm{~L}$ to known climatic forcings during the period 1001 to $2000 \mathrm{CE}$ is studied. Specifically, the model is forced with changes in the Earth's orbital parameters, solar irradiance, anthropogenic greenhouse gases and stratospheric sulphate aerosols arising from volcanic emissions. The resulting simulation is then compared against observations and proxy-based reconstructions of past climate.

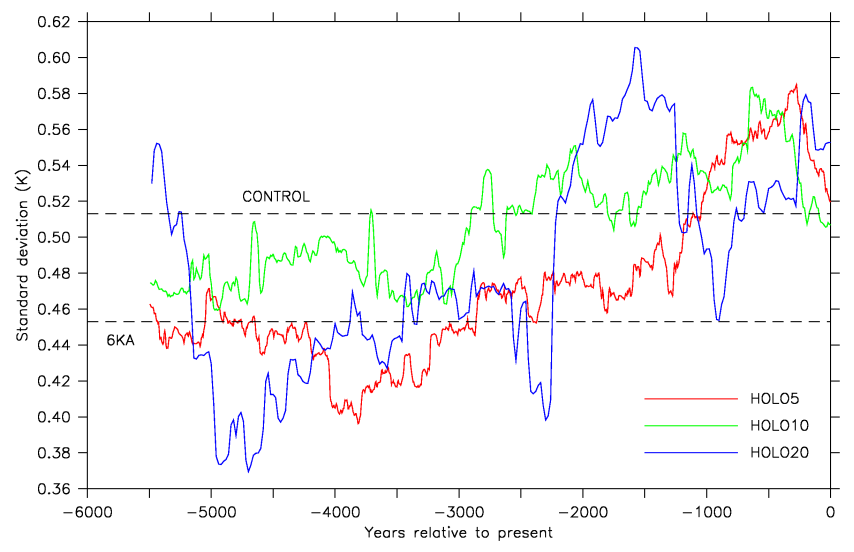

Fig. 12. The evolution of the standard deviation of the monthly sea surface temperature anomaly in the Niño 3.4 region $\left(170-120^{\circ} \mathrm{W}\right.$, $5^{\circ} \mathrm{S}-5^{\circ} \mathrm{N}$ ) during experiments HOLO5 (red), HOLO10 (green) and HOLO20 (blue). A moving window with a width of 1000 calendar years is used to calculate the standard deviation. Horizontal dashed lines show the amplitude of ENSO variability in experiments CONTROL and 6KA.

\subsection{Experimental design}

The Earth's orbital parameters are calculated internally by the model, using the method of Berger (1978). However, the insolation changes arising from orbital forcing over the last millennium are relatively modest (Fig. 13a). At low latitudes, the changes consist of increasing insolation during the first half of the year, accompanied by decreasing insolation during the second half. At high latitudes, relatively strong decreases in insolation occur during the Northern Hemisphere summer and autumn, as well as during the Southern Hemisphere spring and summer. These decreases are accompanied by smaller increases in insolation during the other times of the year.

Total solar irradiance (TSI) was taken from Steinhilber et al. (2009). This reconstruction is derived from measurements of the cosmogenic radionuclide ${ }^{10} \mathrm{Be}$ in polar ice cores and covers the past $9300 \mathrm{yr}$. The data is supplied as $40-\mathrm{yr}$ means and thus does not include the 11-yr solar cycle. Values for TSI are provided at 5-yr intervals, so linear interpolation in time was used to derive annual values. The resulting timeseries is shown in Fig. 13b. Dips in TSI that persist for multiple decades represent the solar grand minima (Eddy, 1976; Usoskin et al., 2007), with the lowest solar activity over the last millennium being associated with the Spörer Minimum ( 1390-1550 CE). Other dips are associated with the Wolf Minimum ( 1270-1340 CE), the Maunder Minimum $(\sim 1645-1715$ CE) and the Dalton Minimum ( $\sim 1790$ 1830 CE). Compared with earlier reconstructions (e.g., Lean et al., 1995; Lean, 2000), the magnitude of the TSI reduction associated with the Maunder Minimum is much smaller. The minimum value of the TSI during the Maunder Minimum 


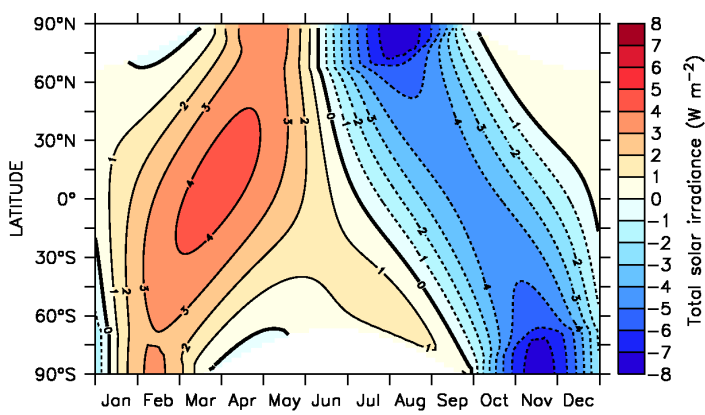

(a) Insolation (2000 CE - $1001 \mathrm{CE})$

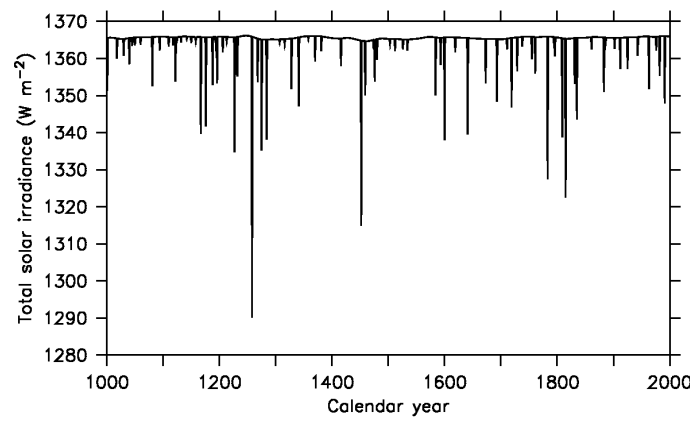

(c) Effective total solar irradiance

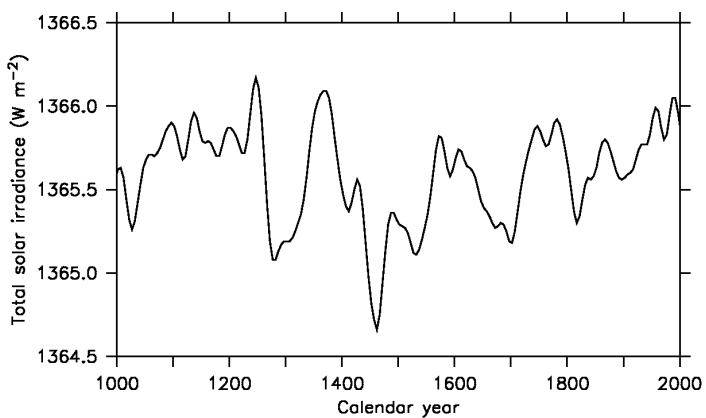

(b) Total solar irradiance

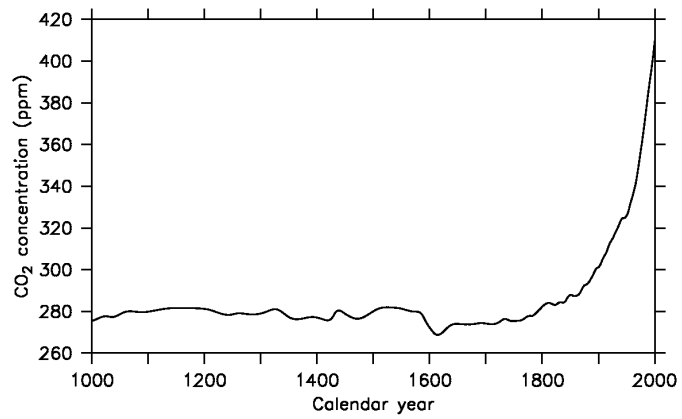

(d) Equivalent $\mathrm{CO}_{2}$ concentration

Fig. 13. The boundary conditions applied during experiment LAST1000: (a) the change in insolation arising from orbital forcing, 2000 CE minus $1001 \mathrm{CE}\left(\mathrm{W} \mathrm{m}^{-2}\right)$, (b) total solar irradiance, (c) effective total solar irradiance, taking into account stratospheric sulphate aerosols arising from volcanic eruptions, and (d) equivalent atmospheric carbon dioxide concentration.

is only $\sim 0.9 \mathrm{~W} \mathrm{~m}^{-2}$ below the mean value for the $1986-$ 1996 CE solar cycle, as opposed to estimates of $\sim 3.2$ and $\sim 2.8 \mathrm{~W} \mathrm{~m}^{-2}$ for Lean et al. (1995) and Lean (2000), respectively.

The values for stratospheric sulphate aerosol loading were taken from the Ice-core Volcanic Index 2 (IVI2; Gao et al., 2008). Following the documentation supplied with the dataset, the 1982 El Chichón eruption was incorporated by adding a loading of $14 \mathrm{Tg}$ to the Northern Hemisphere timeseries. Version 1.0 of Mk3L does not include a sulphate aerosol scheme, and so the values for the stratospheric sulphate aerosol loading were converted into an equivalent anomaly in the TSI. This process involved three distinct stages, as follows. Stage 1: following Stothers (1984) and Gao et al. (2008), the global aerosol loading was divided by $150 \mathrm{Tg}$ to obtain a global-mean value for the aerosol optical depth (which is a dimensionless quantity). To allow for the effects of coagulation, the loadings were scaled according to a two-thirds power law for values greater than $15 \mathrm{Tg}$ (Crowley, 2000). Stage 2: following Wigley et al. (2005) and Gao et al. (2008), the aerosol optical depth was multiplied by $-20 \mathrm{~W} \mathrm{~m}^{-2}$ to obtain a global-mean radiative forcing. Stage 3: to obtain an equivalent anomaly in the TSI, the radiative forcing was multiplied by a factor of 5.69; this represents the ratio between the TSI $\left(1365 \mathrm{~W} \mathrm{~m}^{-2}\right)$ and the observed net downward shortwave flux at the top of the atmosphere $\left(240 \mathrm{~W} \mathrm{~m}^{-2}\right)$.
The volcanic anomalies were added to the timeseries of TSI derived from Steinhilber et al. (2009) to derive values of an effective TSI. The resulting timeseries is shown in Fig. 13c, and it is these values that were used to force the model. The largest volcanic eruption to take place during the last millennium is that of $1258 \mathrm{CE}$, the location of which is unknown (Gao et al., 2008). This gives rise to a radiative forcing of $-13 \mathrm{~W} \mathrm{~m}^{-2}$, equivalent to a $5.5 \%$ reduction in TSI. Other eruptions which give rise to a reduction of at least $2.5 \%$ in TSI are Kuwae (1452 CE), Laki (1783 CE) and Tambora (1815CE). The radiative forcing caused by the $1991 \mathrm{CE}$ Pinatubo eruption is $-3.2 \mathrm{~W} \mathrm{~m}^{-2}$, equivalent to a $1.3 \%$ reduction in TSI and in agreement with both observationally-derived values of $-2.7 \pm$ $1.0 \mathrm{~W} \mathrm{~m}^{-2}$ (Minnis et al., 1993) and calculated values of around $-3 \mathrm{~W} \mathrm{~m}^{-2}$ (Forster et al., 2007). Limitations in both the model physics and the reconstruction result in inherently unrealistic representations of volcanic eruptions. The radiative forcing associated with each eruption is both spatially and seasonally uniform, being applied from 1 January to 31 December of the year in which the eruption took place. However, the annual- and global-scale representation of the impacts should be at least approximately correct.

From Fig. 13, it is apparent that the radiative forcings caused by individual volcanic eruptions can exceed the amplitude of the changes in TSI by up to two orders of magnitude. Even on centennial timescales, volcanic forcing of 


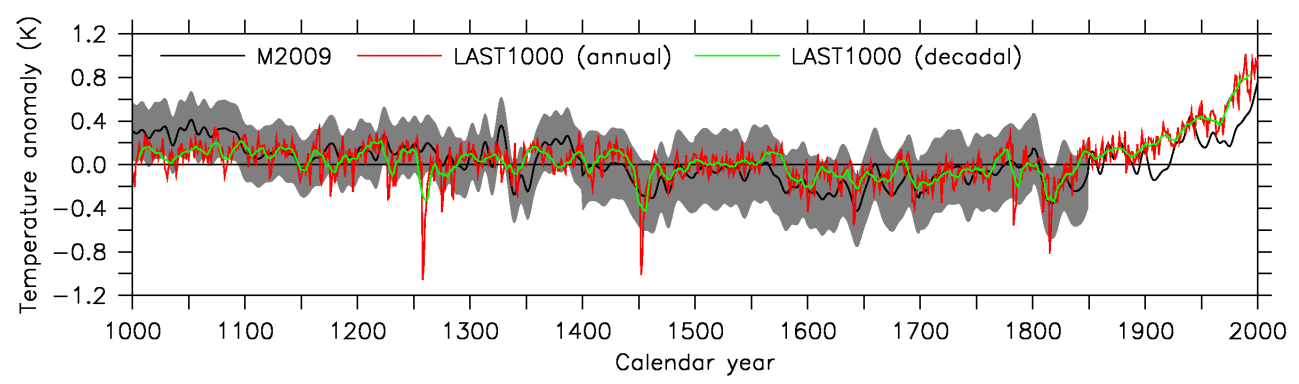

(a) Northern Hemisphere surface air temperature

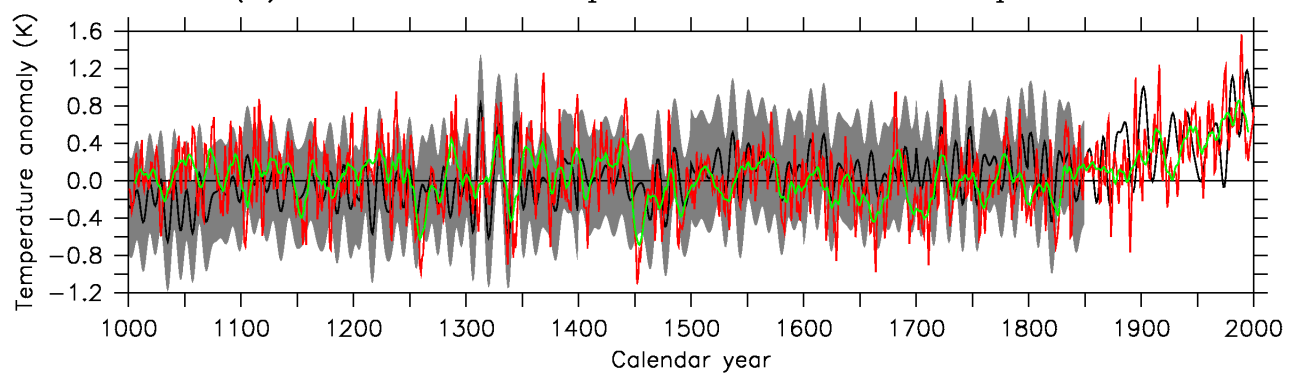

(b) Nino 3 sea surface temperature

Fig. 14. The changes in surface temperature over the last millennium according to the "all proxy" timeseries of Mann et al. (2009) (black) and experiment LAST1000 (annual values in red, 10-yr running mean in green): (a) Northern Hemisphere surface air temperature, and (b) Niño 3 sea surface temperature. The values shown are expressed as anomalies relative to the 1001-1850 CE mean. The $95 \%$ confidence interval for Mann et al. (2009) is indicated by grey shading.

the climate system can therefore be more important than solar forcing on a global scale. Volcanic forcing is strongest in the 13th century, with an average radiative forcing of $-0.34 \mathrm{~W} \mathrm{~m}^{-2}$, and weakest in the 11th, 14th and 16th centuries, with an average radiative forcing of $-0.08 \mathrm{~W} \mathrm{~m}^{-2}$. These figures compare with a peak radiative forcing associated with the Maunder Minimum of $-0.16 \mathrm{~W} \mathrm{~m}^{-2}$, but are still small in magnitude compared with present-day anthropogenic radiative forcing of around $+1.6 \mathrm{~W} \mathrm{~m}^{-2}$ (Forster et al., 2007). However, volcanic eruptions and changes in TSI affect the climate system in ways that cannot be represented by a simple radiative forcing (Shindell et al., 2003). Stratospheric sulphate aerosols and solar ultraviolet irradiance both affect atmospheric ozone concentrations and the thermal structure of the atmosphere. Without an aerosol scheme or an atmospheric chemistry scheme, version 1.0 of $\mathrm{Mk} 3 \mathrm{~L}$ cannot simulate these effects.

Anthropogenic greenhouse gas concentrations were taken from MacFarling Meure et al. (2006). This dataset combines the ice core record from Law Dome in Antarctica with direct measurements taken at Cape Grim in Tasmania, Australia. The concentrations of $\mathrm{CO}_{2}, \mathrm{CH}_{4}$ and $\mathrm{N}_{2} \mathrm{O}$ are provided, with a 20-yr smoother having been applied in the case of $\mathrm{CO}_{2}$ and $\mathrm{CH}_{4}$, and a 40 -yr smoother having been applied in the case of $\mathrm{N}_{2} \mathrm{O}$. These concentrations were converted into equivalent $\mathrm{CO}_{2}$ concentrations $\left(\mathrm{CO}_{2}^{\mathrm{e}}\right)$, which were calculated so as to impose a radiative forcing equivalent to that aris- ing from the changes in the concentrations of each of the three gases. The expressions provided in Table 6.2 of Ramaswamy et al. (2001) were used, with the unperturbed $\mathrm{CH}_{4}$ and $\mathrm{N}_{2} \mathrm{O}$ concentrations set to 760 and $270 \mathrm{ppb}$, respectively. The resulting timeseries of $\mathrm{CO}_{2}^{\mathrm{e}}$ values is shown in Fig. 13d, and it is these values that were used to force the model. Prior to $1800 \mathrm{CE}, \mathrm{CO}_{2}^{\mathrm{e}}$ varies within the narrow range 269 to $282 \mathrm{ppm}$, before rising to $410 \mathrm{ppm}$ by $2000 \mathrm{CE}$. Relative to the $\mathrm{CO}_{2}$ concentration of $280 \mathrm{ppm}$ used in the control simulation, these values equate to a radiative forcing of between -0.22 and $+0.04 \mathrm{~W} \mathrm{~m}^{-2}$ prior to $1800 \mathrm{CE}$, increasing to $+2.04 \mathrm{~W} \mathrm{~m}^{-2}$ by $2000 \mathrm{CE}$. Because version 1.0 of $\mathrm{Mk} 3 \mathrm{~L}$ does not include an aerosol scheme, anthropogenic aerosols were not considered here. However, given a suitable reconstruction of the radiative forcing arising from past changes in anthropogenic aerosols, it would be possible to take these into account via adjustments to the equivalent $\mathrm{CO}_{2}$ concentration.

There are only two differences between the experimental design used here and the protocols specified for the Last Millennium (850-1850 CE) and Historical (1850-2005+ CE) experiments by CMIP5 (http://cmip-pcmdi.llnl.gov/cmip5/) and PMIP3 (http://pmip3.lsce.ipsl.fr/). For consistency, the solar reconstruction of Steinhilber et al. (2009) is used here for the entire period 1001-2000 CE, whereas the CMIP5/PMIP3 protocol specifies a transition to the reconstruction of Wang et al. (2005) after 1850 CE (Schmidt et al., 
2011). The Law Dome dataset of MacFarling Meure et al. (2006) is used here to provide the concentrations of all anthropogenic greenhouse gases, whereas the dataset supplied by CMIP5/PMIP3 uses data from multiple ice cores to derive the $\mathrm{N}_{2} \mathrm{O}$ concentration (Schmidt et al., 2011). Both these differences in the experimental design are negligible.

To conduct a transient simulation of the last millennium, Mk3L was first initialised from the state of the control simulation at the end of model year 100. It was then integrated for $100 \mathrm{yr}$ under static $1000 \mathrm{CE}$ boundary conditions, with this being a sufficient duration for the model to respond to the small change in boundary conditions relative to the control simulation. Finally, the transient simulation was initialised from the state of the model at the end of the 1000 CE snapshot simulation. This transient simulation shall be referred to hereafter as LAST1000. Over the 1000-yr period of the control simulation which corresponds to experiment LAST1000, drift in global-mean SAT amounts to a cooling of just $0.08 \mathrm{~K}$. The results presented here are not corrected for drift.

\subsection{The response of the model}

The simulated changes in Northern Hemisphere (NH) SAT and the mean SST in the Niño 3 region $\left(150-90^{\circ} \mathrm{W}, 5^{\circ} \mathrm{S}-\right.$ $5^{\circ} \mathrm{N}$ ) are shown in Fig. 14. They are compared with the reconstruction of Mann et al. (2009), hereafter referred to as M2009, which is derived from a global multiproxy network comprising more than a thousand individual records. Temperature is reconstructed by calibrating the proxy network against instrumental data covering the period from 1850 to 1995 CE. Proxy data with both annual and decadal resolution are used to derive the reconstruction, so only variations on interdecadal timescales are meaningful. Both the simulated and reconstructed temperatures are expressed in Fig. 14 as anomalies relative to the 1001-1850 CE mean, and the \pm 2 standard deviation uncertainty range is shown for M2009.

During the pre-industrial period, Mk3L captures the decadal-to-centennial scale variations in NH SAT well. Prior to $1850 \mathrm{CE}$, the ten-year running mean for the model rarely exceeds the confidence interval for M2009. However, the model underestimates the magnitude of the relative warmth during the 11th century, being $\sim 0.2 \mathrm{~K}$ cooler than the reconstruction. It also simulates a strong cooling in response to the volcanic eruption of $1258 \mathrm{CE}$. This is not apparent in M2009, although the decadal resolution of the reconstruction would result in a greatly attenuated signal. Prior to $1850 \mathrm{CE}$, there is no long-term trend in the simulated Niño 3 SST. This is consistent with the long-term trend in M2009 over the bulk of this period, except for the failure to capture the relatively cool conditions during the 11th century. Mk3L therefore fails to simulate the La Niña-like conditions that appear to have prevailed during the Mediaeval Climate Anomaly (Mann et al., 2009).

During the industrial period, the model slightly overestimates the warming trend in NH SAT relative to the recon- struction, with the simulated mean temperature anomaly for 1991-2000 CE being $\sim 0.2 \mathrm{~K}$ warmer than M2009. This may reflect the fact that the model simulation does not account for the effects of anthropogenic aerosols. However, as the model correctly simulates the observed global-mean warming during the 20th century (Sect. 4.5), it may also indicate that the reconstruction underestimates the magnitude of the anthropogenic warming trend. Nonetheless, the simulated increase in the Niño 3 SST over the industrial period is consistent with the reconstruction.

The response of the model will now be analysed in more detail, with the sensitivities to natural and anthropogenic forcings considered separately.

\subsection{Sensitivity to natural forcings}

On annual and decadal timescales, volcanic forcing generally exceeds in magnitude the variations in total solar irradiance (TSI). Only on centennial timescales is it therefore possible to determine the sensitivity of the model to changes in solar output. The situation is complicated by the fact that, of the four solar grand minima to have occurred during the last millennium, three have coincided with the three largest volcanic eruptions: the eruption of $1258 \mathrm{CE}$ occurred shortly before the Wolf Minimum, the Kuwae eruption (1452 CE) occurred during the Spörer Minimum, and the Tambora eruption $(1815 \mathrm{CE})$ occurred during the Dalton Minimum. Only the Maunder Minimum ( 1645-1715 CE) was free of major volcanic eruptions.

According to M2009, the NH SAT during the period 1645-1715 CE differs from the 1001-1850 CE mean by a statistically-significant margin only during the first three years $(1645-1647 \mathrm{CE})$. This appears to be in response to the Mount Parker volcanic eruption in $1641 \mathrm{CE}$, which causes the NH SAT to dip $\sim 0.4 \mathrm{~K}$ below the 1001-1850 CE mean. For the remainder of the Maunder Minimum, it is not possible to reject the null hypothesis that the temperature was the same as the 1001-1850 CE mean.

Mk3L simulates an average NH SAT during the Maunder Minimum that is $0.12 \mathrm{~K}$ below the 1001-1850 CE mean, with a $95 \%$ confidence interval of $\pm 0.03 \mathrm{~K}$. Despite the lack of major volcanic eruptions, the coldest 71-yr period during experiment LAST1000 is 1641-1711 CE, which coincides almost exactly with the Maunder Minimum. Furthermore, the period $1641-1711 \mathrm{CE}$ is $0.05 \pm 0.04 \mathrm{~K}$ colder than the 71 $\mathrm{yr}$ period that precedes it and $0.10 \pm 0.04 \mathrm{~K}$ colder than the $71-y r$ period that follows it. This strongly suggests that the simulated cooling during this period is a response to solar forcing, and that the sensitivity of the model to the reduction in solar output associated with the Maunder Minimum is a hemispheric-mean cooling of $\sim 0.05-0.1 \mathrm{~K}$.

The short timescales associated with volcanic forcing make it easier to determine the sensitivity of the model to the radiative forcing arising from volcanic eruptions. In response to the eruption of $1258 \mathrm{CE}, \mathrm{Mk} 3 \mathrm{~L}$ simulates a reduction 
in NH SAT of $\sim 1.1 \mathrm{~K}$. There is considerable evidence of widespread climatic, social and economic disruptions in the aftermath of this eruption (Stothers, 2000), accompanied by a reduction of $1.5 \mathrm{~K}$ in summer temperatures in the European Alps (Büntgen et al., 2006). However, no hemispherewide temperature signal is apparent in M2009. There are a number of possible explanations for this discrepancy: the decadal resolution of the reconstruction; the fact that proxy networks which incorporate tree ring data underestimate the magnitude of the cooling in response to large volcanic eruptions (Robock, 2005); or the fact that the climatic response to volcanic eruptions is neither spatially nor seasonally uniform (Robock, 2000). This latter issue might cause proxy networks to exhibit differing sensitivities to individual eruptions. It would also mean that the parameterisation of volcanic eruptions as a uniform radiative forcing, as in experiment LAST1000, is highly unrealistic on both a regional and seasonal scale. Alternatively, Timmreck et al. (2009) show that once the size distributions of aerosol particles are taken into account in an Earth system model, the magnitude of the simulated temperature response to the $1258 \mathrm{CE}$ eruption can be reduced substantially. This challenges the simple relationship assumed here between stratospheric sulphate aerosol loading and aerosol optical depth, and suggests that the scaling applied to loadings greater than $15 \mathrm{Tg}$ (Sect. 4.2) does not adequately reflect the increase in particle size arising from coagulation.

In contrast, M2009 records decadal-scale cooling in response to the Kuwae (1452 CE) and Tambora (1815 CE) eruptions. The decadal-scale response of Mk3L is consistent with the reconstruction in both cases. During the three years following the $1991 \mathrm{CE}$ Pinatubo eruption, which begins on 1 January 1991 CE in experiment LAST1000, the model simulates a NH SAT that remains at least $0.2 \mathrm{~K}$ below the 1990 CE value. The three-year period 1991-1993 CE is $0.28 \pm 0.09 \mathrm{~K}$ cooler than the preceding three-year period 1988-1990 CE. This is consistent with the analysis of Thompson et al. (2009) who, after removing other influences on global-mean SAT, find a peak cooling of $\sim 0.4 \mathrm{~K}$ one year after the eruption, with cooling of at least $\sim 0.2 \mathrm{~K}$ persisting for three years.

Figure 15 shows the simulated temperature anomalies during the Mediaeval Climate Anomaly (MCA; 1001-1250 CE) and the Little Ice Age (LIA; 1400-1700 CE). These periods represent the pre-industrial extremes in the centennial-scale NH SAT over the last millennium, and thus they provide a test of the ability of the model to simulate centennial-scale changes in the climate. Although Mann et al. (2009) define the MCA as beginning in $950 \mathrm{CE}$, the year $1001 \mathrm{CE}$ is used here as this is the first year of experiment LAST1000; regardless, Mann et al. (2009) note that the temperature patterns associated with the MCA and LIA are not sensitive to the precise time intervals used. Relative to the 1001-1850 CE mean, the model simulates weak warming during the MCA and weak cooling during the LIA. These changes are amplified

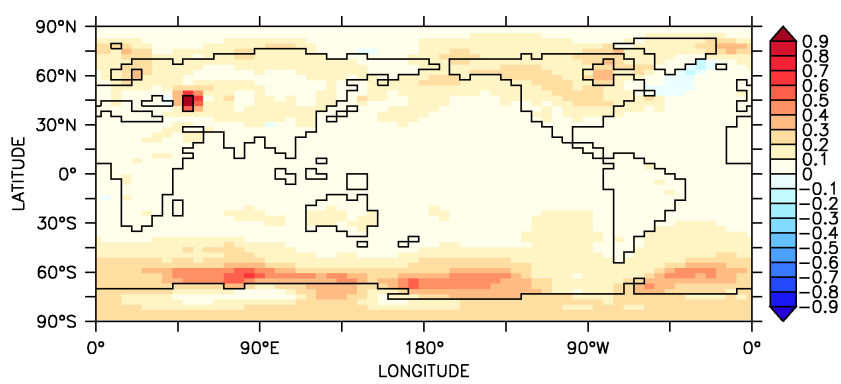

(a) Mediaeval Climate Anomaly

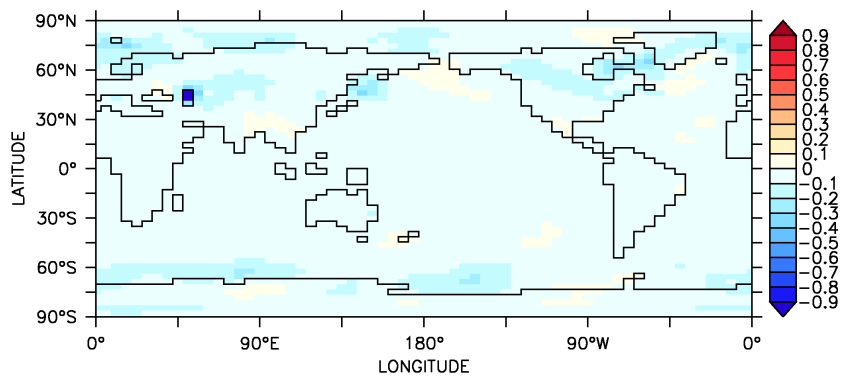

(b) Little Ice Age

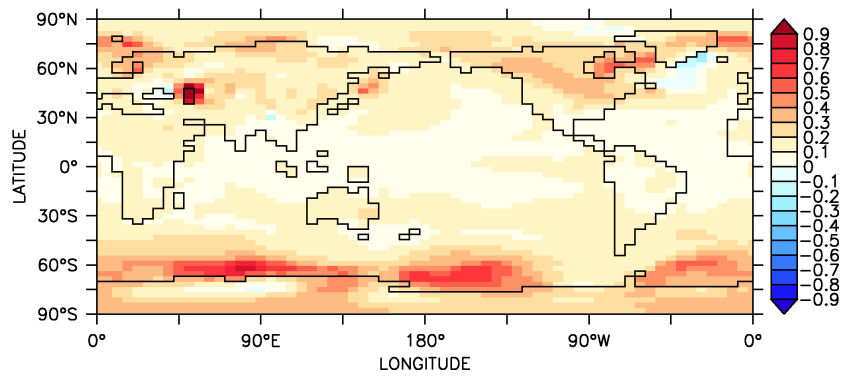

(c) MCA minus LIA

Fig. 15. The simulated changes in surface air temperature $(\mathrm{K})$ during the Mediaeval Climate Anomaly (MCA; 1001-1250 CE) and the Little Ice Age (LIA; 1400-1700 CE), according to experiment LAST1000: (a) the MCA minus the 1001-1850 CE mean, (b) the LIA minus the 1001-1850 CE mean, and (c) the MCA minus the LIA.

over Central Asia and at high latitudes, particularly over the Southern Ocean. However, apart from some regional cooling over the North Atlantic during the MCA, the changes are otherwise relatively uniform. The model therefore appears to simulate a primarily thermal response to the forcing changes, with the lack of spatial variations indicating little in the way of a dynamical response.

Nonetheless, the simulated spatial pattern of the MCALIA temperature difference is broadly consistent with Mann et al. (2009). The MCA is generally warmer than the LIA, particularly at high latitudes, with the simulated global-mean SAT difference being $0.14 \pm 0.02 \mathrm{~K}$. This is slightly less than the reconstructed difference of $0.24 \mathrm{~K}$ (Mann et al., 2009), and reflects the failure of the model to capture the relatively warm conditions that prevailed during the 11 th century. The model also fails to capture some of the regional-scale 
cooling, particularly that associated with the La Niña-like pattern of temperature changes over the Pacific Basin. However, neither the GISS-ER nor the NCAR CSM 1.4 models capture this signature either, suggesting that it may be stochastic in origin (Mann et al., 2009).

\subsection{Sensitivity to anthropogenic forcings}

Mk3L simulates an increase in global-mean SAT between 1861-1900 CE and 1991-2000 CE of $0.62 \pm 0.06 \mathrm{~K}$, which is consistent with the observationally-based estimate of $0.6 \pm$ $0.2 \mathrm{~K}$ (Folland et al., 2001). Over the 20th century, the transient sensitivity of the model to increasing concentrations of anthropogenic greenhouse gases is therefore consistent with observations. However, the model simulation does not account for the effects of anthropogenic aerosols, which act to cool the climate system (Forster et al., 2007). This may indicate that the transient climate sensitivity of $\mathrm{Mk} 3 \mathrm{~L}$ is too low. The simulated global-mean SAT for the period 1991$2000 \mathrm{CE}$ is $14.08 \pm 0.05^{\circ} \mathrm{C}$, which is $0.46 \mathrm{~K}$ warmer than the pre-industrial control simulation (Part 1; Phipps et al., 2011) but still $0.33 \mathrm{~K}$ cooler than the mean value of $14.41^{\circ} \mathrm{C}$ according to the NCEP-DOE Reanalysis 2 (Kanamitsu et al., 2002, hereafter referred to as NCEP2).

The spatial pattern of the 20th century warming is shown in Fig. 16a and is consistent with observed trends (Folland et al., 2001). Warming occurs over most of the Earth's surface, and is strongest at high latitudes and over Central Asia. However, there is also some localised cooling; this is particularly strong in the North Atlantic Ocean, where the cooling signal arises within the model because of a weakening of the meridional overturning circulation (Fig. 17). North Atlantic Deep Water formation decreases in response to elevated anthropogenic greenhouse gas concentrations during the industrial period, with the mean rate for the period 1951-2000 CE $(12.8 \mathrm{~Sv})$ being $14 \%$ weaker than the mean rate for the period 1001-1850 CE (14.9 Sv).

The discrepancy in the average SAT for 1991-2000 CE, relative to NCEP2, is shown in Fig. 16b. Relative to the preindustrial control simulation (Fig. 4 of Part 1; Phipps et al., 2011), the warming at high latitudes and cooling over Hudson Bay leads to a slightly improved agreement with the reanalysis. The root-mean-square error in annual-mean SAT relative to NCEP2 is $1.77 \mathrm{~K}$, as opposed to an error of $1.90 \mathrm{~K}$ for the pre-industrial control.

During the 20th century, the model simulates a warming trend throughout the troposphere, accompanied by a cooling trend throughout the stratosphere (Fig. 16c). The magnitude of these trends is consistent with observations, which indicate cooling of the stratosphere between $1958 \mathrm{CE}$ and $2004 \mathrm{CE}$ of $\sim 1.5 \mathrm{~K}$, accompanied by a warming of the troposphere of up to $0.5 \mathrm{~K}$ (Trenberth et al., 2007). The discrepancy in the average zonal-mean temperature for 19912000 CE, relative to NCEP2, is shown in Fig. 16d. The simulated 20th century changes improve the agreement with the reanalysis, relative to the pre-industrial control simulation (Fig. 7 of Part 1; Phipps et al., 2011). In particular, the stratospheric cooling reduces the magnitude of the positive anomalies in the lower stratosphere.

\subsection{Summary}

Mk3L is broadly successful at capturing the observed changes in the climate system over the last millennium. The response to solar and volcanic forcing during the preindustrial period is largely consistent with the reconstruction of Mann et al. (2009), with the model simulating a hemispheric-mean cooling of $\sim 0.05-0.1 \mathrm{~K}$ in response to the reduction in solar output associated with the Maunder Minimum. However, the model simulates strong cooling in response to the volcanic eruption of $1258 \mathrm{CE}$, which does not appear in the reconstruction. The model also underestimates the magnitude of the relative warmth associated with the Mediaeval Climate Anomaly, and fails to reproduce the La Niñalike signature in the temperature changes. This suggests that it may be failing to capture the dynamical response of the climate system to the natural radiative forcings that appear to have given rise to the MCA (Mann et al., 2009).

The simulated response to increasing concentrations of anthropogenic greenhouse gases is consistent with observations, with the model simulating warming of $0.62 \pm 0.06 \mathrm{~K}$ during the 20th century. However, as the effects of anthropogenic aerosols are not taken into account, this suggests that the transient climate sensitivity of the model may be too low. The warming trend extends throughout the troposphere, accompanied by a stronger cooling trend in the stratosphere.

The incorporation of schemes for aerosols and atmospheric chemistry would allow the effects of solar and volcanic forcing to be better represented within $\mathrm{Mk} 3 \mathrm{~L}$; in particular, the model would be able to take into account the size distributions of aerosol particles and would be able to simulate the effects of ozone photochemistry. Such enhancements would also allow the model to represent the effects of anthropogenic aerosols. Rotstayn et al. (2007), for example, used a version of the CSIRO model similar to Mk3L but including an interactive aerosol scheme. They found that their model was successful at reproducing the observed decadal changes in global-mean SAT over the period 1871-2000 CE, including the mid-20th century cooling.

\section{$5 \mathrm{CO}_{2}$ stabilisation experiments}

\subsection{Introduction}

In this section, the transient and equilibrium responses of $\mathrm{Mk} 3 \mathrm{~L}$ to an increase in the atmospheric carbon dioxide concentration are investigated. Scenarios are employed in which the $\mathrm{CO}_{2}$ concentration is increased at $1 \%$ per year, before being stabilised at two, three and four times the pre-industrial level. These idealised scenarios allow a direct comparison 


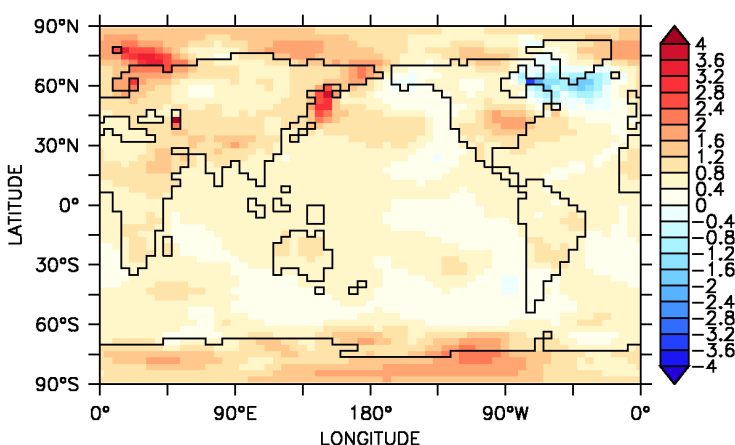

(a) 1991-2000 minus 1861-1900

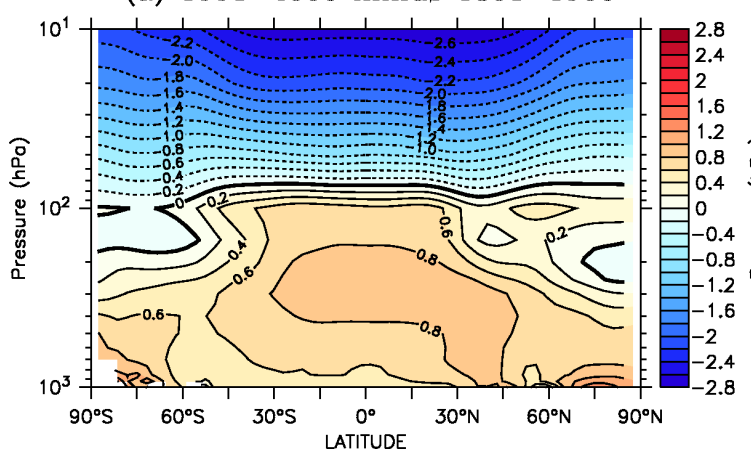

(c) 1991-2000 minus 1861-1900

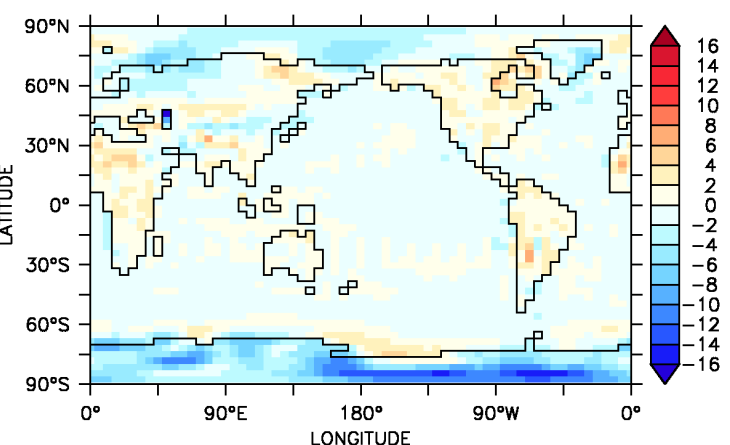

(b) Mk3L minus NCEP2

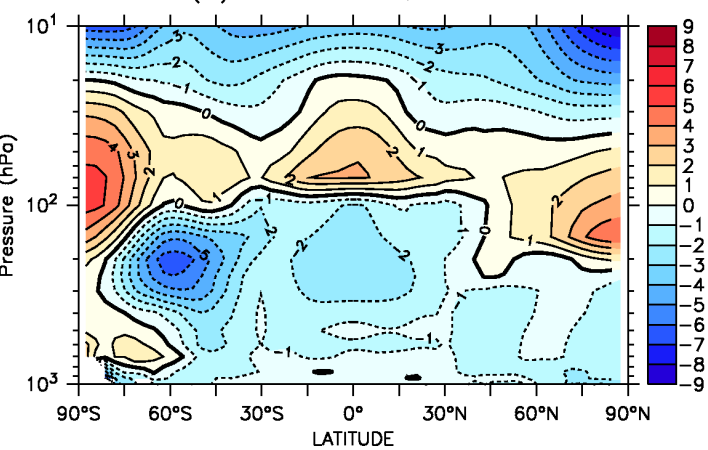

(d) Mk3L minus NCEP2

Fig. 16. The changes in atmospheric temperature $(\mathrm{K})$ over the 20th century according to experiment LAST1000: (a) surface air temperature, 1991-2000 CE average minus 1861-1900 CE average, (b) average surface air temperature for 1991-2000 CE, Mk3L minus NCEP2, (c) zonal-mean temperature, 1991-2000 CE average minus 1861-1900 CE average, and (d) average zonal-mean temperature for 19912000 CE, Mk3L minus NCEP2.

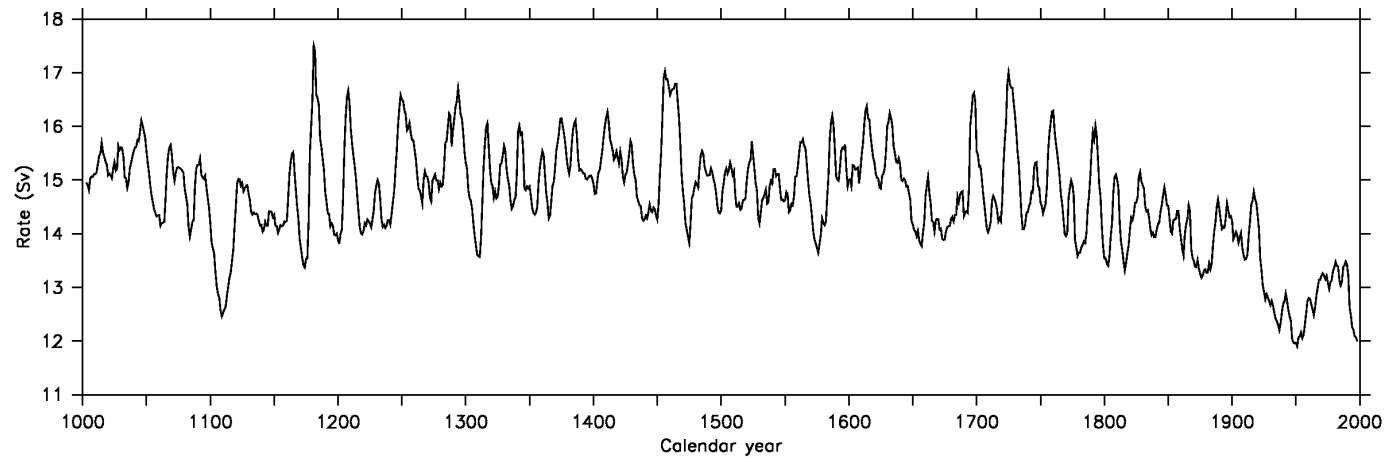

Fig. 17. The change in the rate of North Atlantic Deep Water formation during experiment LAST1000. The values shown are five-year running means.

with the models which participated in the Coupled Model Intercomparison Project (CMIP; Meehl et al., 2000, 2007a).

A number of studies have assessed the response of versions of the CSIRO model to increases in atmospheric carbon dioxide. Using slab ocean versions of the CSIRO Mk1 and Mk2 general circulation models, Watterson et al. (1999) found climate sensitivities, defined as the equilibrium globalmean SAT increase in response to a doubling of the $\mathrm{CO}_{2}$ concentration, of 4.84 and $4.34 \mathrm{~K}$, respectively. A subsequent study assessed the slab ocean version of the CSIRO Mk3.0 general circulation model, and found that weaker feedbacks gave it a lower climate sensitivity of $3.08 \mathrm{~K}$ (Watterson and Dix, 2005). Another version of the CSIRO model, similar in nature to $\mathrm{Mk} 3 \mathrm{~L}$, was found to have a climate sensitivity of $3.52 \mathrm{~K}$ when coupled to a mixed-layer ocean model (Rotstayn and Penner, 2001).

The response of the CSIRO Mk2 coupled atmosphereocean general circulation model (AOGCM) has also been 


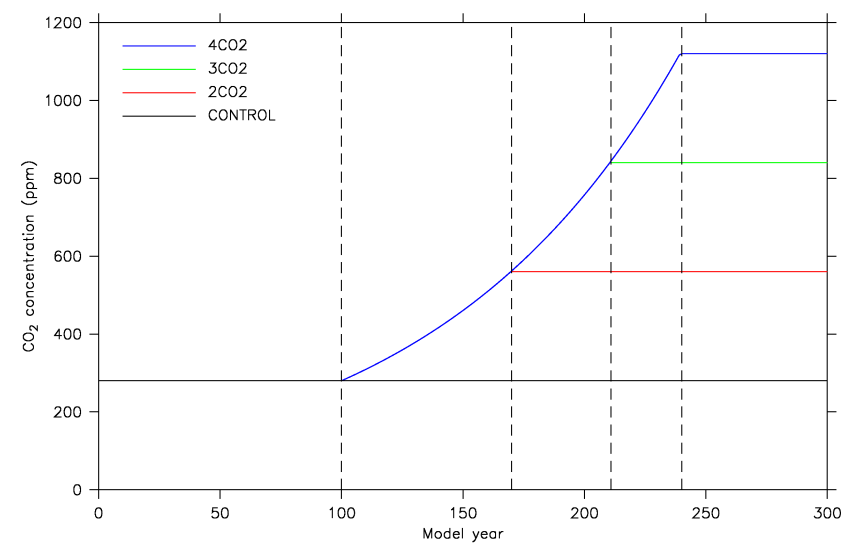

Fig. 18. The atmospheric carbon dioxide concentration applied during experiments CONTROL (black), $2 \mathrm{CO} 2$ (red), 3CO2 (green) and 4CO2 (blue). Vertical dashed lines indicate model years 100, 170, 211 and 240 .

studied. Hirst (1999) investigated both the transient and the long-term responses of the model to a trebling of the $\mathrm{CO}_{2}$ concentration. Bi et al. $(2001,2002)$ and $\mathrm{Bi}(2002)$ expanded upon this work, using the acceleration technique of Bryan (1984) to integrate the model to equilibrium. The final response to a $\mathrm{CO}_{2}$ trebling was found to be an increase in global-mean SAT of $7.3 \mathrm{~K}$.

The long-term responses of other AOGCMs to increased atmospheric $\mathrm{CO}_{2}$ concentrations have also been studied (Manabe and Stouffer, 1993, 1994; Stouffer and Manabe, 1999, 2003; Senior and Mitchell, 2000; Voss and Mikolajewicz, 2001; Bryan et al., 2006; Danabasoglu and Gent, 2009). In combination with the CMIP models, these simulations provide a basis against which to compare the response of Mk3L.

\subsection{Experimental design}

Three transient climate change simulations are presented. They were initialised from the state of the control simulation at the end of model year 100. The atmospheric carbon dioxide concentration was then increased at $1 \%$ per year from the start of model year 101, until it reached either two, three or four times the pre-industrial value of $280 \mathrm{ppm}$ (experiments $2 \mathrm{CO} 2,3 \mathrm{CO} 2$ and $4 \mathrm{CO} 2$, respectively). The final $\mathrm{CO}_{2}$ concentrations of 560, 840 and $1120 \mathrm{ppm}$ were reached in model years 170, 211 and 240, respectively, and the concentration was held constant thereafter (Fig. 18). Each experiment was then integrated until the end of model year 4000 .

Previous sections have compared the response of Mk3L with observations and palaeoclimate reconstructions, and have sought to identify deficiencies in the model physics. Such an approach is not possible for simulations of future climate states, whether realistic or idealised, and this section is therefore restricted to a comparison of the transient and equilibrium responses of $\mathrm{Mk} 3 \mathrm{~L}$ with those of other models.

\subsection{Surface air temperature}

The evolution of the simulated global-mean SAT during each experiment is shown in Fig. 19a. The global-mean SAT increases rapidly as the $\mathrm{CO}_{2}$ concentration is increased, and continues to increase once the $\mathrm{CO}_{2}$ concentration has been stabilised. However, the rate of change decreases over time as the simulations progress towards thermal equilibrium. The slow cooling trend exhibited by the control simulation, as discussed in Part 1 (Phipps et al., 2011), is apparent.

Prior to model year 170, the $\mathrm{CO}_{2}$ concentrations for each of the three transient experiments are identical; each experiment therefore exhibits the same temperature increases. During the transient stage of experiment $4 \mathrm{CO} 2$, the global-mean SAT warms by $1.6 \mathrm{~K}$ upon a doubling of the $\mathrm{CO}_{2}$ concentration, and by $3.7 \mathrm{~K}$ upon a quadrupling. The ongoing warming exhibited by experiments $2 \mathrm{CO} 2,3 \mathrm{CO} 2$ and $4 \mathrm{CO} 2$ indicates that they have not reached thermal equilibrium, even by the end of a 4000-yr simulation. By the final century of experiment $2 \mathrm{CO} 2$, global-mean SAT has increased by $3.9 \mathrm{~K}$ relative to the first century of the control simulation and is still increasing at a rate of $0.015 \mathrm{~K}$ century $^{-1}$.

The transient climate response (TCR) of a climate model is defined as the global-mean SAT anomaly for the period 61-80 yr after the $\mathrm{CO}_{2}$ concentration begins to increase (e.g. Gregory and Forster, 2008). The value obtained here for Mk3L, and the $95 \%$ confidence interval, is $1.59 \mathrm{~K} \pm 0.08 \mathrm{~K}$. This value lies within the 5-95\% uncertainty range of $1.2-$ $2.4 \mathrm{~K}$ for the AOGCMs which were analysed by the IPCC Fourth Assessment Report (AR4), but is slightly less than the mean value of $1.76 \mathrm{~K}$ (Meehl et al., 2007b). It is also consistent with the estimated 5-95\% uncertainty range for the true climate system of 1.3-2.3 K (Gregory and Forster, 2008). A low value for the TCR is consistent with the fact that the model correctly simulates the magnitude of the 20th century warming trend, despite not being forced with changes in anthropogenic aerosols (Sect. 4.5). Given that anthropogenic aerosols act to cool the climate system (Forster et al., 2007), the model might be expected to over-estimate the 20th century warming trend if its TCR was the same as that of the true climate system.

The equilibrium climate sensitivity (ECS) of a climate model is defined as the equilibrium increase in global-mean SAT in response to a doubling of the $\mathrm{CO}_{2}$ concentration. Based on the warming experienced by the final century of experiment $2 \mathrm{CO} 2$, the ECS of Mk3L is at least $3.85 \pm 0.02 \mathrm{~K}$. The magnitude of the ongoing warming suggests that the equilibriated response of the model is likely to be several tenths of a degree greater. Taking the drift in the control simulation into account also gives a larger value for the ECS; relative to the final century of the control simulation, rather than the first, global-mean SAT has increased by $4.41 \pm 0.02 \mathrm{~K}$ by 


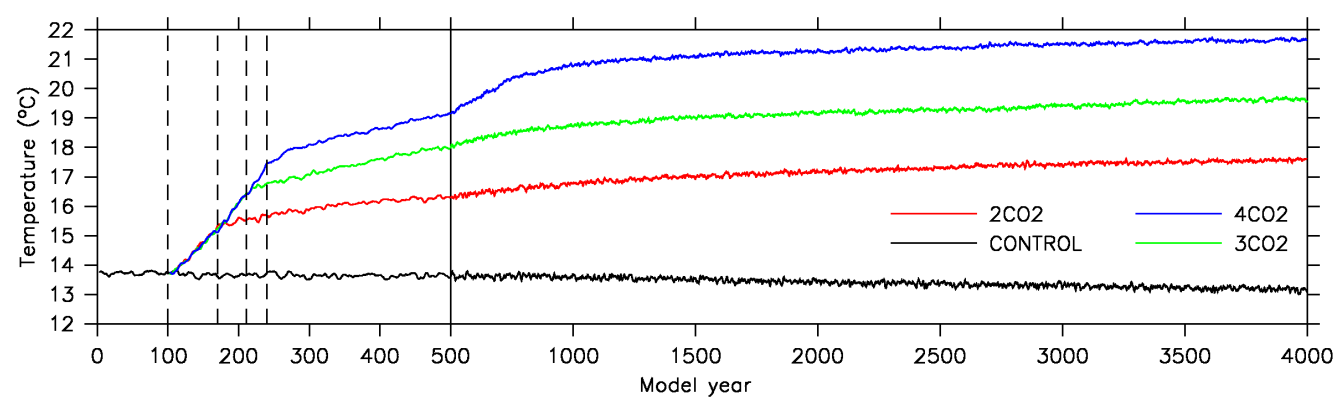

(a) Global-mean surface air temperature

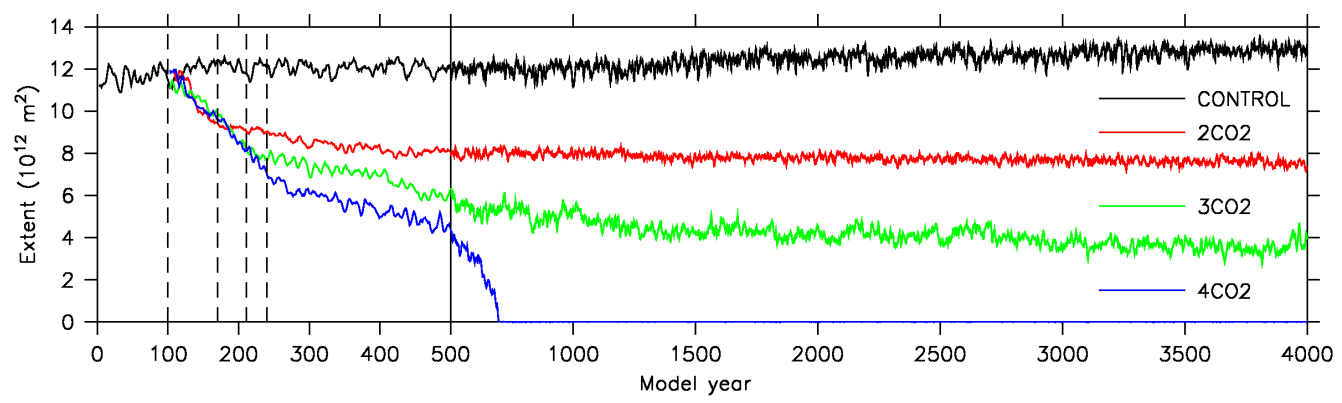

(b) Northern Hemisphere sea ice extent

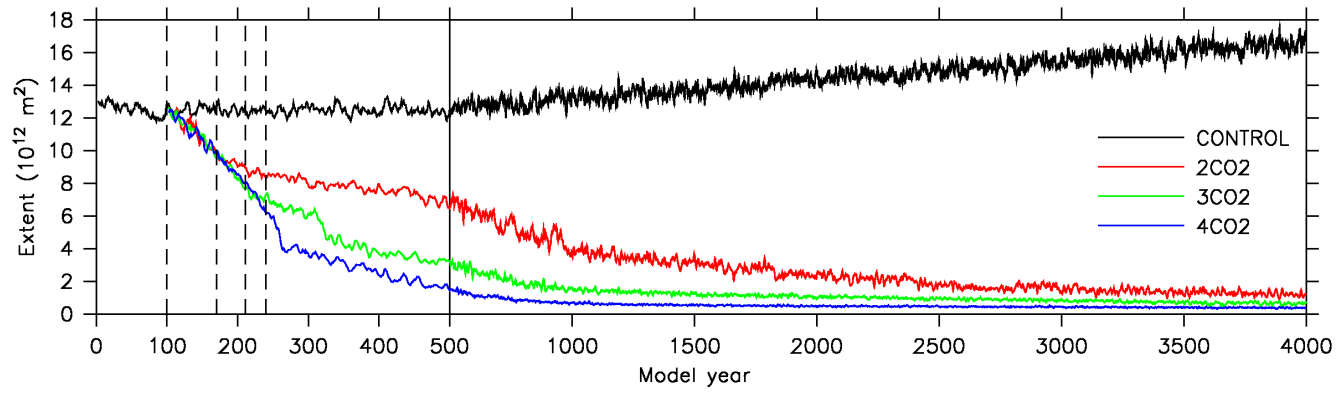

(c) Southern Hemisphere sea ice extent

Fig. 19. The changes in annual-mean surface air temperature and sea ice extent during experiments CONTROL (black), $2 \mathrm{CO} 2$ (red), $3 \mathrm{CO} 2$ (green) and 4CO2 (blue): (a) the global-mean surface air temperature, (b) the Northern Hemisphere sea ice extent, and (c) the Southern Hemisphere sea ice extent. The values shown are five-year running means. Vertical dashed lines indicate model years 100, 170,211 and 240. Note the change in the scale of the time axis at year 500 .

the end of experiment $2 \mathrm{CO} 2$. Values of the ECS between 3.85 and $4.41 \mathrm{~K}$ are consistent with the 5-95\% uncertainty range for the AR4 AOGCMs of 2.1-4.4 K, but are greater than the mean value of $3.26 \mathrm{~K}$ (Meehl et al., 2007b). They are also consistent with the "likely" range for the true climate system of 2-4.5 K (Meehl et al., 2007b).

It should be emphasised that there is a difference in methodology between this study and AR4. As a result of the computational expense of state-of-the-art AOGCMs, the ECS is typically determined by replacing the oceanic component of a model with a non-dynamic slab ocean (e.g. Meehl et al., 2007b). In contrast, the full Mk3L AOGCM is studied here. Although flux adjustments are used, the thermohaline circulation - and therefore the ocean heat transport - is free to evolve, unlike in a slab ocean model. Danabasoglu and Gent (2009) show that the slab ocean approach underesti- mates the ECS by just $0.14 \mathrm{~K}$ in the case of CCSM3, but no attempt appears to have been made to validate this approach across multiple models. Earlier studies that addressed this question using other models were unable to reach definitive conclusions, either because the simulations were too short or because of drift in the control simulation (Stouffer and Manabe, 1999; Senior and Mitchell, 2000; Gregory et al., 2004). Prior to Danabasoglu and Gent (2009), only one study appears to have been successful in determining the ECS of an AOGCM other than the CSIRO model by integrating it to equilibrium: Stouffer and Manabe (2003) determine an ECS for the GFDL model of $4.33 \mathrm{~K}$.

For the AR4 models, there is a strong positive correlation between the TCR and the ECS (Meehl et al., 2007b). Thus the fact that the ECS determined here for Mk3L is relatively high, despite the fact that the TCR is relatively low, deserves 


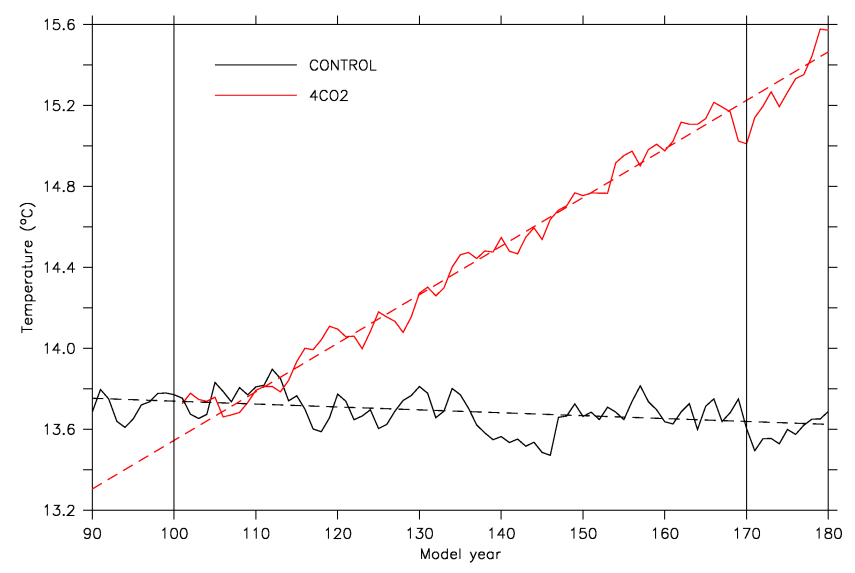

Fig. 20. The change in global-mean surface air temperature during experiments CONTROL (solid black) and 4CO2 (solid red). The values shown are annual means. The dashed black line shows the line of best fit to years 101-170 of CONTROL, and the dashed red line shows the line of best fit to years $111-170$ of $4 \mathrm{CO} 2$. Vertical lines indicate model years 100 and 170 .

further consideration. The theoretical framework of Gregory and Forster (2008) is therefore used to study the transient and equilibrium climate sensitivities of Mk3L. This approach describes the short-term transient response of a model in terms of a climate resistance $\rho$. The heat balance of the climate system is therefore described by $F=\rho \Delta T$, where $F$ is the radiative forcing and $\Delta T$ is the change in global-mean SAT. $\rho$ is the sum of the climate feedback parameter $\alpha$ and an ocean heat uptake efficiency $\kappa$. This latter parameter characterises the transient response of the deep ocean as that of a heatsink, and relates the net heat flux into the climate system $N$ to the global-mean temperature change via the relationship $N=\kappa \Delta T . \kappa$ is a time-dependent property of the climate system, and will tend towards zero as the system approaches thermal equilibrium.

The values of the parameters $\rho, \alpha$ and $\kappa$ are diagnosed for Mk3L by linearly regressing decadal-mean values of $F$, $F-N$ and $N$ against decadal-mean values of $\Delta T$ for the first $70 \mathrm{yr}$ of experiment $4 \mathrm{CO} 2$. The resulting values, and the associated $95 \%$ confidence intervals, are shown in Table 2, along with the 5-95\% uncertainty ranges derived for the CMIP3 AOGCMs by Gregory and Forster (2008). For all three parameters, the values diagnosed for $\mathrm{Mk} 3 \mathrm{~L}$ are consistent with the median values derived for the CMIP3 ensemble, demonstrating that the transient response of $\mathrm{Mk} 3 \mathrm{~L}$ is entirely consistent with that of other models. Given $F_{2 \times}=$ $3.7 \mathrm{~W} \mathrm{~m}^{-2}$, the value of $\rho=2.12 \pm 0.14 \mathrm{~W} \mathrm{~m}^{-2}$ equates to a TCR of $1.75 \pm 0.12 \mathrm{~K}$. This is higher than the value of $1.59 \pm 0.08 \mathrm{~K}$ derived above, with the discrepancy being due to the "cold start" effect (Hasselmann et al., 1993). The presence of this effect within Mk3L is demonstrated by Figure 20, which shows that no warming occurs during the first decade of experiment $4 \mathrm{CO} 2$. This reduces the overall magni- tude of the warming experienced during the first $70 \mathrm{yr}$, and therefore causes the TCR to be lower than would be expected from an analysis of the feedbacks within the model. The magnitude of the cold start can be estimated by calculating the line of best fit to years 11-70 of experiment $4 \mathrm{CO} 2$, extending the line backwards to the start of the experiment, and then comparing it with the line of best fit to the control simulation. This method is demonstrated graphically in Fig. 20, and gives an estimated magnitude for the cold start effect within Mk $3 \mathrm{~L}$ of $0.18 \mathrm{~K}$. This is smaller than the estimated value of $0.33 \mathrm{~K}$ for the CSIRO Mk2 coupled model (Gordon and O'Farrell, 1997).

In contrast, the value of $\alpha=1.48 \pm 0.19 \mathrm{~W} \mathrm{~m}^{-2}$ equates to an ECS of $2.50 \pm 0.32 \mathrm{~K}$. This is much lower than the value of at least $3.85 \pm 0.02 \mathrm{~K}$ derived above, and indicates that the strengths of the feedbacks within the model are strongly dependent upon the simulated state of the climate system. Equivalent behaviour has been found in a version of the Hadley Centre climate model. A 40\% increase in the "effective" ECS was found to occur in response to a doubling of the $\mathrm{CO}_{2}$ concentration, with the cloud feedback found to be responsible (Senior and Mitchell, 2000). Thus the apparent conflict between the relatively low TCR and the relatively high ECS for Mk3L can be attributed to a combination of the cold start effect and the time-dependence of climate feedbacks.

Compared to the CSIRO Mk2 coupled model, Mk3L has a lower TCR and appears to also have a lower ECS. The TCR for Mk2 has been determined to be $1.73 \mathrm{~K}$, increasing to $2.01 \mathrm{~K}$ once drift in the control simulation is allowed for, and up to $2.34 \mathrm{~K}$ once the cold start effect is allowed for as well (Gordon and O'Farrell, 1997). In contrast, the value found here for Mk3L is $1.59 \pm 0.08 \mathrm{~K}$. Although the ECS has not been determined for the Mk2 coupled model, the equilibriated response to a trebling of the $\mathrm{CO}_{2}$ concentration is an increase in global-mean SAT of $7.3 \mathrm{~K}(\mathrm{Bi}, 2002)$. In contrast, by the final century of experiment $3 \mathrm{CO}$, the global-mean SAT has increased by $5.91 \pm 0.02 \mathrm{~K}$ relative to the first century of the control simulation, and by $6.47 \pm 0.02 \mathrm{~K}$ relative to the final century of the control simulation. Mk2 and Mk3L share the same ocean model, and the differences between the climate sensitivities of the two models therefore appear to arise from differences in the physics of the atmosphere models. This is consistent with the lower ECS of the slab ocean version of the CSIRO Mk3.0 model, from which the atmospheric component of $\mathrm{Mk} 3 \mathrm{~L}$ is derived, relative to the slab ocean version of Mk2 (Watterson and Dix, 2005).

\subsection{Sea ice}

The evolution of the hemispheric sea ice extents during each experiment is shown in Fig. 19b and c. There is a rapid decline in sea ice cover as the atmospheric $\mathrm{CO}_{2}$ concentration increases, which continues after the concentration is 
Table 2. The climate feedback parameter $(\alpha)$, ocean heat uptake efficiency $(\kappa)$ and climate resistance $(\rho)$ for the CMIP3 AOGCMs $($ Gregory and Forster, 2008) and Mk3L. The 5-95\% uncertainty range is shown for the CMIP3 ensemble, and the $95 \%$ confidence interval is shown for Mk3L.

\begin{tabular}{lcc}
\hline & CMIP3 & Mk3L \\
\hline Climate feedback parameter $\left(\alpha, \mathrm{W} \mathrm{m}^{-2} \mathrm{~K}^{-1}\right)$ & $1.4 \pm 0.6$ & $1.48 \pm 0.19$ \\
Ocean heat uptake efficiency $\left(\kappa, \mathrm{W} \mathrm{m}^{-2} \mathrm{~K}^{-1}\right)$ & $0.6 \pm 0.2$ & $0.64 \pm 0.17$ \\
Climate resistance $\left(\rho, \mathrm{W} \mathrm{m}^{-2} \mathrm{~K}^{-1}\right)$ & $2.0 \pm 0.7$ & $2.12 \pm 0.14$ \\
\hline
\end{tabular}

stabilised. In experiment $4 \mathrm{CO} 2$, the ice cover in the Northern Hemisphere disappears completely by model year 700 .

During the transient stage of experiment $4 \mathrm{CO} 2$, the response to a doubling of the $\mathrm{CO}_{2}$ concentration is a decrease in the annual-mean sea ice extent of $1.9 \times 10^{12} \mathrm{~m}^{2}(17 \%)$ in the Northern Hemisphere, and $2.7 \times 10^{12} \mathrm{~m}^{2}(21 \%)$ in the Southern Hemisphere, relative to the first century of the control simulation. These changes are consistent with those models which participated in CMIP (Flato and Participating CMIP Modelling Groups, 2004).

By the final century of experiments $2 \mathrm{CO} 2$ and $3 \mathrm{CO} 2$, the average Northern Hemisphere sea ice extent is $36 \%$ and $67 \%$ less, respectively, than for the first century of the control simulation. In the Southern Hemisphere, less than $10 \%$ of the ice cover remains in all three transient experiments. Bi (2002), using the CSIRO Mk2 coupled model, finds larger changes in response to a trebling of the atmospheric $\mathrm{CO}_{2}$ concentration, with the sea ice disappearing completely in the Northern Hemisphere. This behaviour is consistent with the greater climate sensitivity of that model.

The average annual-mean sea ice concentrations for the final century of each experiment are shown in Fig. 21, with the extent to which the sea ice disappears in each hemisphere being apparent. In experiments $2 \mathrm{CO} 2$ and $3 \mathrm{CO} 2$, year-round ice cover persists in both hemispheres; in experiment 4CO2, year-round ice cover persists in the Western Ross Sea (not shown).

\subsection{Ocean temperature}

The evolution of the simulated potential temperature of the world ocean is shown in Fig. 22. Consistent with the changes in surface air temperature, the upper ocean warms rapidly as the atmospheric $\mathrm{CO}_{2}$ concentration increases. It continues to warm, but at a decreasing rate, once the $\mathrm{CO}_{2}$ concentration has been stabilised. By the final century of experiment $2 \mathrm{CO} 2$, the upper ocean has warmed by $3.3 \mathrm{~K}$ relative to the first century of the control simulation and is still warming at a rate of $0.016 \mathrm{~K} \mathrm{century}^{-1}$.

The slow penetration of the surface warming into the ocean interior is apparent from Fig. 22c,d. While the upper ocean exhibits the greatest warming, the temperatures of the mid- and deep oceans are still increasing rapidly by the end of each experiment; this indicates that the model is a long way from reaching equilibrium with the enhanced at- mospheric $\mathrm{CO}_{2}$ concentrations. By the end of experiments $2 \mathrm{CO} 2,3 \mathrm{CO} 2$ and $4 \mathrm{CO} 2$, the deep ocean is still warming at a rate of $0.06,0.10$ and $0.15 \mathrm{~K}$ century $^{-1}$, respectively. Long response timescales are also encountered in other models, with Danabasoglu and Gent (2009) finding ongoing warming of the ocean $3000 \mathrm{yr}$ after a doubling of the $\mathrm{CO}_{2}$ concentration in CCSM3. Stouffer and Manabe (2003) find that it takes the GFDL model around $4000 \mathrm{yr}$ to reach equilibrium in response to a doubling of the $\mathrm{CO}_{2}$ concentration, and around $5000 \mathrm{yr}$ in response to a quadrupling.

\subsection{North Atlantic Deep Water}

The evolution in the rate of North Atlantic Deep Water (NADW) formation during each experiment is shown in Fig. 23a. The rates of deep water formation are determined from the peak values of the meridional overturning streamfunction for the respective cells. NADW formation weakens significantly as the atmospheric $\mathrm{CO}_{2}$ concentration increases, reaching a minimum strength within each experiment during the years immediately after the $\mathrm{CO}_{2}$ concentration has been stabilised. At the end of the transient stage of experiment $4 \mathrm{CO} 2$, the average rate of NADW formation is $7.9 \mathrm{~Sv}$, which is $47 \%$ weaker than for the first century of the control simulation.

The weakening of the thermohaline circulation in response to a transient increase in the atmospheric $\mathrm{CO}_{2}$ concentration is a common feature of AOGCMs, and has been widely studied (Manabe and Stouffer, 1994; Bi et al., 2001; Stouffer and Manabe, 2003; Wood et al., 2003; Hu et al., 2004; Gregory et al., 2005; Bryan et al., 2006). The decrease in the rate of NADW formation exhibited by Mk3L is larger than for most of the CMIP models, which exhibit decreases of $10-50 \%$ upon a quadrupling of the $\mathrm{CO}_{2}$ concentration (Gregory et al., 2005). The response of Mk3L is also stronger than that of CCSM3, which experiences a $22-26 \%$ per century decline in the rate of NADW formation in response to a $1 \%$ per year $\mathrm{CO}_{2}$ increase (Bryan et al., 2006).

Once the $\mathrm{CO}_{2}$ concentration has been stabilised, the rate of NADW formation gradually recovers, and has returned to or exceeded its original strength by the end of each experiment. The recovery of the thermohaline circulation after a doubling of the $\mathrm{CO}_{2}$ concentration is a robust feature of AOGCMs (Manabe and Stouffer, 1993, 1994; Stouffer and 


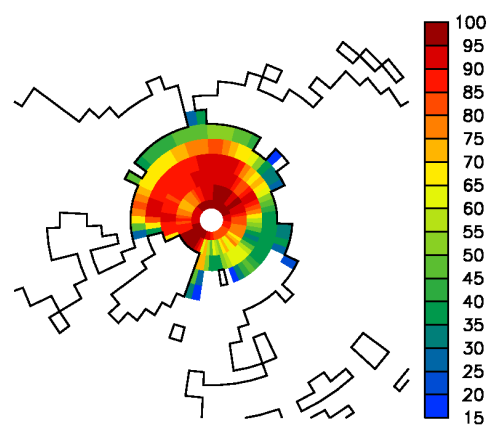

(a) NH: 2CO2

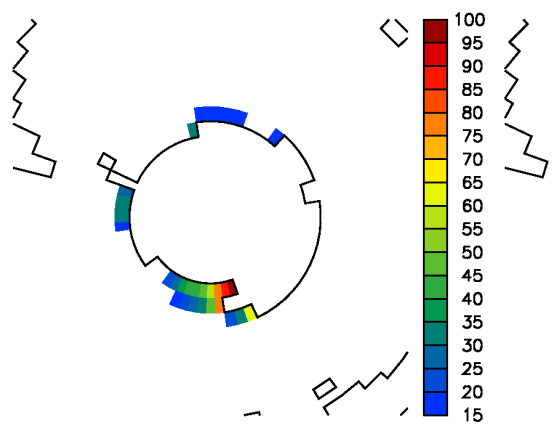

(d) $\mathrm{SH}: 2 \mathrm{CO}$

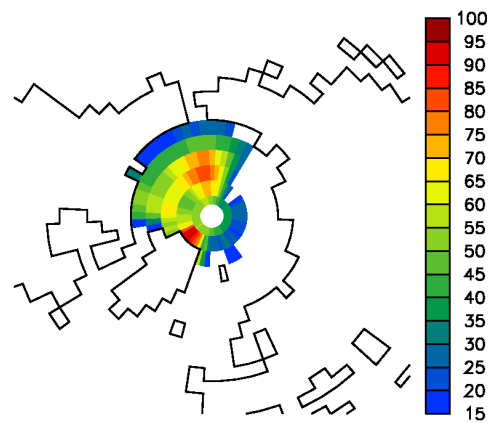

(b) $\mathrm{NH}: 3 \mathrm{CO} 2$

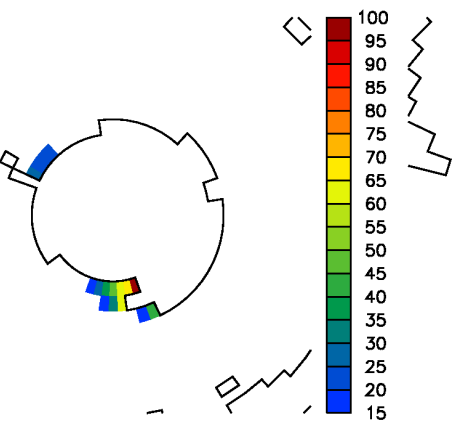

(e) $\mathrm{SH}: 3 \mathrm{CO} 2$

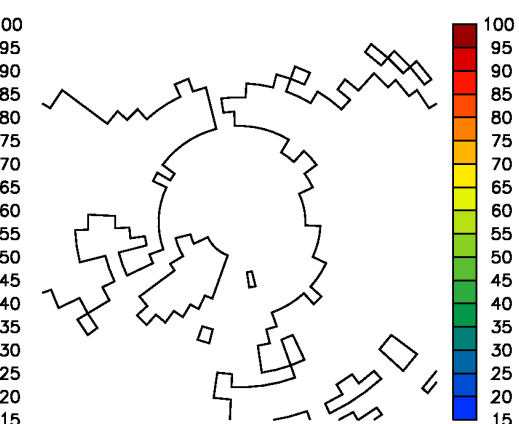

(c) $\mathrm{NH}: 4 \mathrm{CO} 2$

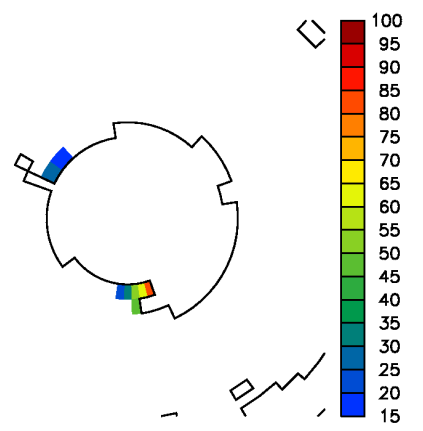

(f) $\mathrm{SH}: 4 \mathrm{CO} 2$

Fig. 21. The average annual-mean sea ice concentration (percent) for years 3901-4000 of each experiment: (a-c) Northern Hemisphere, experiments $2 \mathrm{CO} 2,3 \mathrm{CO} 2$ and $4 \mathrm{CO} 2$, respectively, and (d-f) Southern Hemisphere, experiments 2CO2, 3CO2 and 4CO2, respectively. The sea ice concentration is only shown where the value is greater than or equal to $15 \%$.

Manabe, 1999; Voss and Mikolajewicz, 2001), and the response of $\mathrm{Mk} 3 \mathrm{~L}$ is consistent with that of other models.

In contrast to the response to a doubling of the $\mathrm{CO}_{2}$ concentration, AOGCMs do not exhibit a consistent long-term response to a quadrupling of the $\mathrm{CO}_{2}$ concentration. Wood et al. (2003) integrate HadCM3 for $1000 \mathrm{yr}$, and find that the thermohaline circulation remains in a weakened state after a $\mathrm{CO}_{2}$ quadrupling. Manabe and Stouffer $(1993,1994)$ find that the thermohaline circulation shuts down completely in the GFDL model during the centuries following a quadrupling of $\mathrm{CO}_{2}$; however, Stouffer and Manabe (2003) continue this experiment and find that the rate of NADW formation exhibits a rapid recovery $1000 \mathrm{yr}$ after the $\mathrm{CO}_{2}$ concentration is stabilised. In contrast, Voss and Mikolajewicz (2001) find that the thermohaline circulation in ECHAM3/LSG begins to recover immediately.

The recovery of the thermohaline circulation after a $\mathrm{CO}_{2}$ increase is a robust feature of the CSIRO model as well (Hirst, 1999; Bi et al., 2001; Bi, 2002). In response to a trebling of the $\mathrm{CO}_{2}$ concentration, the rate of NADW formation in the CSIRO Mk2 coupled model recovers once the $\mathrm{CO}_{2}$ concentration is stabilised. However, the recovery is somewhat slower than in $\mathrm{Mk} 3 \mathrm{~L}$, which is consistent with the greater climate sensitivity of Mk2.
To identify the mechanisms which drive the changes in the thermohaline circulation in Mk3L, Fig. 24 shows the changes in the North Atlantic Ocean $\left(50-65^{\circ} \mathrm{N}\right)$ during each of the stabilisation experiments. The upper panel shows the anomalies in the area-integrated virtual salt flux, expressed relative to the first century of the control simulation. These values incorporate all the components of the surface balances of freshwater and salt: precipitation, evaporation, runoff and sea ice freeze/melt. The virtual salt flux responds almost immediately to increases in the $\mathrm{CO}_{2}$ concentration, with the net salt flux into the North Atlantic decreasing as a result of enhanced poleward moisture transport. Once the $\mathrm{CO}_{2}$ concentration is stabilised, the virtual salt flux stabilises almost immediately within experiments $2 \mathrm{CO} 2$ and $3 \mathrm{CO} 2$. However, in experiment $4 \mathrm{CO} 2$, a further slow decrease continues until around year 500 .

Following the approach of Manabe and Stouffer (1994), Bi et al. (2001) and Bi (2002), the changes in the sea surface density (SSD) are now decomposed into two components:

$$
\begin{aligned}
\Delta_{T} \sigma_{t} & =\sigma_{t}\left(T, S_{0}\right)-\sigma_{t}\left(T_{0}, S_{0}\right) \\
\Delta_{S} \sigma_{t} & =\sigma_{t}\left(T_{0}, S\right)-\sigma_{t}\left(T_{0}, S_{0}\right)
\end{aligned}
$$

Here, $T$ and $S$ are the SST and SSS, respectively, within the stabilisation experiments, while $T_{0}$ and $S_{0}$ are the mean values for the first century of the control simulation. $\Delta_{T} \sigma_{t}$ 


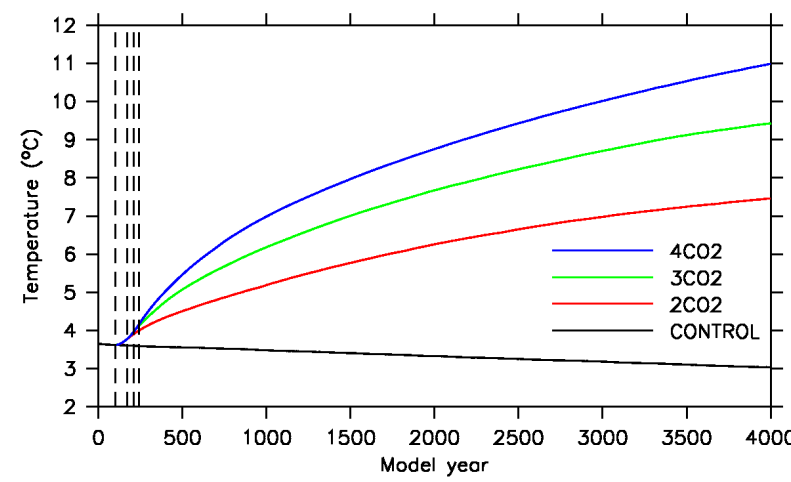

(a) Entire ocean

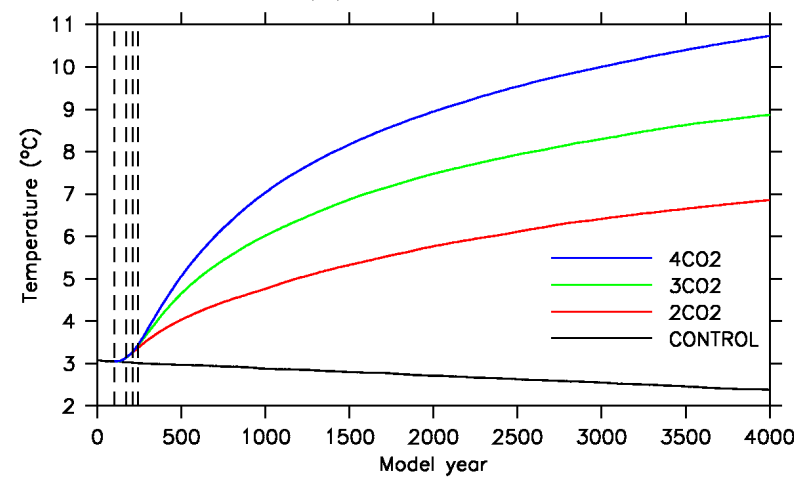

(c) Mid-ocean (800-2350 m)

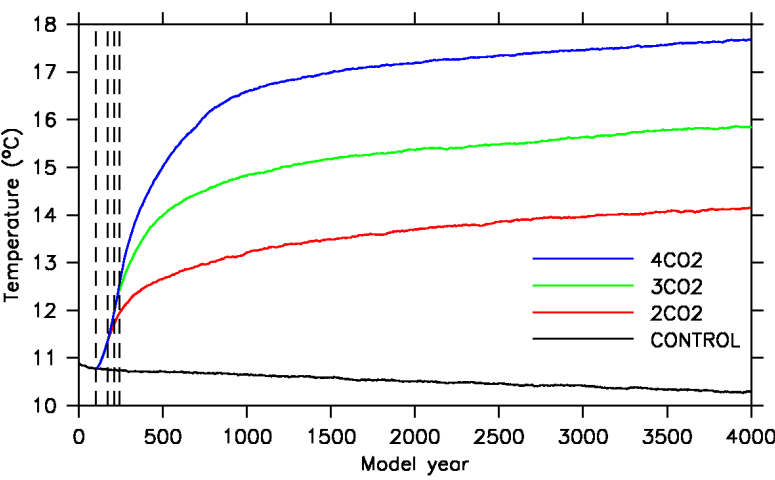

(b) Upper ocean $(0-800 \mathrm{~m})$

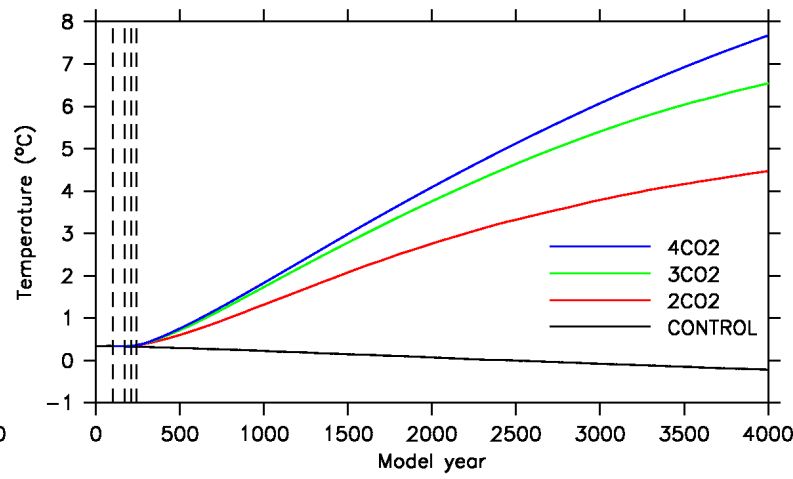

(d) Deep ocean (2350-4600 m)

Fig. 22. The change in annual-mean potential temperature during experiments CONTROL (black), $2 \mathrm{CO} 2$ (red), $3 \mathrm{CO} 2$ (green) and $4 \mathrm{CO} 2$ (blue): (a) the entire ocean, (b) the upper ocean $(0-800 \mathrm{~m})$, (c) the mid-ocean $(800-2350 \mathrm{~m})$, and (d) the deep ocean $(2350-4600 \mathrm{~m})$. The values shown are five-year running means and vertical dashed lines indicate model years 100, 170, 211 and 240.

is therefore the SSD change induced by changes in the SST, while $\Delta_{S} \sigma_{t}$ is the SSD change induced by changes in the SSS. These values are shown in Fig. $24 \mathrm{~b}$ for each of the stabilisation experiments. The initial changes in the virtual salt flux give rise to a rapid decrease in $\mathrm{SSD}$, as can be seen from the increasingly negative values of $\Delta_{S} \sigma_{t}$. However, as soon as the virtual salt flux stabilises, the values of $\Delta_{S} \sigma_{t}$ begin to increase again. This indicates a slow recovery from the reduction in the net surface salt flux. In contrast, changes in the SST have no impact upon the SSD during the period of increasing $\mathrm{CO}_{2}$. Only once the $\mathrm{CO}_{2}$ concentration is stabilised, and the ocean gradually warms, do SST changes begin to influence the SSD. By the end of each simulation, SST and SSS changes make similar contributions towards the reduction in SSD. These results are consistent with those of Bi et al. (2001), who find that surface freshening accounts for the initial reduction in the rate of NADW formation in the CSIRO Mk2 coupled model.

Finally, Fig. 24c shows the changes in the mean stratification of the upper $905 \mathrm{~m}$ of the water column; this depth is chosen as it corresponds to the maximum strength of the meridional overturning streamfunction in the North Atlantic. The stratification is defined as the difference in $\sigma_{905}$ between a depth of $905 \mathrm{~m}$ and the surface. $\sigma_{905}$ is the potential den- sity with respect to a pressure of $905 \mathrm{dbar}$, which is approximately equal to the pressure at this depth. Over the course of experiment $2 \mathrm{CO} 2$, there is little change in the stratification. In contrast, experiments $3 \mathrm{CO} 2$ and $4 \mathrm{CO} 2$ both experience an initial increase in stratification as the surface ocean warms, followed by a slow decrease over time as the warming penetrates to depth.

Thus, the evolution of the thermohaline circulation within each simulation is governed by a balance between rapid atmospheric processes and slow oceanic processes. Enhanced poleward moisture transport gives rise to an immediate surface freshening in all experiments as the $\mathrm{CO}_{2}$ concentration increases. In experiment $2 \mathrm{CO} 2$, the surface density then recovers almost to its original value within a few centuries, allowing the thermohaline circulation to return to its original strength. In experiments $3 \mathrm{CO} 2$ and $4 \mathrm{CO} 2$, however, the initial surface freshening is much stronger, giving rise to increasing stratification of the water column. While the thermohaline circulation also recovers to its original strength in both experiments, the recovery is slower because it requires the surface warming to penetrate to depth.

In the experiments analysed here, the SSD begins to recover as soon as the net surface salt flux into the North Atlantic is stabilised. This demonstrates that Mk3L belongs to 


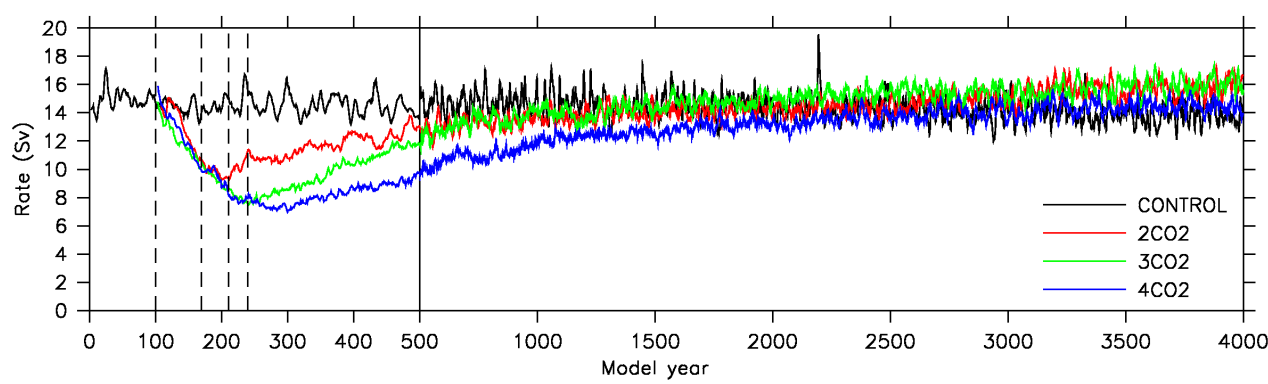

(a) North Atlantic Deep Water

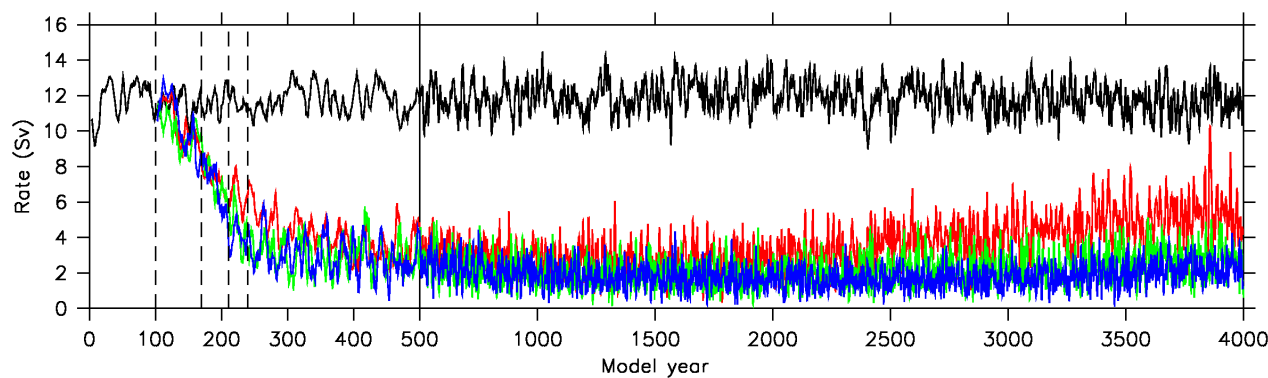

(b) Antarctic Bottom Water

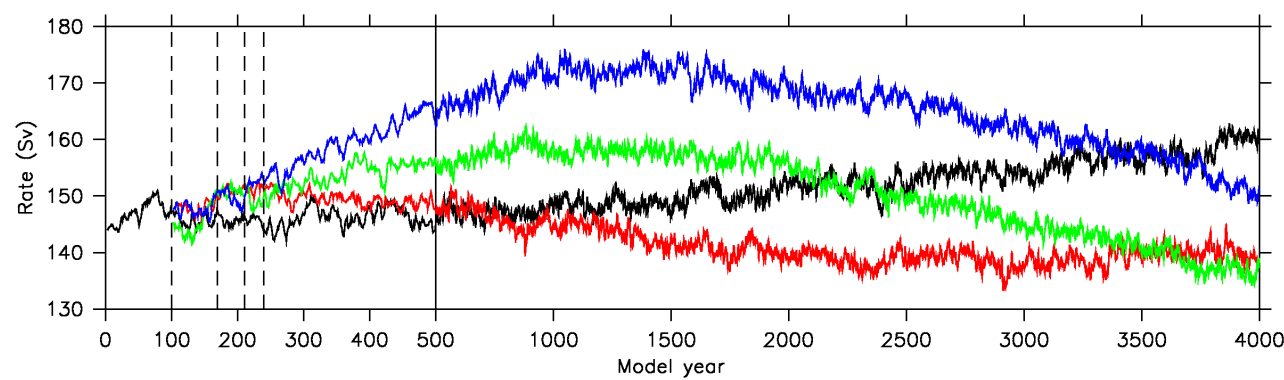

(c) Antarctic Circumpolar Current

Fig. 23. The changes in the rates of deep water formation and the strength of the Antarctic Circumpolar Current during experiments CONTROL (black), 2CO2 (red), 3CO2 (green) and 4CO2 (blue): (a) North Atlantic Deep Water, (b) Antarctic Bottom Water, and (c) the Antarctic Circumpolar Current. The values shown are five-year running means and vertical dashed lines indicate model years 100, 170,211 and 240. Note the change in the scale of the time axis at year 500 .

the category of models that feature a negative salt advection feedback in the Atlantic Basin (Drijfhout et al., 2011; Hawkins et al., 2011). Most coupled atmosphere-ocean models are found to belong to this category, including the CSIRO Mk3.0 and Mk3.5 coupled models (Drijfhout et al., 2011). These models will always recover from freshwater perturbations, as the North Atlantic overturning circulation exports salt from the Atlantic Basin. A weakening of the thermohaline circulation therefore reduces salt export, leading to a gradual re-salinification of the basin. This precludes the existence of multiple equilibria, characterised by stable "on" and "off" states of the North Atlantic overturning circulation (Drijfhout et al., 2011; Hawkins et al., 2011).

\subsection{Antarctic Bottom Water}

The rate of Antarctic Bottom Water (AABW) formation also weakens significantly as the atmospheric $\mathrm{CO}_{2}$ concentration increases (Fig. 23b). However, unlike the decline in NADW, the rate of $\mathrm{AABW}$ formation continues to decline once the $\mathrm{CO}_{2}$ concentration is stabilised. A slight recovery occurs in experiment $2 \mathrm{CO} 2$, with a mean rate of $\mathrm{AABW}$ formation for the final century of $5.7 \mathrm{~Sv}$. However, at higher $\mathrm{CO}_{2}$ concentrations, no such recovery is encountered. This can be attributed to the large reduction in Antarctic sea ice cover and to the corresponding reduction in seasonal brine rejection. As a result, the surface water masses no longer have sufficient density to reach the abyssal ocean. The transient response of AABW formation in AOGCMs has received less attention than the response of NADW formation. However, a similar shutdown of AABW formation is exhibited by the CSIRO Mk2 coupled model (Hirst, 1999; Bi et al., 2001, 2002; Bi, 2002). Using the technique of Bryan (1984) to accelerate the convergence of the model to equilibrium, a resumption of 


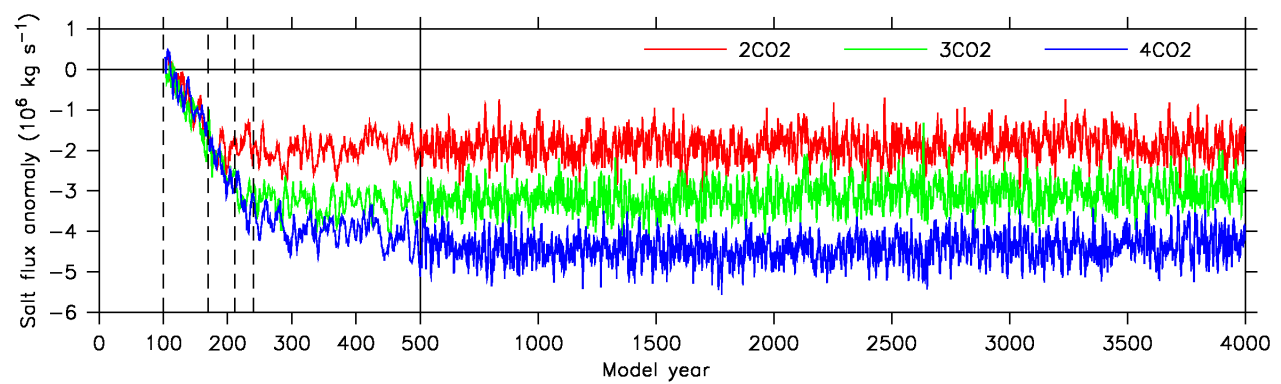

(a) Virtual salt flux anomaly
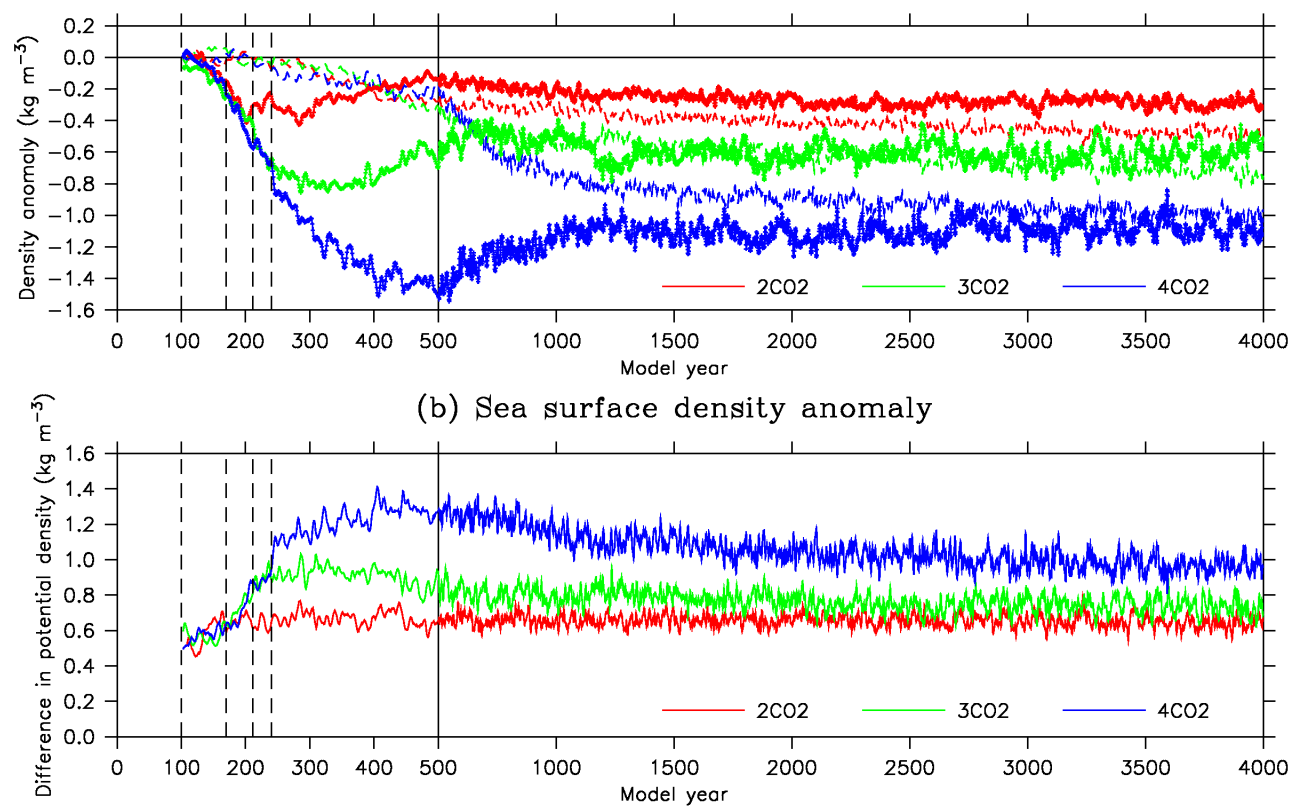

(c) Stratification of upper $905 \mathrm{~m}$ of water column

Fig. 24. The changes in the North Atlantic $\left(50-65^{\circ} \mathrm{N}\right)$ during experiments $2 \mathrm{CO} 2$ (red), $3 \mathrm{CO} 2$ (green) and $4 \mathrm{CO} 2$ (blue): (a) the area-integrated virtual salt flux, expressed as an anomaly relative to the first century of CONTROL; (b) the mean changes in the sea surface density, relative to the first century of CONTROL, due to changes in temperature (dashed lines) and salinity (solid lines); and (c) the mean stratification of the upper $905 \mathrm{~m}$ of the water column, defined as the difference in $\sigma_{905}$ between a depth of $905 \mathrm{~m}$ and the surface. The values shown are five-year running means and vertical dashed lines indicate model years 100, 170, 211 and 240. Note the change in the scale of the time axis at year 500 .

AABW formation occurs once the surface warming penetrates into the ocean interior (Bi et al., 2001; Bi, 2002).

The mean meridional overturning streamfunctions for the final century of each experiment are shown in Fig. 25. The cessation of $\mathrm{AABW}$ formation is apparent, particularly in experiments $3 \mathrm{CO} 2$ and $4 \mathrm{CO} 2$, as is the recovery of NADW formation. By the final century of all the $\mathrm{CO}_{2}$ stabilisation scenarios, the overturning cell in the North Atlantic has recovered to a state that is almost identical to that for the equivalent period of the control simulation; there is little change in either the strength or vertical extent of the overturning cell. Bi et al. (2001), Bi (2002) and Stouffer and Manabe (2003) find similar responses in the CSIRO Mk2 coupled model and GFDL model, respectively.

\subsection{Antarctic Circumpolar Current}

The Antarctic Circumpolar Current (ACC) strengthens slightly as the atmospheric $\mathrm{CO}_{2}$ concentration increases (Fig. 23c). For experiment 2CO2, the strength begins to decline again as soon as the $\mathrm{CO}_{2}$ concentration is stabilised; for experiments $3 \mathrm{CO} 2$ and $4 \mathrm{CO} 2$, however, the ACC continues to strengthen for a number of centuries after stabilisation, before ultimately weakening. By the final century of all of the transient experiments, the ACC is weaker than in the control simulation. The response of $\mathrm{Mk} 3 \mathrm{~L}$ to a trebling of the $\mathrm{CO}_{2}$ concentration is consistent with that of the CSIRO Mk2 coupled model, which exhibits an initial strengthening of the ACC followed by a slow weakening. These changes are found to be driven by changes in the density structure 


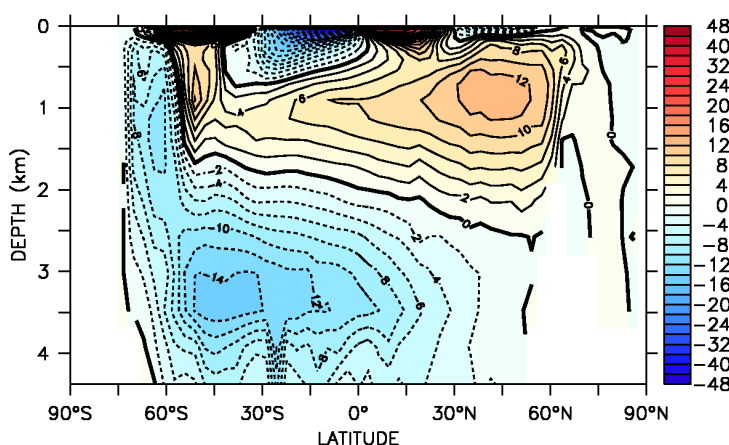

(a) CONTROL

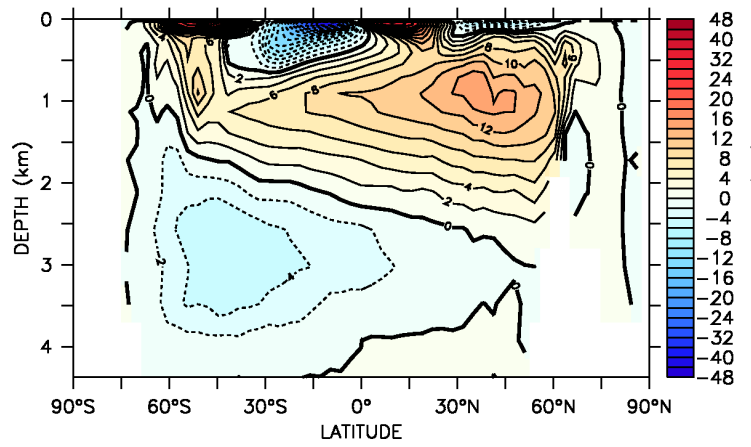

(c) $3 \mathrm{CO2}$

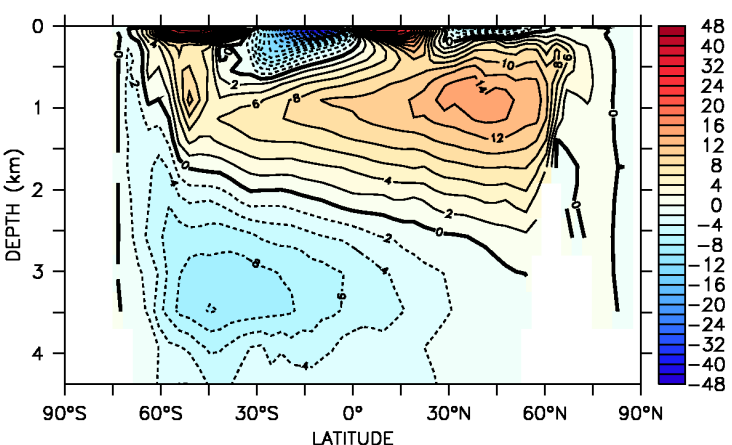

(b) $2 \mathrm{CO2}$

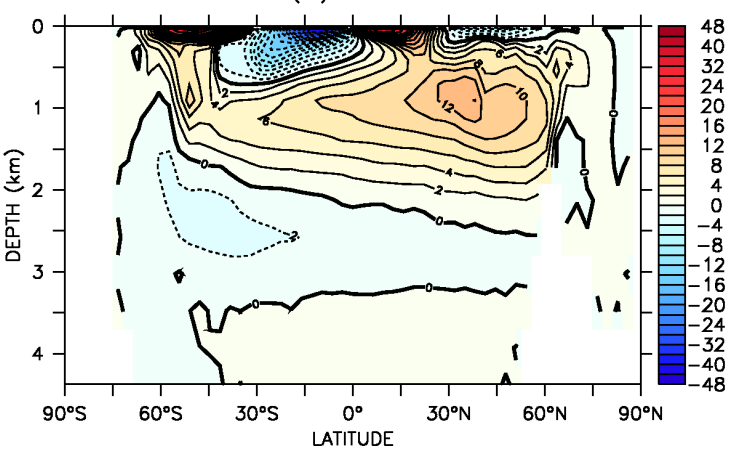

(d) $4 \mathrm{CO2}$

Fig. 25. The average global meridional overturning streamfunction (Sv) for years 3901-4000 of each experiment: (a) CONTROL, (b) 2CO2, (c) 3CO2, and (d) 4CO2.

of the ocean interior and the reduction in the rate of $\mathrm{AABW}$ formation (Bi et al., 2002; Bi, 2002).

The transient response of $\mathrm{Mk} 3 \mathrm{~L}$ is also consistent with that of the 12 AOGCMs studied by Fyfe and Saenko (2006), who find a consistent strengthening and poleward shift of the ACC during the 20th and 21st centuries in response to increasing atmospheric greenhouse gases.

\subsection{Summary}

The response of Mk3L to scenarios in which the atmospheric carbon dioxide concentration is stabilised at two, three and four times the pre-industrial level is consistent with that of other climate system models. The global-mean SAT increases rapidly as the $\mathrm{CO}_{2}$ concentration is increased, and slow ongoing warming is still occurring by the end of each 4000 -yr simulation. The sea ice extent exhibits rapid and ongoing declines in both hemispheres, with the ice cover disappearing completely in the Northern Hemisphere when the $\mathrm{CO}_{2}$ concentration is quadrupled.

The thermohaline circulation weakens as the $\mathrm{CO}_{2}$ concentration increases, but the rate of NADW formation then recovers and has exceeded its original strength by the end of each experiment. The rate of AABW formation also weakens as the atmospheric $\mathrm{CO}_{2}$ concentration is increased. $\mathrm{Al}-$ though there is a partial recovery in response to a doubling of the $\mathrm{CO}_{2}$ concentration, no such recovery occurs in re- sponse to larger increases. The Antarctic Circumpolar Current strengthens at first in each experiment, before ultimately declining to a strength similar to the first century of the control simulation. With the shutdown of AABW formation, ventilation of the abyssal ocean ceases and the penetration of the surface warming to depth is slow. By the end of each 4000-yr experiment, the deep ocean is still exhibiting strong ongoing warming.

The TCR of Mk3L is $1.59 \pm 0.08 \mathrm{~K}$, which is consistent with the estimated uncertainty range for the true climate system and in the lower half of the 5-95\% uncertainty range for the AR4 models. In contrast, although the model was not integrated to equilibrium, it is determined that the ECS is at least $3.85 \pm 0.02 \mathrm{~K}$. This is consistent with the "likely" range for the true climate system, and in the upper half of the 5$95 \%$ uncertainty range for the AR4 models. The relatively low value of the TCR appears to be due to the "cold start" effect, while the relatively high value of the ECS appears to be due to the time-dependence of climate feedbacks. Relative to other versions of the CSIRO model, $\mathrm{Mk} 3 \mathrm{~L}$ has a lower climate sensitivity than $\mathrm{Mk} 2$ but appears to have a higher sensitivity than Mk3.0. This is consistent with the nature of the model physics, with the oceanic component of Mk3L being derived from $\mathrm{Mk} 2$ but the atmospheric component being derived from Mk3.0. 
Flux adjustments are applied in Mk3L, both to improve the realism of the simulated control climate and to minimise drift. Previous studies have found no evidence that flux adjustments directly influence the climate sensitivity of models. For example, Sen Gupta et al. (2012) examine the CMIP3 models and find no evidence that the magnitude of the simulated 20th century warming trend differs between flux-adjusted and non-flux-adjusted models. Although Gregory and Mitchell (1997) find that the TCR is $30 \%$ less in the non-flux-adjusted version of HadCM2 than in the fluxadjusted version, this is attributed to the effect of the control climate on the magnitude of cloud feedbacks. Flux adjustments are therefore found to have only an indirect effect on the climate sensitivity. As the flux-adjusted version of the model has a more realistic control state, Gregory and Mitchell (1997) therefore conclude that this version is more likely to be correct. Thus, there is no reason to believe that the application of flux adjustments has any direct effect on the climate sensitivity of Mk3L. By ensuring a stable and realistic control state, it is likely that they act instead to improve the representation of climate feedbacks within the model.

\section{Conclusions}

The response of the CSIRO Mk3L climate system model to external forcings corresponding to past and future changes in the climate system has been evaluated.

$\mathrm{Mk} 3 \mathrm{~L}$ is able to simulate the larger-scale differences between the climate of the mid-Holocene and that of the present day, including increased summer temperatures at northern mid-latitudes and cooling in the tropics. However, it is unable to capture the full extent of the estimated precipitation changes over Northern Africa, possibly as a consequence of the static nature of the vegetation. While the model simulates a reduction of between 7 and $15 \%$ in the amplitude of ENSO, this is a smaller reduction than that implied by the palaeoclimate record. This discrepancy may reflect deficiencies in the realism of the simulated ENSO, arising from the model's reduced spatial resolution.

$\mathrm{Mk} 3 \mathrm{~L}$ is also able to simulate the main features of the transient response of the climate system to insolation changes over the late Holocene. Decreasing insolation during the Northern Hemisphere summer drives large-scale cooling, while increasing insolation during the Southern Hemisphere summer drives large-scale warming. The model also simulates an overall upward trend in ENSO variability. However, the static nature of the vegetation prevents it from being able to reproduce the abrupt desertification of the Sahara that appears to have occurred at around $5500 \mathrm{yr}$ BP. The acceleration technique of Lorenz and Lohmann (2004) has also been shown to have utility, although larger values of the acceleration factor reduce the ability to constrain trends in surface air temperature, precipitation or ENSO variability. The use of acceleration also influences the simulated temperatures in the ocean interior, indicating that large acceleration factors should not be used to simulate very long periods of time.

A transient simulation of the last millennium is broadly successful at capturing the observed changes in the climate system, including the transition from the Mediaeval Climate Anomaly to the Little Ice Age and the decadal-scale cooling in response to major volcanic eruptions. The magnitude and spatial pattern of the simulated 20th century warming are also consistent with observed trends. However, Mk3L appears to overestimate the cooling in response to the volcanic eruption of $1258 \mathrm{CE}$. This may indicate deficiencies in the model physics, but it could also indicate deficiencies in the volcanic reconstruction used to force the model or in the temperature reconstruction used to evaluate the model simulation. The model also underestimates the magnitude of the relative warmth associated with the Mediaeval Climate Anomaly, and fails to reproduce the apparent La Niña-like pattern of temperature changes over the Pacific Basin.

The response of Mk3L to a doubling, trebling and quadrupling of the atmospheric carbon dioxide concentration has also been assessed. The simulated changes are consistent with those of other models, with ongoing surface warming, reduced sea ice cover, a weakening and then recovery of the rate of NADW formation, and a permanent shutdown of $\mathrm{AABW}$ formation when the $\mathrm{CO}_{2}$ concentration is trebled or quadrupled. The transient and equilibrium climate sensitivities are consistent with those of other models, although the transient response is relatively weak while the equilibrium response appears to be relatively strong.

Flux adjustments are applied within Mk3L. While flux adjustments are non-physical, an unrealistic control climate and excessive drift are arguably also non-physical (Sen Gupta et al., 2012). By ensuring that Mk3L has a realistic control state, flux adjustments act to improve the representation of climate feedbacks within the model. They also act to minimise drift, which is particularly important in a model that is intended primarily for millennial-scale climate simulation. Nonetheless, future development work should seek to produce a version of the model that does not require the application of flux adjustments to ensure a stable and realistic control climatology.

This evaluation has shown that Mk3L has considerable utility for studying the response of the climate system to a range of external forcings, particularly on the hemispheric and global scales. However, it has also identified areas where the utility of the model would be improved by enhancements to the physics. Incorporation of a dynamic vegetation scheme and/or a dust scheme might improve the ability of the model to simulate regional changes in the hydroclimate. A more realistic representation of El Niño-Southern Oscillation within the model might also improve its ability to simulate the response of ENSO to external forcings. Finally, the incorporation of schemes for aerosols and atmospheric chemistry would improve the ability of Mk3L to represent the effects 
Table A1. The names of the experiments analysed herein.

\begin{tabular}{lc}
\hline Experiment & Name \\
\hline CONTROL & $\mathrm{d} 73$ \\
6KA & $\mathrm{d} 95$ \\
HOLO5 & $\mathrm{e} 21$ \\
HOLO10 & $\mathrm{e} 20$ \\
HOLO20 & $\mathrm{e} 22$ \\
LAST1000 & $\mathrm{e} 24$ \\
2CO2 & $\mathrm{e} 14$ \\
3CO2 & $\mathrm{d} 86$ \\
4 CO2 & $\mathrm{e} 15$ \\
\hline
\end{tabular}

of solar and volcanic forcing, as well as allowing it to simulate the effects of anthropogenic aerosols.

\section{Appendix A}

The names of each of the experiments analysed herein are shown in Table A1.

Years 201-1200 of experiments CONTROL (d73) and 6KA (d95) have been submitted to the PMIP2 database under experiments pmip2_0k_oa and pmip2_6k_oa, respectively, with the model name CSIRO-Mk3L-1.0.

Acknowledgements. The authors wish to acknowledge CSIRO Marine and Atmospheric Research for providing access to their climate model. Leon Rotstayn supplied reduced-resolution versions of the model components, while Dave Bi, Martin Dix, Hal Gordon, Tony Hirst, Eva Kowalczyk, Siobhan O'Farrell and Ian Watterson also contributed towards the development of Mk3L. Invaluable assistance was received from staff at the NCI National Facility (formerly the Australian Partnership for Advanced Computing), particularly Stuart Midgley and David Singleton. The authors also wish to acknowledge the many other people, too numerous to list here, who have contributed towards the development and release of $\mathrm{Mk} 3 \mathrm{~L}$. Particular thanks are due to CSIRO Marine and Atmospheric Research and the Antarctic Climate and Ecosystems Co-operative Research Centre for allowing the model to be made freely available to the research community.

The lead author's contribution towards some of this work was performed as part of his $\mathrm{PhD}$ project. Financial support was received from the Australian Government (an International Postgraduate Research Scholarship), the University of Tasmania (a Tasmania Research Scholarship), the Antarctic CRC (an Antarctic CRC Top-Up Scholarship) and the Trans-Antarctic Association (grant TAA/99/12). Steven Phipps would like to thank Bill Budd, Nathan Bindoff, Jason Roberts, Scott Power, Xingren Wu and Tas van Ommen for their supervision and guidance throughout his candidature.

The development of $\mathrm{Mk} 3 \mathrm{~L}$ was supported by awards under the Merit Allocation Scheme on the NCI National Facility at the Australian National University. Grants of computer time were also received from the Tasmanian Partnership for Advanced Computing
(Hobart, Tasmania) and iVEC (Perth, Western Australia). The authors wish to acknowledge use of the Ferret program for analysis and graphics in this paper (http://ferret.pmel.noaa.gov/Ferret/). The Ice-core Volcanic Index 2 dataset was obtained from the website of the Department of Environmental Sciences, Rutgers, The State University of New Jersey at http://climate.envsci.rutgers.edu/IVI2/. The anthropogenic greenhouse gas concentrations of MacFarling Meure et al. (2006) were supplied by David Etheridge. The Global $1500 \mathrm{yr}$ Spatial Temperature Reconstructions of Mann et al. (2009) were obtained from the World Data Center for Paleoclimatology at http:// www.ncdc.noaa.gov/paleo/pubs/mann2009b/mann2009b.html. The NCEP-DOE Reanalysis 2 was provided by the NOAA-ESRL Physical Sciences Division, Boulder, Colorado, USA from their website at http://www.esrl.noaa.gov/psd/.

Suggestions by Joelle Gergis, Chris Jones and two anonymous referees have improved this manuscript.

Edited by: H. Goosse

\section{References}

Bartlein, P. J., Harrison, S. P., Brewer, S., Connor, S., Davis, B. A. S., Gajewski, K., Guiot, J., Harrison-Prentice, T. I., Henderson, A., Peyron, O., Prentice, I. C., Scholze, M., Seppä, H., Shuman, B., Sugita, S., Thompson, R. S., Viau, A. E., Williams, J., and $\mathrm{Wu}, \mathrm{H}$. : Pollen-based continental climate reconstructions at 6 and $21 \mathrm{ka}$ : a global synthesis, Clim. Dynam., 37, 775-802, doi:10.1007/s00382-010-0904-1, 2011.

Berger, A. L.: Long-term variations of daily insolation and Quaternary climatic changes, J. Atmos. Sci., 35, 2362-2367, 1978.

Bi, D.: Transient and Long-Term Behaviour of the World Ocean Under Global Warming, Ph. D. thesis, University of Tasmania, Hobart, Tasmania, Australia, 2002.

Bi, D., Budd, W. F., Hirst, A. C., and Wu, X.: Collapse and reorganisation of the Southern Ocean overturning under global warming in a coupled model, Geophys. Res. Lett., 28, 3927-3930, 2001.

Bi, D., Budd, W. F., Hirst, A. C., and Wu, X.: Response of the Antarctic Circumpolar Current transport to global warming in a coupled model, Geophys. Res. Lett., 29, 2173 , doi:10.1029/2002GL015919, 2002.

Bonfils, C., de Noblet-Ducoudré, N., Guiot, J., and Bartlein, P.: Some mechanisms of mid-Holocene climate change in Europe, inferred from comparing PMIP models to data, Clim. Dynam., 23, 79-98, doi:10.1007/s00382-004-0425-x, 2004.

Braconnot, P., Joussaume, S., Marti, O., and de Noblet, N.: Synergistic feedbacks from ocean and vegetation on the African monsoon response to mid-Holocene insolation, Geophys. Res. Lett., 26, 2481-2484, 1999

Braconnot, P., Joussaume, S., de Noblet, N., and Ramstein, G.: MidHolocene and Last Glacial Maximum African monsoon changes as simulated within the Paleoclimate Modelling Intercomparison Project, Global Planet. Change, 26, 51-66, 2000.

Braconnot, P., Otto-Bliesner, B., Harrison, S., Joussaume, S., Peterschmitt, J.-Y., Abe-Ouchi, A., Crucifix, M., Driesschaert, E., Fichefet, Th., Hewitt, C. D., Kageyama, M., Kitoh, A., Laîné, A., Loutre, M.-F., Marti, O., Merkel, U., Ramstein, G., Valdes, P., Weber, S. L., Yu, Y., and Zhao, Y.: Results of PMIP2 coupled simulations of the Mid-Holocene and Last Glacial Maximum - 
Part 1: experiments and large-scale features, Clim. Past, 3, 261277, doi:10.5194/cp-3-261-2007, 2007a.

Braconnot, P., Otto-Bliesner, B., Harrison, S., Joussaume, S., Peterschmitt, J.-Y., Abe-Ouchi, A., Crucifix, M., Driesschaert, E., Fichefet, Th., Hewitt, C. D., Kageyama, M., Kitoh, A., Loutre, M.-F., Marti, O., Merkel, U., Ramstein, G., Valdes, P., Weber, L., Yu, Y., and Zhao, Y.: Results of PMIP2 coupled simulations of the Mid-Holocene and Last Glacial Maximum - Part 2: feedbacks with emphasis on the location of the ITCZ and mid- and high latitudes heat budget, Clim. Past, 3, 279-296, doi:10.5194/cp-3-279-2007, 2007b.

Brewer, S., Guiot, J., and Torre, F.: Mid-Holocene climate change in Europe: a data-model comparison, Clim. Past, 3, 499-512, doi:10.5194/cp-3-499-2007, 2007.

Brovkin, V. and Claussen, M.: Comment on "Climate-Driven Ecosystem Succession in the Sahara: The Past 6000 Years", Science, 322, 1326b, doi:10.1126/science.1163381, 2008.

Brown, J., Tudhope, A. W., Collins, M., and McGregor, H. V.: Mid-Holocene ENSO: Issues in quantitative modelproxy data comparisons, Paleoceanography, 23, PA3202, doi:10.1029/2007PA001512, 2008.

Bryan, F. O., Danabasoglu, G., Nakashiki, N., Yoshida, Y., Kim, D.H., Tsutsui, J. and Doney, S. C.: Response of the North Atlantic thermohaline circulation and ventilation to increasing carbon dioxide in CCSM3, J. Climate, 19, 2382-2397, 2006.

Bryan, K.: Accelerating the convergence to equilibrium of oceanclimate models, J. Phys. Oceanogr., 14, 666-673, 1984.

Büntgen, U., Frank, D. C., Nievergelt, D., and Esper, J.: Summer temperature variations in the European Alps, AD 755-2004, J. Climate, 19, 5606-5623, 2006.

Cheddadi, R., Yu, G., Guiot, J., Harrison, S. P., and Prentice, I. C.: The climate of Europe 6000 years ago, Clim. Dynam., 13, 1-9, 1997.

Crowley, T. J.: Causes of climate change over the past 1000 years, Science, 289, 270-277, 2000.

Danabasoglu, G. and Gent, P. R.: Equilibrium climate sensitivity: is it accurate to use a slab ocean model?, J. Climate, 22, 24942499, doi:10.1175/2008JCLI2596.1, 2009.

deMenocal, P., Ortiz, J., Guilderson, T., Adkins, J., Sarnthein, M., Baker, L., and Yarusinsky, M.: Abrupt onset and termination of the African Humid Period: rapid climate responses to gradual insolation forcing, Quaternary Sci. Rev., 19, 347-361, 2000.

Drijfhout, S. S., Weber, S. L., and van der Swaluw, E: The stability of the MOC as diagnosed from model projections for preindustrial, present and future climates, Clim. Dynam., 37, 15751586, doi:10.1007/s00382-010-0930-z, 2011.

Eddy, J. A.: The Maunder Minimum, Science, 192, 1189-1202, 1976.

Fan, F., Mann, M. E., and Ammann, C. M.: Understanding changes in the Asian Summer Monsoon over the past millennium: insights from a long-term coupled model simulation, J. Climate, 22, 1736-1748, doi:10.1175/2008JCLI2336.1, 2009.

Fischer, N. and Jungclaus, J. H.: Evolution of the seasonal temperature cycle in a transient Holocene simulation: orbital forcing and sea-ice, Clim. Past, 7, 1139-1148, doi:10.5194/cp-7-1139-2011, 2011.

Flato, G. M. and Participating CMIP Modelling Groups: Sea-ice and its response to $\mathrm{CO}_{2}$ forcing as simulated by global climate models, Clim. Dynam., 23, 229-241, doi:10.1007/s00382-004-
0436-7, 2004.

Folland, C. K., Karl, T. R., Christy, J. R., Clarke, R. A., Gruza, G. V., Jouzel, J., Mann, M. E., Oerlemans, J., Salinger, M. J., and Wang, S.-W.: Observed Climate Variability and Change, in: Climate Change 2001: The Scientific Basis, edited by: Houghton, J. T., Ding, Y., Griggs, D. J., Noguer, M., van der Linden, P. J., Dai, X., Maskell, K., and Johnson, C. A., Chap. 2, Cambridge University Press, 99-181, 2001.

Forster, P., Ramaswamy, V., Artaxo, P., Berntsen, T., Betts, R., Fahey, D. W., Haywood, J., Lean, J., Lowe, D. C., Myhre, G., Nganga, J., Prinn, R., Raga, G., Schulz, M., and Van Dorland, R.: Changes in Atmospheric Constituents and in Radiative Forcing, in: Climate Change 2007: The Physical Science Basis, edited by: Solomon, S., Qin, D., Manning, M., Chen, Z., Marquis, M., Averyt, K. B., Tignor, M., and Miller, H. L., Chap. 2, Cambridge University Press, Cambridge, 129-234, 2007.

Fyfe, J. C. and Saenko, O. A.: Simulated changes in the extratropical Southern Hemisphere winds and currents, Geophys. Res. Lett., 33, L06701, doi:10.1029/2005GL025332, 2006.

Gao, C., Robock, A., and Ammann, C.: Volcanic forcing of climate over the past 1500 years: An improved ice-core based index for climate models, J. Geophys. Res., 113, D23111, doi:10.1029/2008JD010239, 2008.

Gordon, H. B. and O'Farrell, S. P.: Transient climate change in the CSIRO coupled model with dynamic sea ice, Mon. Weather Rev., 125, 875-907, 1997.

Gordon, H. B., Rotstayn, L. D., McGregor, J. L., Dix, M. R., Kowalczyk, E. A., O’Farrell, S. P., Waterman, L. J., Hirst, A. C., Wilson, S. G., Collier, M. A., Watterson, I. G., and Elliott, T. I.: The CSIRO Mk3 Climate System Model, Technical Paper 60, CSIRO Atmospheric Research, available at: http://www.cmar. csiro.au/e-print/open/gordon_2002a.pdf (last access: November 2011), 2002.

Gregory, J. M. and Forster, P. M.: Transient climate response estimated from radiative forcing and observed temperature change, J. Geophys. Res., 113, D23105, doi:10.1029/2008JD010405, 2008.

Gregory, J. M. and Mitchell, J. F. B.: The climate response to $\mathrm{CO}_{2}$ of the Hadley Centre coupled AOGCM with and without flux adjustment, Geophys. Res. Lett., 24, 1943-1946, 1997.

Gregory, J. M., Ingram, W. J., Palmer, M. A., Jones, G. S., Stott, P. A., Thorpe, R. B., Lowe, J. A., Johns, T. C., and Williams, K. D.: A new method for diagnosing radiative forcing and climate sensitivity, Geophys. Res. Lett., 31, L03205, doi:10.1029/2003GL018747, 2004.

Gregory, J. M., Dixon, K. W., Stouffer, R. J., Weaver, A. J., Driesschaert, E., Eby, M., Fichefet, T., Hasumi, H., Hu, A., Jungclaus, J. H., Kamenkovich, I. V., Levermann, A., Montoya, M., Murakami, S., Nawrath, S., Oka, A., Solokov, A. P., and Thorpe, R. B.: A model intercomparison of changes in the Atlantic thermohaline circulation in response to increasing atmospheric $\mathrm{CO}_{2}$ concentration, Geophys. Res. Lett., 32, L12703, doi:10.1029/2005GL023209, 2005.

Harrison, S. P., Jolly, D., Laarif, F., Abe-Ouchi, A., Dong, B., Herterich, K., Hewitt, C., Joussaume, S., Kutzbach, J. E., Mitchell, J., de Noblet, N., and Valdes, P.: Intercomparison of Simulated Global Vegetation Distributions in Response to 6 kyr BP Orbital Forcing, J. Climate, 11, 2721-2742, 1998. 
Hasselmann, K., Sausen, R., Maier-Reimer, E., and Voss, R.: On the cold start problem in transient simulations with coupled atmosphere-ocean models, Clim. Dynam., 9, 53-61, 1993.

Hawkins, E., Smith, R. S., Allison, L. C., Gregory, J. M., Woollings, T. J., Pohlmann, H., and de Cuevas, B.: Bistability of the Atlantic overturning circulation in a global climate model and links to ocean freshwater transport, Geophys. Res. Lett., 38, L10605, doi:10.1029/2011GL047208, 2011.

Hirst, A. C.: The Southern Ocean response to global warming in the CSIRO coupled ocean-atmosphere model, Environ. Modell. Softw., 14, 227-241, 1999.

Hoar, M. R., Palutikof, J. P., and Thorne, M. C.: Model intercomparison for the present day, the mid-Holocene, and the Last Glacial Maximum over Western Europe, J. Geophys. Res., 109, D08104, doi:10.1029/2003JD004161, 2004.

Hoelzmann, P., Jolly, D., Harrison, S. P., Laarif, F., Bonnefille, R., and Pachur, H.-J.: Mid-Holocene land-surface conditions in Northern Africa and the Arabian peninsula: A data set for the analysis of biogeophysical feedbacks in the climate system, Global Biogeochem. Cy., 12, 35-51, 1998.

Hofer, D., Raible, C. C., and Stocker, T. F.: Variations of the Atlantic meridional overturning circulation in control and transient simulations of the last millennium, Clim. Past, 7, 133-150, doi:10.5194/cp-7-133-2011, 2011.

Hu, A., Meehl, G. A., Washington, W. M., and Dai, A.: Response of the Atlantic thermohaline circulation to increased atmospheric $\mathrm{CO}_{2}$ in a coupled model, J. Climate, 17, 4267-4279, 2004.

Jolly, D., Harrison, S. P., Damnati, B., and Bonnefille, R.: Simulated climate and biomes of Africa during the late Quaternary: comparison with pollen and lake status data, Quaternary Sci. Rev., 17, 629-657, 1998a.

Jolly, D., Prentice, I. C., Bonnefille, R., Ballouche, A., Bengo, M., Brenac, P., Buchet, G., Burney, D., Cazet, J.-P., Cheddadi, R., Edorh, T., Elenga, H., Elmoutaki, S., Guiot, J., Laarif, F., Lamb, H., Lezine, A.-M., Maley, J., Mbenza, M., Peyron, O., Reille, M., Reynaud-Farrera, I., Riollet, G., Ritchie, J. C., Roche, E., Scott, L., Ssemmanda, I., Straka, H., Umer, M., Campo, E. V., Vilimumbalo, S., Vincens, A., and Waller, M.: Biome reconstruction from pollen and plant macrofossil data for Africa and the Arabian peninsula at 0 and 6000 years, J. Biogeogr., 25, 1007-1027, 1998b.

Joussaume, S., Taylor, K. E., Braconnot, P., Mitchell, J. F. B., Kutzbach, J. E., Harrison, S. P., Prentice, I. C., Broccoli, A. J., Abe-Ouchi, A., Bartlein, P. J., Bonfils, C., Dong, B., Guiot, J., Herterich, K., Hewitt, C. D., Jolly, D., Kim, J. W., Kislov, A., Kitoh, A., Loutre, M. F., Masson, V., McAvaney, B., McFarlane, N., de Noblet, N., Peltier, W. R., Peterschmitt, J. Y., Pollard, D., Rind, D., Royer, J. F., Schlesinger, M. E., Sytkus, J., Thompson, S., Valdes, P., Vettoretti, G., Webb, R. S., and Wyputta, U.: Monsoon changes for 6000 years ago: results of 18 simulations from the Paleoclimate Modeling Intercomparison Project (PMIP), Geophys. Res. Lett., 26, 859-862, 1999.

Jungclaus, J. H., Lorenz, S. J., Timmreck, C., Reick, C. H., Brovkin, V., Six, K., Segschneider, J., Giorgetta, M. A., Crowley, T. J., Pongratz, J., Krivova, N. A., Vieira, L. E., Solanki, S. K., Klocke, D., Botzet, M., Esch, M., Gayler, V., Haak, H., Raddatz, T. J., Roeckner, E., Schnur, R., Widmann, H., Claussen, M., Stevens, B., and Marotzke, J.: Climate and carboncycle variability over the last millennium, Clim. Past, 6, 723-
737, doi:10.5194/cp-6-723-2010, 2010.

Kanamitsu, M., Ebisuzaki, W., Woollen, J., Yang, S.-K., Hnilo, J. J., Fiorino, M., and Potter, G. L.: NCEP-DOE AMIP-II Reanalysis (R-2), B. Am. Meteorol. Soc., 83, 1631-1643, doi:10.1175/BAMS-83-11-1631, 2002.

Kitoh, A., Motoi, T., and Murakami, S.: El Niño-Southern Oscillation Simulation at 6000 Years before Present with the MRICGCM2.3: Effect of Flux Adjustment, J. Climate, 284, 24842499, doi:10.1175/JCLI4141.1, 2007.

Kohfeld, K. E. and Harrison, S. P.: How well can we simulate past climates?, Evaluating the models using global palaeoenvironmental datasets, Quaternary Sci. Rev., 19, 321-346, 2000.

Kröpelin, S., Verschuren, D., Lézine, A.-M., Eggermont, H., Cocquyt, C., Francus, P., Cazet, J.-P., Fagot, M., Rumes, B., Russell, J. M., Darius, F., Conley, D. J., Schuster, M., von Suchodoletz, H., and Engstrom, E. R.: Climate-Driven Ecosystem Succession in the Sahara: The Past 6000 Years, Science, 320, 765-768, doi:10.1126/science.1154913, 2008.

Lean, J.: Evolution of the Sun's spectral irradiance since the Maunder Minimum, Geophys. Res. Lett., 27, 2425-2428, 2000.

Lean, J., Beer, J., and Bradley, R.: Reconstruction of solar irradiance since 1610: Implications for climate change, Geophys. Res. Lett., 22, 3195-3198, 1995.

Levis, S., Bonan, G. B., and Bonfils, C.: Soil feedback drives the mid-Holocene North African monsoon northward in fully coupled CCSM2 simulations with a dynamic vegetation model, Clim. Dynam., 23, 791-802, doi:10.1007/s00382-004-0477-y, 2004.

Liu, J., Wang, B., Ding, Q., Kuang, X., Soon, W., and Zorita, E.: Centennial variations of the global monsoon precipitation in the last millennium: results from ECHO-G model, J. Climate, 22, 2356-2371, doi:10.1175/2008JCLI2353.1, 2009.

Liu, Y., Liang, X. S., and Weisberg, R. H.: Rectification of the bias in the wavelet power spectrum, J. Atmos. Ocean. Tech., 24, 2093-2102, doi:10.1175/2007JTECHO511.1, 2007.

Liu, Z., Kutzbach, J., and Wu, L.: Modeling climate shift of El Niño variability in the Holocene, Geophys. Res. Lett., 27, 2265-2268, 2000.

Liu, Z., Wang, Y., Gallimore, R., Notaro, M., and Prentice, I. C.: On the cause of abrupt vegetation collapse in North Africa during the Holocene: climate variability vs. vegetation feedback, Geophys. Res. Lett., 33, L22709, doi:10.1029/2006GL028062, 2006.

Lohmann, K. and Latif, M.: Tropical Pacific decadal variability and the subtropical-tropical cells, J. Climate, 18, 5163-5178, 2005.

Lorenz, S. J. and Lohmann, G.: Acceleration technique for Milankovitch type forcing in a coupled atmosphere-ocean circulation model: method and application for the Holocene, Clim. Dynam., 23, 727-743, doi:10.1007/s00382-004-0469-y, 2004.

Lorenz, S. J., Kim, J.-H., Rimbu, N., Schneider, R. R., and Lohmann, G.: Orbitally driven insolation forcing on Holocene climate trends: evidence from alkenone data and climate modeling, Paleoceanography, 21, PA1002, doi:10.1029/2005PA001152, 2006.

MacFarling Meure, C., Etheridge, D., Trudinger, C., Steele, P., Langenfelds, R., van Ommen, T., Smith, A., and Elkins, J.: Law Dome $\mathrm{CO}_{2}, \mathrm{CH}_{4}$ and $\mathrm{N}_{2} \mathrm{O}$ ice core records extended to 2000 years BP, Geophys. Res. Lett., 33, L14810, doi:10.1029/2006GL026152, 2006. 
Manabe, S. and Stouffer, R. J.: Century-scale effects of increased atmospheric $\mathrm{CO}_{2}$ on the ocean-atmosphere system, Nature, 364, 215-218, 1993.

Manabe, S. and Stouffer, R. J.: Multiple-century response of a coupled ocean-atmosphere model to an increase of atmospheric carbon dioxide, J. Climate, 7, 5-23, 1994.

Mann, M. E., Zhang, Z., Rutherford, S., Bradley, R. S., Hughes, M. K., Shindell, D., Ammann, C., Faluvegi, G., and Ni, F.: Global signatures and dynamical origins of the Little Ice Age and Medieval Climate Anomaly, Science, 326, 1256-1260, doi:10.1126/science.1177303, 2009.

Masson, V., Cheddadi, R., Braconnot, P., Joussaume, S., Texier, D., and PMIP participants: Mid-Holocene climate in Europe: what can we infer from PMIP model-data comparisons?, Clim. Dynam., 15, 163-182, 1999.

Meehl, G. A., Boer, G. J., Covey, C., Latif, M., and Stouffer, R. J.: The Coupled Model Intercomparison Project (CMIP), B. Am. Meteorol. Soc., 81, 313-318, 2000.

Meehl, G. A., Covey, C., Delworth, T., Latif, M., McAvaney, B., Mitchell, J. F. B., Stouffer, R. J., and Taylor, K. E.: The WCRP CMIP3 multimodel dataset, B. Am. Meteorol. Soc., 88, 13831394, doi:10.1175/BAMS-88-9-1383, 2007a.

Meehl, G. A., Stocker, T. F., Collins, W. D., Friedlingstein, P., Gaye, A. T., Gregory, J. M., Kitoh, A., Knutti, R., Murphy, J. M., Noda, A., Raper, S. C. B., Watterson, I. G., Weaver, A. J., and Zhao, Z.-C.: Global climate projections, in: Climate Change 2007: The Physical Science Basis, edited by: Solomon, S., Qin, D., Manning, M., Chen, Z., Marquis, M., Averyt, K. B., Tignor, M., and Miller, H. L., Chap. 10, Cambridge University Press, Cambridge, 747-845, 2007b.

Minnis, P., Harrison, E. F., Stowe, L. L., Gibson, G. G., Denn, F. M., Doelling, D. R., and Smith, Jr., W. L.: Radiative climate forcing by the Mount Pinatubo eruption, Science, 259, 1411-1415, 1993.

Moy, C. M., Seltzer, G. O., Rodbell, D. T., and Anderson, D. M.: Variability of El Niño/Southern Oscillation activity at millennial timescales during the Holocene epoch, Nature, 420, 162-165, 2002.

Otto-Bliesner, B. L.: El Niño/La Niña and Sahel precipitation during the middle Holocene, Geophys. Res. Lett., 26, 87-90, 1999.

Otto-Bliesner, B. L., Brady, E. C., Clauzet, G., Tomas, R., Levis, S., and Kothavala, Z.: Last Glacial Maximum and Holocene Climate in CCSM3, J. Climate, 19, 2526-2544, 2006.

Philander, S. G.: El Niño, La Niña, and the Southern Oscillation, Academic Press, San Diego, California, 1990.

Phipps, S. J., Rotstayn, L. D., Gordon, H. B., Roberts, J. L., Hirst, A. C., and Budd, W. F.: The CSIRO Mk3L climate system model version 1.0 - Part 1: Description and evaluation, Geosci. Model Dev., 4, 483-509, doi:10.5194/gmd-4-483-2011, 2011.

Prentice, I. C. and Webb III, T.: BIOME 6000: reconstructing global mid-Holocene vegetation patterns from palaeoecological records, J. Biogeogr., 25, 997-1005, 1998.

Prentice, I. C., Jolly, D., and BIOME 6000 participants: MidHolocene and glacial-maximum vegetation and geography of the northern continents and Africa, J. Biogeogr., 27, 507-519, 2000.

Ramaswamy, V., Boucher, O., Haigh, J., Hauglustaine, D., Haywood, J., Myhre, G., Nakajima, T., Shi, G. Y., and Solomon, S.: Radiative forcing of climate change, in: Climate Change 2001: The Scientific Basis, edited by: Houghton, J. T., Ding, Y., Griggs, D. J., Noguer, M., van der Linden, P. J., Dai, X.,
Maskell, K., and Johnson, C. A., Chap. 6, Cambridge University Press, Cambridge, 349-416, 2001.

Robock, A.: Volcanic eruptions and climate, Rev. Geophys., 38, 191-219, 2000.

Robock, A.: Cooling following large volcanic eruptions corrected for the effect of diffuse radiation on tree rings, Geophys. Res. Lett., 32, L06702, doi:10.1029/2004GL022116, 2005.

Rodbell, D. T., Seltzer, G. O., Anderson, D. M., Abbott, M. B., Enfield, D. B., and Newman, J. H.: An 15 000-year record of El Niño-driven alluviation in Southwestern Ecuador, Science, 283, 516-520, 1999.

Rotstayn, L. D. and Penner, J. E.: Indirect aerosol forcing, quasi forcing, and climate response, J. Climate, 14, 2960-2975, 2001.

Rotstayn, L. D., Cai, W., Dix, M. R., Farquhar, G. D., Feng, Y., Ginoux, P., Herzog, M., Ito, A., Penner, J. E., Roderick, M. L., and Wang, M.: Have Australian rainfall and cloudiness increased due to the remote effects of Asian anthropogenic aerosols?, J. Geophys. Res., 112, D09202, doi:10.1029/2006JD007712, 2007.

Schmidt, G. A., Jungclaus, J. H., Ammann, C. M., Bard, E., Braconnot, P., Crowley, T. J., Delaygue, G., Joos, F., Krivova, N. A., Muscheler, R., Otto-Bliesner, B. L., Pongratz, J., Shindell, D. T., Solanki, S. K., Steinhilber, F., and Vieira, L. E. A.: Climate forcing reconstructions for use in PMIP simulations of the last millennium (v1.0), Geosci. Model Dev., 4, 33-45, doi:10.5194/gmd4-33-2011, 2011.

Schurgers, G., Mikolajewicz, U., Gröger, M., Maier-Reimer, E., Vizcaíno, M., and Winguth, A.: Dynamics of the terrestrial biosphere, climate and atmospheric $\mathrm{CO}_{2}$ concentration during interglacials: a comparison between Eemian and Holocene, Clim. Past, 2, 205-220, doi:10.5194/cp-2-205-2006, 2006.

Sen Gupta, A., Muir, L. C., Brown, J. N., Phipps, S. J., Durack, P. J., Monselesan, D., and Wijffels, S. E.: Climate drift in the CMIP3 models, J. Climate, doi:10.1175/JCLI-D-11-00312.1, in press, 2012.

Senior, C. A. and Mitchell, J. F. B.: The time-dependence of climate sensitivity, Geophys. Res. Lett., 27, 2685-2688, 2000.

Servonnat, J., Yiou, P., Khodri, M., Swingedouw, D., and Denvil, S.: Influence of solar variability, $\mathrm{CO}_{2}$ and orbital forcing between 1000 and 1850 AD in the IPSLCM4 model, Clim. Past, 6, 445460, doi:10.5194/cp-6-445-2010, 2010.

Shindell, D. T., Schmidt, G. A., Miller, R. L., and Mann, M. E.: Volcanic and solar forcing of climate change during the preindustrial era, J. Climate, 16, 4094-4107, 2003.

Shulmeister, J. and Lees, B. G.: Pollen evidence from tropical Australia for the onset of an ENSO-dominated climate at c. $4000 \mathrm{BP}$, Holocene, 5, 10-18, 1998.

Smith, I.: Global climate modelling within CSIRO: 1981 to 2006, Aust. Meteorol. Mag., 56, 153-166, 2007.

Steinhilber, F., Beer, J., and Fröhlich, C.: Total solar irradiance during the Holocene, Geophys. Res. Lett., 36, L19704, doi:10.1029/2009GL040142, 2009.

Stothers, R. B.: The great Tambora eruption in 1815 and its aftermath, Science, 224, 1191-1198, 1984.

Stothers, R. B.: Climatic and demographic consequences of the massive volcanic eruption of 1258, Clim. Change, 45, 361-374, 2000.

Stouffer, R. J. and Manabe, S.: Response of a coupled oceanatmosphere model to increasing atmospheric carbon dioxide: sensitivity to the rate of increase, J. Climate, 12, 2224-2237, 
1999.

Stouffer, R. J. and Manabe, S.: Equilibrium response of thermohaline circulation to large changes in atmospheric $\mathrm{CO}_{2}$ concentration, Clim. Dynam., 20, 759-773, doi:10.1007/s00382-0020302-4, 2003.

Thompson, D. W. J., Wallace, J. M., Jones, P. D., and Kennedy, J. J.: Identifying signatures of natural climate variability in time series of global-mean surface temperature: methodology and insights, J. Climate, 22, 6120-6141, doi:10.1175/2009JCLI3089.1, 2009.

Timmreck, C., Lorenz, S. J., Crowley, T. J., Kinne, S., Raddatz, T. J., Thomas, M. A., and Jungclaus, J. H.: Limited temperature response to the very large AD 1258 volcanic eruption, Geophys. Res. Lett., 36, L21708, doi:10.1029/2009GL040083, 2009.

Torrence, C. and Compo, G. P.: A practical guide to wavelet analysis, B. Am. Meteorol. Soc., 79, 61-78, 1998.

Trenberth, K. E., Jones, P. D., Ambenje, P., Bojariu, R., Easterling, D., Tank, A. K., Parker, D., Rahimzadeh, F., Renwick, J. A., Rusticucci, M., Soden, B., and Zhai, P.: Observations: surface and atmospheric climate change, in: Climate Change 2007: The Physical Science Basis, edited by: Solomon, S., Qin, D., Manning, M., Chen, Z., Marquis, M., Averyt, K. B., Tignor, M., and Miller, H. L., Chap. 3, Cambridge University Press, Cambridge, 235-336, 2007.

Tudhope, A. W., Chilcott, C. P., McCulloch, M. J., Cook, E. R., Chappell, J., Ellam, R. M., Lea, D. W., Lough, J. M., and Shimmield, G. B.: Variability in the El Niño-Southern Oscillation through a glacial-interglacial cycle, Science, 291, 1511-1517, 2001.

Usoskin, I. G., Solanki, S. K., and Kovaltsov, G. A.: Grand minima and maxima of solar activity: new observational constraints, Astron. Astrophys., 471, 301-309, doi:10.1051/00046361:20077704, 2007

Vamborg, F. S. E., Brovkin, V., and Claussen, M.: The effect of a dynamic background albedo scheme on Sahel/Sahara precipitation during the mid-Holocene, Clim. Past, 7, 117-131, doi:10.5194/cp-7-117-2011, 2011.

Varma, V., Prange, M., Merkel, U., Kleinen, T., Lohmann, G., Pfeiffer, M., Renssen, H., Wagner, A., Wagner, S., and Schulz, M.: Holocene evolution of the Southern Hemisphere westerly winds in transient simulations with global climate models, Clim. Past, 8, 391-402, doi:10.5194/cp-8-391-2012, 2012.
Voss, R. and Mikolajewicz, U.: Long-term climate changes due to increased $\mathrm{CO}_{2}$ concentration in the coupled atmosphere-ocean general circulation model ECHAM3/LSG, Clim. Dynam., 17, 45-60, 2001.

Wang, Y.-M., Lean, J. L., and Sheeley, Jr., N. R.: Modeling the Sun's magnetic field and irradiance since 1713, Astrophys. J., 625, 522-538, 2005.

Watterson, I. G. and Dix, M. R.: Effective sensitivity and heat capacity in the response of climate models to greenhouse gas and aerosol forcings, Q. J. Roy. Meteor. Soc., 131, 259-279, doi:10.1256/qj.03.232, 2005.

Watterson, I. G., Dix, M. R., and Colman, R. A.: A comparison of present and doubled $\mathrm{CO}_{2}$ climates and feedbacks simulated by three general circulation models, J. Geophys. Res., 104, 19431956, 1999.

Wigley, T. M. L., Ammann, C. M., Santer, B. D., and Raper, S. C. B.: Effect of climate sensitivity on the response to volcanic forcing, J. Geophys. Res., 110, D09107, doi:10.1029/2004JD005557, 2005.

Wittenberg, A. T.: Are historical records sufficient to constrain ENSO simulations?, Geophys. Res. Lett., 36, L12702, doi:10.1029/2009GL038710, 2009.

Wood, R. A., Vellinga, M., and Thorpe, R.: Global warming and thermohaline circulation stability, Philos. T. Roy. Soc. A, 361, 1961-1975, doi:10.1098/rsta.2003.1245, 2003.

Yoshioka, M., Mahowald, N. M., Conley, A. J., Collins, W. D., Fillmore, D. W., Zender, C. S., and Coleman, D. B.: Impact of desert dust radiative forcing on Sahel precipitation: relative importance of dust compared to sea surface temperature variations, vegetation changes, and greenhouse gas warming, J. Climate, 20, 14451467, doi:10.1175/JCLI4056.1, 2007.

Yu, G. and Harrison, S. P.: An evaluation of the simulated water balance of Eurasia and Northern Africa at 6000 y BP using lake status data, Clim. Dynam., 12, 723-735, 1996.

Zhang, Y., Wallace, J. M., and Battisti, D. S.: ENSO-like Interdecadal variability: 1900-1993, J. Climate, 10, 1004-1020, 1997.

Zheng, W., Braconnot, P., Guilyardi, E., Merkel, U., and Yu, Y.: ENSO at $6 \mathrm{ka}$ and $21 \mathrm{ka}$ from ocean-atmosphere coupled model simulations, Clim. Dynam., 30, 745-762, doi:10.1007/s00382007-0320-3, 2008. 